\title{
The Effects Of Lifestyle And Dietary Intake On Health Outcomes And The Metabolic Syndrome Among Lebanese University Students
}

Citation for published version (APA):

Haidar, S. A. (2019). The Effects Of Lifestyle And Dietary Intake On Health Outcomes And The Metabolic Syndrome Among Lebanese University Students. [Doctoral Thesis, Maastricht University].

ProefschriftMaken Maastricht. https://doi.org/10.26481/dis.20190118sh

Document status and date:

Published: 01/01/2019

DOI:

10.26481/dis.20190118sh

Document Version:

Publisher's PDF, also known as Version of record

Please check the document version of this publication:

- A submitted manuscript is the version of the article upon submission and before peer-review. There can be important differences between the submitted version and the official published version of record.

People interested in the research are advised to contact the author for the final version of the publication, or visit the DOI to the publisher's website.

- The final author version and the galley proof are versions of the publication after peer review.

- The final published version features the final layout of the paper including the volume, issue and page numbers.

Link to publication

\footnotetext{
General rights rights.

- You may freely distribute the URL identifying the publication in the public portal. please follow below link for the End User Agreement:

www.umlib.nl/taverne-license

Take down policy

If you believe that this document breaches copyright please contact us at:

repository@maastrichtuniversity.nl

providing details and we will investigate your claim.
}

Copyright and moral rights for the publications made accessible in the public portal are retained by the authors and/or other copyright owners and it is a condition of accessing publications that users recognise and abide by the legal requirements associated with these

- Users may download and print one copy of any publication from the public portal for the purpose of private study or research.

- You may not further distribute the material or use it for any profit-making activity or commercial gain

If the publication is distributed under the terms of Article 25fa of the Dutch Copyright Act, indicated by the "Taverne" license above, 
The effect of

\section{lifestyle habits and dietary intake}

on Health Outcomes and Metabolic Syndrome in Lebanese University students

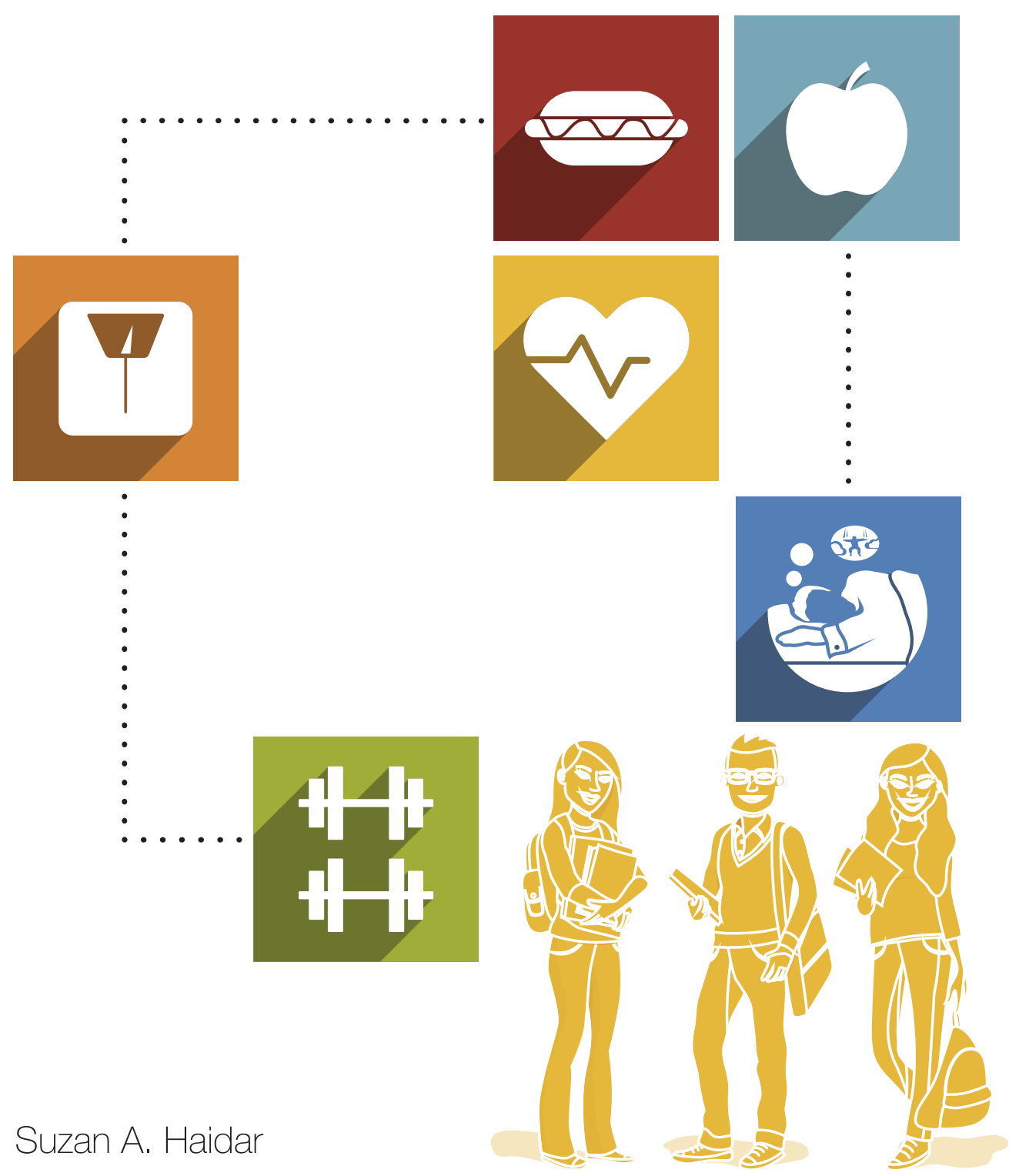



The Effect Of Lifestyle And Dietary Intake On Health Outcomes And The Metabolic Syndrome Among Lebanese University Students

Suzan A. Haidar

2018 
The studies existing in this thesis were conducted at the Lebanese International University in Lebanon under the supervision and direction of the School for Public Health \& Primary Care (CAPHRI), at Maastricht University.

Printed: ProefschriftMaken || www.proefschriftmaken.nl

\section{Layout cover by: Fatima Zaytoun}

ISBN: 978-94-6380-199-7

\section{Copyright @ Suzan A Haidar, Maastricht, 2018}

No parts of this thesis may be reproduced, stored in a retrieved system, or transmitted, in any forms or by any means, electronically, mechanically, by photocopying, recording or otherwise, without the prior written permission of the author. For articles published or accepted, the copyright has been transferred to the respective journals. 


\title{
The Effect Of Lifestyle And Dietary Intake On Health Outcomes And The Metabolic Syndrome Among Lebanese University Students
}

\begin{abstract}
Proefschrift
ter verkrijging van de graad van doctor aan de Universiteit Maastricht op gezag van de rector magnificus Rianne Letschert volgens het besluit van het College van Decanen, in het openbaar te verdedigen op Vrijdag 18 januari 2019 om 10:45 uur

door
\end{abstract}

Suzan A. Haidar 


\section{Supervisor:}

Prof. Dr. Nanne de Vries, Maastricht University, Maastricht, Netherlands

\section{Co-supervisor:}

Dr. Mirey Karavetian, Zayed University, Dubai, UAE

\section{Assessment Committee:}

Prof. S. Kremers (Maastricht University) / chair

Prof. N. Schaper (MUMC+)

Prof. G. Kok (Maastricht University)

Dr. J. de Vries (Wageningen University)

Dr. A. Laviano (University of Rome)

Funding obtained for this research was generously received from Zayed University. 


\section{Contents}

Chapter 1

Chapter 2

Chapter 3

Chapter 4

Chapter 5

Chapter 6

Chapter 7
General Introduction

6

Stress, Anxiety and Weight gain among university

and college students: a systematic review

18

Published in Journal of the Academy of Nutrition and Dietetics,

2018, 118(2), 261-274

Association between $\beta$-amino-isobutyric acid and

cardiometabolic risk factors: A preliminary study

44

Submitted

University Lebanese students are not immune to

the metabolic syndrome

60

Published in Mediterranean Journal of Nutrition and Metabolism,

2018, Pre-press pp 1-10

The freshman weight gain phenomenon: Does it apply

to Lebanese students

Published in Open Access Macedonian Journal of Medical Sciences, 2018 6(11):2214-2220

General Discussion

94

Future health promotion programs

112

List of publications of the thesis

Valorization

Summary

127

Words of thanks

131

Curriculum Vitae 


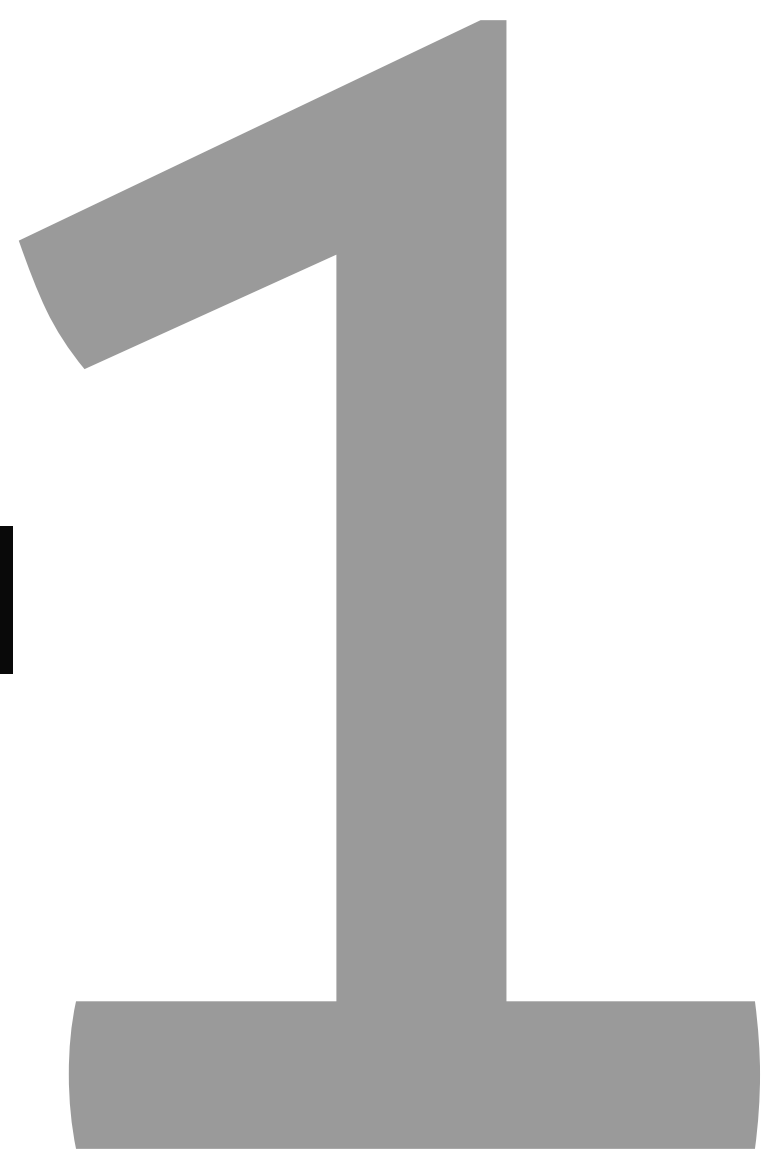


General Introduction 


\section{Introduction}

The Lebanese Republic, commonly known as Lebanon, is a small country that lies in the Middle East along the coast of the Mediterranean Sea and is grouped under the Eastern Mediterranean region by the World Health Organization. ${ }^{1}$ In 1990, Lebanon came out of a civil war that lasted approximately 15 years $^{2}$ which destabilized the country. Regrettably, this had catastrophic consequences on the health care system. Lebanon devotes approximately $12 \%$ of its Gross Domestic Product to health care, which mostly comes out of the pocket of the private sector and almost half of the Lebanese do not have adequate insurance coverage. ${ }^{3}$

To make matters worse, since the civil war, the country has witnessed a demographic transition, where there is an aging of the population and a decrease in fertility rates. ${ }^{3}$ This was parallel to a nutrition transition ${ }^{4}$ : a shift from consumption of a healthy "Mediterranean diet" food pattern, that is characteristically rich in legumes, fruits and whole grains to that of a "Westernized diet" that is rich in simple carbohydrates, salt, animal sources of protein and high intakes of fat, especially trans and saturated fats. ${ }^{5}$

Thus the combination of the transitions, in addition to a lack of adequate resources allocated to public health interventions, has contributed to an exponential increase in the rates of obesity and chronic diseases in Lebanon; the rates are comparable and have even exceeded those of developed countries. ${ }^{6,7}$ For example, estimated rates for obesity in those under 20 years of age in the United States were $12.4 \%$ and $13.4 \%$ for males and females respectively, whereas in Lebanon, the prevalence of obesity was found to be $15.9 \%$ for males and $12.5 \%$ for females for the same under age category. ${ }^{8}$ Another study found that the overweight and obesity percentages in the 6-19 year age bracket were $21.7 \%$ and $6.5 \%$ respectively. ${ }^{9}$ Hence the prevalence of obesity amongst the young in Lebanon is distressing, as the numbers are now similar to those of other Arab countries, which have been threatened by obesity in alarming rates. ${ }^{10}$ Kuwait for example is considered a country with one of highest obesity rates in the world ${ }^{11}$ and estimated rates of obesity were found to be $16.7 \%$ for males and $23.3 \%$ for females in the under 20 years of age category. ${ }^{8}$

The numbers are disturbing since obesity in adolescence is a strong predictor of adulthood obesity and it is estimated that obese adolescents have an $80 \%$ risk of becoming obese adults. ${ }^{12}$ Therefore, if things continue as they are going now, Lebanon could be on the verge of a health crisis with catastrophic consequences on the well-being of the population and may impose an additional financial burden on an already struggling population.

The etiology of obesity is multifaceted and numerous factors have been identified as risk factors ${ }^{13}$ such as unhealthy diets, low physical activity, high stress levels and lack of sleep. ${ }^{13,14}$ Furthermore, gaining weight early in life such as during the period of transition from school to university can make a person more prone to obesity later in life and lead to a subsequent significant rise in comorbidities. ${ }^{15,16}$ The weight increase that occurs 
when students transition from school to university has been extensively studied in the West and the phenomena has been coined as the "Freshman 15", since it was previously thought that the amount of weight gained during the freshman year was approximately 15 pounds. ${ }^{17}$ However, recent reviews have concluded that although weight gain does seem to occur in freshman students, the actual increase is more modest and ranges from 3 to 5 pounds. ${ }^{18,19}$ However the freshman 15/5 phenomenon has not yet been researched in any of the Arab countries, as there seems to be a general impression that students are healthy and protected from health hazards by their young age. There is evidence for this in the lack of public health programs targeting these students and in the fact that whatever prevailing programs that do exist target mainly those who are above 40 years of age. ${ }^{3}$ However we do know from other parts of the world that university students are vulnerable to obesity and its comorbidities ${ }^{20,21}$ and that part of this problem may be partially explained by the freshman 15 phenomenon.

The projected burden of obesity is crippling, as it is estimated that in 2030 more than half of the adults worldwide will be obese and subsequently the costs attributable to obesity and its complications will increase exponentially. ${ }^{22}$ It is undisputed that obesity causes a multitude of abnormalities and can result in a marked increase in the risk of cardiovascular diseases and the metabolic syndrome (MetS). ${ }^{23-25}$ The MetS is a cluster of symptoms that when present, doubles risk of heart disease ${ }^{26}$ and increases the chance of developing diabetes by almost five times. ${ }^{27}$ MetS is diagnosed, as per International Diabetes Federation (IDF) guidelines, when an individual has an increased waist circumference alongside two or more of the following abnormalities: elevated blood pressure, elevated fasting blood glucose, elevated triglyceride levels and reduced high-density lipoprotein cholesterol. ${ }^{28}$ In Lebanon, it has been estimated that more than one third of the Lebanese suffer from the MetS. ${ }^{29}$ This is alarming data in a developing country with restricted access to health care and resources.

Fortunately, obesity and the MetS are largely preventable as their risk factors are modifiable. ${ }^{30}$ It has been suggested that the nutrition transition, hence a change from a Mediterranean diet to that of a western one, is a modifiable cause for non-communicable diseases $^{31}$ as is exercise level, and numerous lifestyle factors. ${ }^{32}$

Since an ounce of prevention is worth a pound of cure, appropriate, prevention strategies and public health programs need to be implemented to halt or limit the rise of the noncommunicable diseases that may pose a serious public health burden in the future. One potential strategy that has proved beneficial is to pinpoint vulnerable groups and implement preventive public health programs tailored to them. One such high risk group may be university students who are often stressed and suffer from inadequate sleep, unhealthy eating habits and decreased physical activity. ${ }^{33,34}$ Perry (1999) noted that improving health habits among youth leads to healthy adults. ${ }^{35}$ Thus integrating health awareness programs within the educational system of youth may be the solution for the freshman $15 / 5$ and for the ever-rising non-communicable disease rate. 
However in order to implement successful public health programs, baseline data about lifestyle and dietary intake should be collected so that the risks may be identified and subsequently addressed. Since little is known about the extent of metabolic abnormalities and their predictors in Lebanese university students, the aim of the present thesis is to better understand their health and lifestyle habits and to determine if an association exists between these habits and the occurrence of obesity and the MetS. Furthermore, we hope to understand whether weight gain occurs during the transitional period that takes place when students graduate from school and enroll in university in order to determine whether this time is indeed a critical one for weight gain and adoption of unhealthy health habits in Lebanese students, which may be subsequently carried out into their adult self. Furthermore, as it is well documented that stress increases risk of obesity, ${ }^{36}$ we want to understand through a systematic review whether increased stress and anxiety raise the risk of adiposity specifically among collegians. Additionally, since lifestyle changes are difficult, and since obesity management has failed over the years and has become a major threat to global health, ${ }^{8}$ we aim to investigate whether a recently discovered myokine Beta-amino-isobutyric acid (BAIBA) would be associated with lower levels of obesity. BAIBA is an amino acid that is produced by the transcriptor factor "proliferator activated receptor gamma 1-alpha" (PGC-1a). PGC-1a has been proven to aid in browning of white adipose tissue when acting through the peroxisome proliferator activator receptor alpha (PPAR a) and thus contributing to increased fatty acid oxidation and increased metabolic rate. ${ }^{37}$ Thus we aim to study whether there is an association between BAIBA levels, BMI and MetS components in hope of finding promising results, which can pave the way for clinical interventions on BAIBA supplementation for successful obesity management.

This thesis will allow us to better understand the above factors in order to pave the way for evidence based public health programs that can specifically target Lebanese university students, as universities are institutions that can provide effective and easily accessible channels for introducing and implementing public health programs. ${ }^{38-40}$

The objectives of this dissertation and its organization are summarized in Figure 1. 


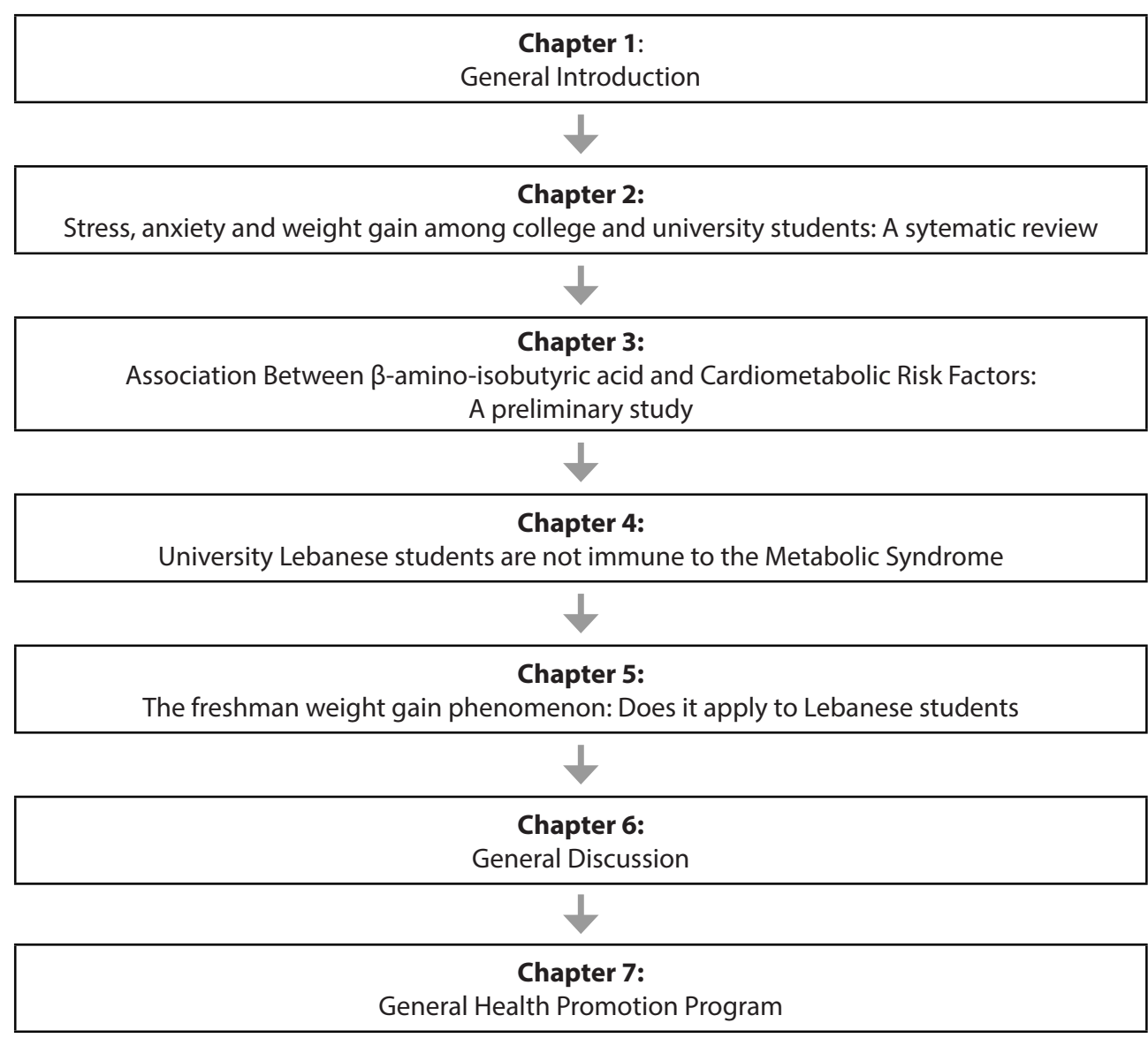

Figure 1. Outline of the dissertation

\section{Study Design}

The setting of the studies included in this thesis is a local Lebanese University. The university was chosen because it has a large number of students (approximately 22000) and because the university has nine campuses located in all the geographical parts of Lebanon. Ethical approval was obtained from the Lebanese International University's committee on Research Ethics (CRE) (case number: LIUCRE-141117-2)

Five out of nine campuses were selected to harbor the study. The reasons for such a purposive sampling was to recruit students from both rural and urban areas and to provide geographical diversity and include students from all socioeconomic levels. Students from the chosen campuses were then contacted first through classroom visits and then via mass email and were invited to participate in the study. Students filled out forms so they could be communicated with at a later time. The research team then contacted all 
willing freshman students to participate in the study. Overall, 80 students showed up to participate in data collection. Consenting students were contacted the night before data collection to remind them of the need to be fasting for 12 hours and direct them to the location of the nutrition clinic, where the study would take place.

The eligibility criteria included:

1. Free of chronic disease

2. Not pregnant

3. Not taking medication

Students were excluded from the study if they were sick at the time of the study, suffered from chronic diseases, were not fasting and if they did not meet the inclusion criteria. The students were informed about the objectives and methodology of the study, and about their right to withdraw from it at any time.

\section{Data collection}

The following information was collected from the students:

- Anthropometry

- Blood pressure

- Blood collection and analysis

- Food intake

- Sleep information

- Physical activity level

- Nutrition knowledge information

- Stress

- Demographic and lifestyle information

All questionnaires to be filled out were available in both English and Arabic. All questionnaires were back translated into both languages to ensure accuracy. The respondents were able to choose their language of preference when filling out the questionnaires and were able to get help from research assistants should they need it. Prior to the study, all questionnaires were pilot-tested for in a sample of twenty students so that we could be sure that there were no vagueness or problems with comprehension with the questions. Those piloted questionnaires were not included in the analysis.

The students were then contacted after seven months to be reassessed. Only 40 of them accepted to fill out the information and only 27 out of the 40 agreed to undergo further biochemical testing.

Additionally, two weeks after the first data collection (T0), all university students from all years of enrollment were invited to participate in a cross-sectional study to assess the 
same parameters that were taken with the freshman students. A total of 186 students showed up to be assessed.

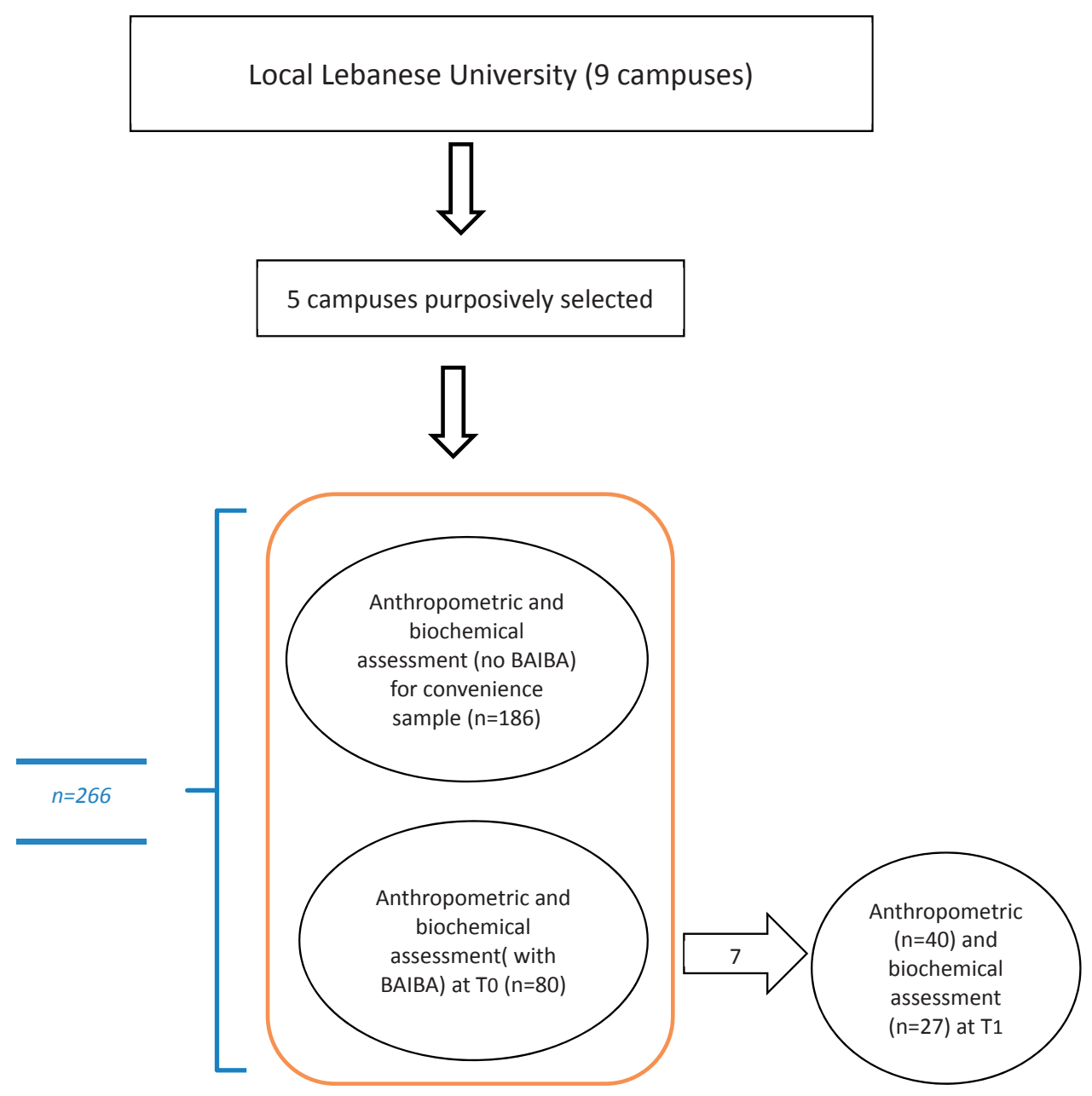

Figure 2: Flow chart of the study design 


\section{References}

1. World Health Organization. Health statistics and information systems. Definition of Regional Groupings 2018. Word Health Organization. http://www.who.int/healthinfo/global_burden_ disease/definition_regions/en/. Accessed February 10, 2018.

2. Lebanese Civil War: 1975-1991: Lebanese Civil War: 1975-1991 2018. American University of Beirut.http://aub.edu.lb.libguides.com/lebanesecivilwar. Accessed February 10, 2018.

3. Ammar W. Health System and Reform in Lebanon. Beyrouth Lebanon: Entreprises Universitaire d'Etudes et de Publicactions; 2003.

4. Mehio Sibai A, Nasreddine L, Mokdad AH, Adra N, Tabet M, Hwalla N. Nutrition transition and cardiovascular disease risk factors in Middle East and North Africa countries: reviewing the evidence. Ann Nutr Metab. 2010;57(3-4):193-203.

5. Popkin BM, Adair LS, Ng SW. Now and Then: The Global Nutrition Transition: The Pandemic of Obesity in Developing Countries. Nutrition Reviews. 2012;70(1):3-21.

6. Sibai AM, Hwalla N, Adra N, Rahal B. Prevalence and covariates of obesity in Lebanon: Findings from the first epidemiological study. Obes Res. 2003;11.

7. Zeidan RK, Farah R, Chahine MN, et al. Prevalence and correlates of coronary heart disease: first population-based study in Lebanon. Vascular Health and Risk Management. 2016;12:7584.

8. $\mathrm{Ng} \mathrm{M}$, Fleming $\mathrm{T}$, Robinson $\mathrm{M}$, et al. Global, regional, and national prevalence of overweight and obesity in children and adults during 1980-2013: a systematic analysis for the Global Burden of Disease Study 2013. Lancet. 2014;384(9945):766-781.

9. Hwalla N, Sibai AM, Adra N. Adolescent obesity and physical activity. World review of nutrition and dietetics. 2005;94:42-50.

10. Alnohair S. Obesity in Gulf Countries. International Journal of Health Sciences. 2014;8(1):79-83.

11. Karageorgi S, Alsmadi O, Behbehani K. A Review of Adult Obesity Prevalence, Trends, Risk Factors, and Epidemiologic Methods in Kuwait. Journal of Obesity. 2013;2013:14.

12. The NS, Suchindran C, North KE, Popkin BM, Gordon-Larsen P. Association of adolescent obesity with risk of severe obesity in adulthood. Jama. 2010;304(18):2042-2047.

13. Wright SM, Aronne LJ. Causes of obesity. Abdominal imaging. 2012;37(5):730-732.

14. Kyrou I, Chrousos GP, Tsigos C. Stress, visceral obesity, and metabolic complications. Annals of the New York Academy of Sciences. 2006;1083:77-110.

15. Zheng Y, Manson JE, Yuan C, et al. Associations of Weight Gain From Early to Middle Adulthood With Major Health Outcomes Later in Life. Jama. 2017;318(3):255-269.

16. Hoffman DJ, Policastro P, Quick V, Lee SK. Changes in body weight and fat mass of men and women in the first year of college: A study of the "freshman 15". J Am Coll Health. 2006;55.

17. Brown C. The information trail of the 'Freshman 15'-a systematic review of a health myth within the research and popular literature. Health Info Libr J. 2008;25.

18. Vadeboncoeur C, Townsend N, Foster C. A meta-analysis of weight gain in first year university students: is freshman 15 a myth? BMC Obesity. 2015;2(1):22. 
19. Vella-Zarb RA, Elgar FJ. The 'freshman 5': a meta-analysis of weight gain in the freshman year of college. J Am Coll Health. 2009;58.

20. Yahia N, Brown CA, Snyder E, et al. Prevalence of Metabolic Syndrome and Its Individual Components Among Midwestern University Students. Journal of community health. 2017;42(4):674-687.

21. Peltzer K, Pengpid S, Samuels TA, et al. Prevalence of overweight/obesity and its associated factors among university students from 22 countries. International Journal of Environmental Research \& Public Health [Electronic Resource]. 2014;11(7):7425-7441.

22. Kelly T, Yang W, Chen CS, Reynolds K, He J. Global burden of obesity in 2005 and projections to 2030. International journal of obesity (2005). 2008;32(9):1431-1437.

23. Field AE, Coakley EH, Must A, et al. Impact of overweight on the risk of developing common chronic diseases during a 10-year period. Archives of internal medicine. 2001;161(13):15811586.

24. Must A, Spadano J, Coakley EH, Field AE, Colditz G, Dietz WH. The disease burden associated with overweight and obesity. Jama. 1999;282(16):1523-1529.

25. Gortmaker SL, Must A, Perrin JM, Sobol AM, Dietz WH. Social and economic consequences of overweight in adolescence and young adulthood. N Engl J Med. 1993;329(14):1008-1012.

26. Mottillo S, Filion KB, Genest J, et al. The metabolic syndrome and cardiovascular risk a systematic review and meta-analysis. J Am Coll Cardiol. 2010;56(14):1113-1132.

27. Grundy SM. Metabolic syndrome pandemic. Arteriosclerosis, thrombosis, and vascular biology. 2008;28(4):629-636.

28. Alberti KG, Eckel RH, Grundy SM, et al. Harmonizing the metabolic syndrome: a joint interim statement of the International Diabetes Federation Task Force on Epidemiology and Prevention; National Heart, Lung, and Blood Institute; American Heart Association; World Heart Federation; International Atherosclerosis Society; and International Association for the Study of Obesity. Circulation. 2009;120(16):1640-1645.

29. Naja F, Nasreddine L, Itani L, Adra N, Sibai AM, Hwalla N. Association between dietary patterns and the risk of metabolic syndrome among Lebanese adults. European Journal of Nutrition. 2013;52(1):97-105.

30. Milam AJ, Jones CD, Debnam KJ, et al. School environments and obesity: The mediating role of personal stress. J Community Psychol. 2017;45:715-726.

31. Hawkes C. Uneven dietary development: linking the policies and processes of globalization with the nutrition transition, obesity and diet-related chronic diseases. Globalization and health. 2006;2:4.

32. Nammi S, Koka S, Chinnala KM, Boini KM. Obesity: An overview on its current perspectives and treatment options. Nutrition Journal. 2004;3:3-3.

33. Vella-Zarb RA, Elgar FJ. Predicting the 'freshman 15': Environmental and psychological predictors of weight gain in first-year university students. Health Educ J. 2010;69.

34. Economos CD, Hildebrandt ML, Hyatt RR. College freshman stress and weight change: differences by gender. Am J Health Behav. 2008;32. 
35. Perry CL. Cardiovascular disease prevention among youth: visioning the future. Preventive medicine. 1999;29(6 Pt 2):S79-83.

36. Wardle J, Chida Y, Gibson EL, Whitaker KL, Steptoe A. Stress and adiposity: a meta-analysis of longitudinal studies. Obesity (Silver Spring). 2011;19(4):771-778.

37. Roberts LD, Bostrom P, O'Sullivan JF, et al. beta-Aminoisobutyric acid induces browning of white fat and hepatic beta-oxidation and is inversely correlated with cardiometabolic risk factors. Cell metabolism. 2014;19(1):96-108.

38. Matvienko O, Lewis DS, Schafer E. A college nutrition science course as an intervention to prevent weight gain in female college freshmen. J Nutr Educ. 2001;33.

39. Plotnikoff R, Collins CE, Williams R, Germov J, Callister R. Effectiveness of interventions targeting health behaviors in university and college staff: a systematic review. American journal of health promotion : AJHP. 2015;29(5):e169-187.

40. Gow RW, Trace SE, Mazzeo SE. Preventing weight gain in first year college students: an online intervention to prevent the "freshman fifteen". Eat Behav. 2010;11. 


\section{CHAPTER}




\section{Stress, Anxiety and Weight gain among university and college students: a systematic review}

Suzan A. Haidar, Nanne K. de Vries, Mirey Karavetian, Rola El Rassi 


\section{Abstract}

Stress, anxiety and weight gain among university and college students: A systematic review

\section{Background:}

Stress and anxiety levels are elevated among university and college students. Although high stress levels may lead to an increase in adiposity, it is not clear whether stress and anxiety, experienced when in university or college, have an influence on the weight of students.

\section{Objective:}

The aim of this systemic review was to investigate whether stress and anxiety levels, encountered during university and college enrollment, were associated with higher adiposity or weight changes among students.

\section{Method:}

A search strategy was used to identify peer-reviewed studies published between 1985 and March 2017 using the following databases: Medline using Ovid; PubMed, Medline, CINAHL using EBSCO, Embase using Ovid, PSYCHINFO and Open Access Theses and Dissertation. Two reviewers independently assessed the title, abstract and then the full article of the studies that met the inclusion criteria. Data were extracted and quality assessment was conducted for the included studies.

\section{Results:}

Twenty-five observational studies were identified in this review ( 23 cross-sectional and 2 longitudinal); eleven found that there was no association between stress and BMI or weight change. Additionally, five studies did not find a significant association between anxiety and BMI. A few studies revealed stress and anxiety may be associated with higher or lower weight status, thus there is a possibility that stress may increase or decrease weigh demonstrating a bidirectional influence on BMI may exist

\section{Conclusion:}

The current data in this review is inadequate to draw firm conclusions about the role of stress on weight change in university and college students. The inconsistency of results in the literature reviewed for this paper would suggest a focus on longitudinal studies with adequate sample size to better evaluate the relationship between stress or anxiety and its influence on weight status or weight change among collegians.

Keywords: Stress; weight gain; university; anxiety; systematic review 


\section{Introduction}

Stress is an unavoidable part of life and occurs when demands are placed on individuals that exceed their ability to cope'; it is also a predictor of anxiety. ${ }^{2}$ Unfortunately, high levels of stress and anxiety have been reported among university and college students ${ }^{3-}$ ${ }^{6} ;$ it is estimated that at any given time $20-25 \%$ of students are stressed globally, ${ }^{7}$ and $50 \%$ of students may experience stress in the form of anxiety and depression. ${ }^{8}$ The reasons for increased stress and anxiety levels among students are numerous and include both academic and non-academic factors, which include but are not limited to high academic burden, financial strains, colleague competition, the need to excel, homesickness, social problems and disturbed sleep patterns. . $^{7,9} 10$

Increased stress levels have negative consequences on both the body and the mind. ${ }^{1}$ Some of the psychological problems that may occur secondary to stress include anxiety, depression, and engagement in high-risk behavior. ${ }^{1,2,7}$ Furthermore, the physiological health problems that can occur are numerous as stress, through increased cortisol secretion, promotes increased food intake, especially intake of sweet and nutrient-poor foods. ${ }^{11,12}$ Hence, increased stress may raise the risk of obesity and its comorbidities some of which are hypertension, metabolic syndrome, heart disease and diabetes. ${ }^{13-15}$ Although there is evidence of high stress levels being a risk factor for an increase in adiposity, ${ }^{14}$ the relationship between stress and anxiety encountered during university or college enrollment and weight status is still not well understood, nor is the evidence strong enough to generalize.

Obesity is a global health burden and its rates are on the rise. ${ }^{16}$ In the United States, the greatest increase in obesity rates was found to be among 18-29 year olds and among those with some college education. ${ }^{17}$ Levitsky and colleagues ${ }^{18}$ investigated whether weight gained by university freshman students was higher than the average weight gain of the general population within the same age range. The findings suggested the weight gain was greater among students than in the general population. The weight gain phenomenon during the freshman year has been coined "the freshman 15"; however, a meta-analysis reported by Vella-Zarb and Elgar ${ }^{19}$ showed a mean weight gain of 3.86 pounds (1.75 kilograms). Nevertheless, even a modest weight gain occurring during this time increases the risk that weight gain will more likely continue throughout life putting weight gainers at a higher risk for developing obesity and its comorbidities. ${ }^{20}$ Consequently, it is important to identify the determinants of weight gain during university and college enrollment. The findings can serve as building blocks for obesity prevention programs in the target population.

Therefore, the aim of this systematic review was to thoroughly assess the literature in order to determine whether there is an association between stress and anxiety encountered during university and college life and weight gain among university and college students. 


\section{Methods}

This systematic review was performed using the standard methods for conducting and reporting systematic protocol guidelines. ${ }^{21}$ The protocol for this systematic review was registered with the International Prospective Register of Systematic Reviews (PROSPERO, registration number CRD42015029731).

\section{Search Strategy}

A literature search was run in September 2015 in the following databases: Medline using Ovid, PubMed, CINAHL using EBSCO, Embase using Ovid, PsycINFO and Open Access Theses and Dissertation. To facilitate the retrieval of the most relevant studies, the search was run without any filters, using both free text words and controlled vocabulary. An information specialist assisted in composing, revising and validating the search strategy for all the different databases. A sample query for PubMed is included in table one.

All the articles were exported to Endnote software (version $X 7^{22}$ ), where duplicates were removed manually during screening and by using the 'find duplicate' function. All articles were screened first by title and then abstract. Only the articles that were relevant to the topic were fully read. All the relevant article bibliographies were reviewed in order to identify any significant studies that could be included in this review, and those which may have been missed through the electronic search.

\section{Inclusion and exclusion criteria}

Studies were included in the review if they measured psychological stress and/or anxiety among university or college students at undergraduate or graduate level; using validated stress questionnaire/scale or anxiety scale and which examined the relationship between stress/anxiety and weight. The studies had to be original or empirical studies in the languages of English, Arabic, Dutch, or German. The languages were selected for ease of translation by the authors who have a good command of the chosen languages. Articles were included if they were published after the year 1985.

Articles were excluded if they were qualitative studies or if they were dissertations, posters, conference abstracts, commentaries, reviews, letters to editors or research studies which assessed stress as a consequence of elevated BMI. All studies addressing eating disorders, disordered eating, body image, body dissatisfaction and post-traumatic stress disorder were also excluded. Additionally, articles were omitted if they were looking specifically at college/university athletes or addressing working populations or students with psychiatric problems or high school students. Studies which aimed to validate instruments and questionnaires or test programs were not used in this review.

\section{Selection Process}

Two reviewers screened titles and abstracts independently to identify potential studies 
that met the inclusion criteria. A calibration exercise, which included the screening of 100 articles, was conducted to clarify the eligibility criteria. Once agreement was achieved, the reviewers identified the relevant articles independently and removed additional duplicates that were not detected with Endnote software. All potentially eligible articles were retrieved and a full text screening was conducted by two reviewers. The Kappa statistic was calculated to measure inter-rater agreement for full text screening, resulting in $\mathrm{Kw}=0.646(P<0.05)$, thus indicating a good level of agreement. When the two reviewers were in disagreement, a third reviewer settled the debate.

\section{Data Extraction and Quality Assessment}

Two reviewers independently extracted data from the studies that met the inclusion criteria. The extracted data included the place/institution where the study was conducted, the study design, the number of participants, gender, the student population, the stress instruments used in the study and their outcomes, as well as how weight was reported, and the results of the study. When differences were detected, discussions between the reviewers was used to resolve the divergence. The same reviewers also assessed the quality of the studies using the GRADE 4 guidelines which evaluates observational studies according to four distinct criteria: developing and including eligibility criteria, unflawed measurement of exposure and outcome, controlling for cofounding, and incomplete follow-up. ${ }^{23}$ 
Table 1: PubMed search strategy for the systematic review investigating the association of stress and anxiety with weight gain in university and college students.

\begin{tabular}{|c|c|c|}
\hline Search & Query & $\begin{array}{l}\text { Items } \\
\text { found }\end{array}$ \\
\hline$\# 13$ & Search (\#5 AND \#9 AND \#12) & 6139 \\
\hline \#12 & Search (\#10 OR \#11) & 1065357 \\
\hline$\# 11$ & $\begin{array}{l}\text { Search (universit*[tw] OR college*[tw] OR student*[tw] OR freshman*[tw] } \\
\text { OR sophomore*[tw] OR faculty[tw] OR faculties[tw] OR school*[tw] OR } \\
\text { institut*[tw] OR undergrad*[tw] OR under grad*[tw] OR academi*[tw] OR } \\
\text { classroom*[tw] OR class room*[tw]) }\end{array}$ & 1065357 \\
\hline$\# 10$ & Search (universities[mesh] OR students[mesh]) & 103106 \\
\hline \#9 & Search (\#6 OR \#7 OR \#8) & 731731 \\
\hline \#8 & $\begin{array}{l}\text { Search (waist circumference*[tw] OR abdominal circumference*[tw] OR } \\
\text { waist size*[tw] OR abdominal size*[tw] OR abdomen size*[tw] OR waist } \\
\text { adiposit*[tw] OR abdominal adiposit*[tw] OR abdomen adiposit*[tw] } \\
\text { OR waist fat[tw] OR abdominal fat[tw] OR abdominal fats[tw]OR waist } \\
\text { fat[tw] OR BMI[tw] OR body mass index[tw] OR over nutrition[tw] OR } \\
\text { overnutrition[tw] OR body size[tw] OR body weight*[tw] OR body fat[tw]) }\end{array}$ & 477134 \\
\hline \#7 & $\begin{array}{l}\text { Search (obese[tw] OR obesity[tw] OR over weight*[tw] OR } \\
\text { overweight* }[\text { tw] OR weight gain*[tw] OR weight increas*[tw] OR weight } \\
\left.\text { chang*[tw] OR excess weight }{ }^{*}[t w]\right)\end{array}$ & 301062 \\
\hline \#6 & $\begin{array}{l}\text { Search (overweight[mesh] OR body size[mesh]OR waist } \\
\text { circumference[mesh] OR Body Fat Distribution[mesh] OR body mass } \\
\text { index[mesh] OR Adipose tissue[mesh]) }\end{array}$ & 468953 \\
\hline \#5 & Search (\#1 OR \#2 OR \#3 OR \#4) & 2077829 \\
\hline \#4 & $\begin{array}{l}\text { Search (well being*[tw] OR wellbeing*[tw] OR strain*[tw] OR } \\
\text { burden*[tw]) }\end{array}$ & 1018060 \\
\hline \#3 & $\begin{array}{l}\text { Search (Burnout*[tw] OR burn out*[tw] OR workload*[tw] OR work } \\
\text { load*[tw] OR family support*[tw] OR familial support*[tw] OR social } \\
\text { support*[tw] OR society support*[tw] OR family pressure*[tw] OR familial } \\
\text { pressure*[tw] OR social pressure*[tw] OR society pressure }{ }^{*}[\text { tw] OR family } \\
\text { help*[tw] OR familial help*[tw] OR social help*[tw] OR society help*[tw] } \\
\text { OR family adjust*[tw] OR familial adjust*[tw] OR social adjust*[tw] OR } \\
\text { society adjust*[tw]) }\end{array}$ & 247452 \\
\hline \#2 & $\begin{array}{l}\text { Search (stress*[tw] OR anxious[tw] OR anxiet*[tw] OR hydro-cortiso*[tw] } \\
\text { OR hydrocortiso*[tw] OR cortiso*[tw] OR hypercortiso*[tw] OR } \\
\text { hyperhydrocortiso*[tw]) }\end{array}$ & 919666 \\
\hline$\# 1$ & $\begin{array}{l}\text { Search (stress, physiological[mesh] OR stress, psychological[mesh] OR } \\
\text { anxiety[mesh] OR performance anxiety[mesh] OR social support[mesh] } \\
\text { OR mental health[mesh] OR“Hydrocortisone/biosynthesis"[Mesh] OR } \\
\text { "Hydrocortisone/blood"[Mesh] OR “Hydrocortisone/secretion"[Mesh]) }\end{array}$ & 379748 \\
\hline
\end{tabular}

tw: text word; Mesh: medical subject headings; and a $\left.{ }^{*}\right)$ indicates truncation 


\section{Results}

\section{Study selection}

The PRISMA flow chart for describing the search process is reported in figure 1. Out of a total of 15851 records identified, Endnote removed 4279 duplicates, and 11572 records were screened by title and then by abstract. 11345 records were excluded since 9672 were irrelevant to the topic of this review; 558 did not meet the language criteria, 1103 were duplicates not detected by Endnote, ${ }^{22}$ and 12 were published before 1985 . The resulting 227 studies were read fully and an additional 207 articles were excluded for the following exclusion criteria: nine of the studies did not meet our language criteria for eligibility, 60 did not assess the relation between BMI and stress, 66 studies did not use a validated stress questionnaire, seven studies did not report any weight, eight studies assessed body image and eating disorders, one study was conducted on athletes, 41 were abstracts, posters, dissertations, editor letters or reviews, seven studies did not use university or college students as their sample population and six studies were testing a program or validating a tool. One study was removed because it was assessing post-traumatic stress disorder and another study was found to be a duplicate study that was published in two separate journals and hence after contacting the author, it was confirmed that it was duplicate and thus removed. Of the screened records, 20 met the inclusion criteria and were judged as eligible for this systematic review (Figure one). ${ }^{24-43}$ An updated literature search was repeated in March 2017 to identify any new eligible manuscripts that had been published since September 2015. A total of 2720 publications were retrieved. Two reviewers re-assessed the articles independently and determined that five were eligible to be added to this review. ${ }^{44-48}$ Therefore, a total of 25 studies have been included and assessed in this systematic review. 


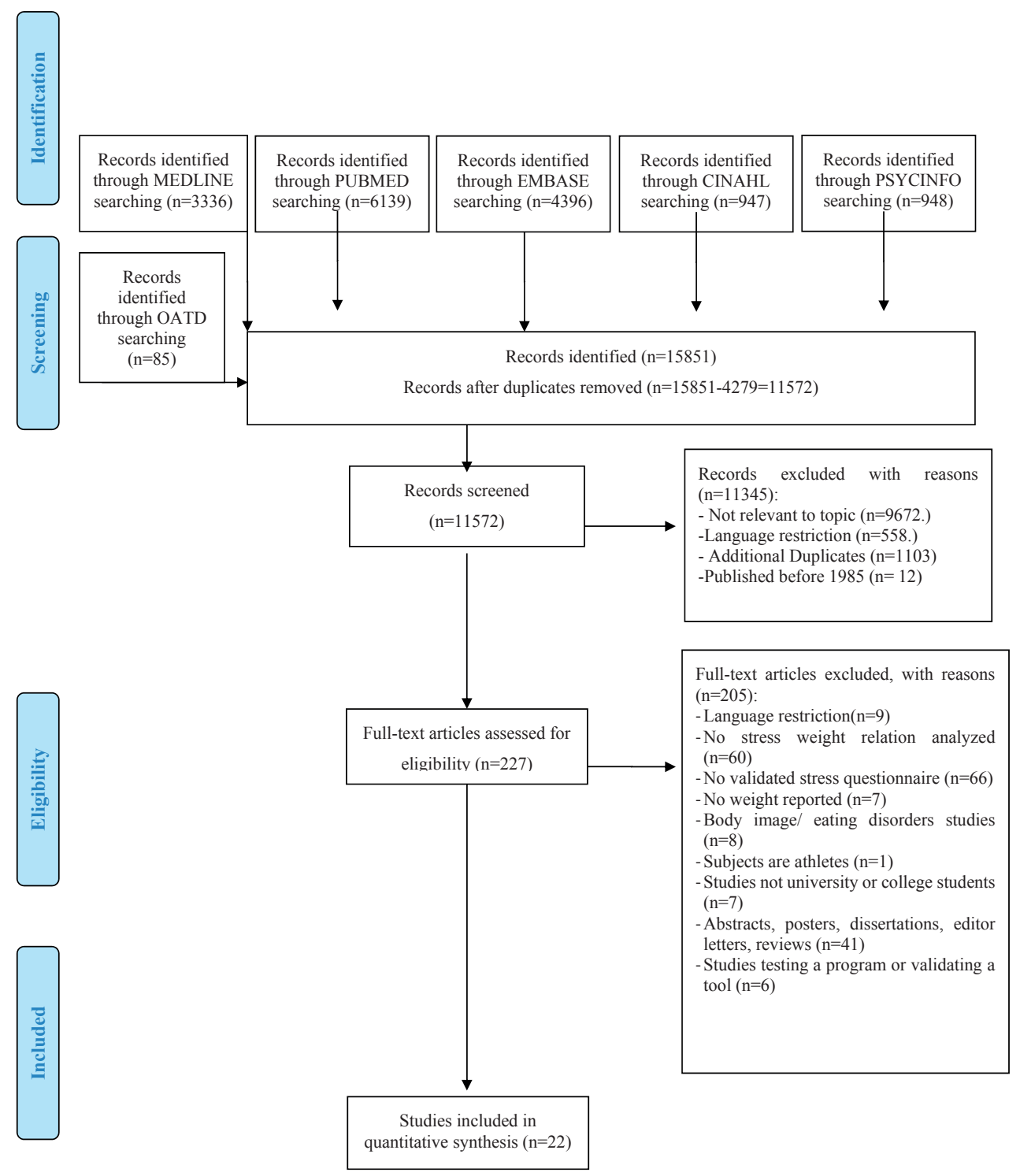

\section{Figure 1:}

PRISMA Flow Chart for article selection process for systematic review assessing weight change as related to stress in university and college students 


\section{Study Characteristics}

The characteristics of the included studies assessing the association between stress and weight or BMI are reported in table 2.

\section{Methodology:}

The included studies were all observational and used a survey methodology including validated stress questionnaires. Twenty three studies used a cross-sectional design, comparing groups, ${ }^{24-26,28-41,43-48}$ and two were longitudinal. ${ }^{27,42}$

\section{Stress/anxiety:}

Stress and/or anxiety were assessed using validated questionnaires which were: The Perceived Stress Survey, ${ }^{24}$ The Perceived Stress Score Index, ${ }^{28}$ a pre-designed validated questionnaire, ${ }^{25}$ The Inventory of College Students' Recent Life Experiences Scale, ${ }^{43}$ The Speilberger State/Trait Anxiety Strain Questionnaire, ${ }^{26}$ a 40 -item health behavior survey, ${ }^{27}$ The Hospital Anxiety and Depression Scale, ${ }^{29}$ The Stress Rating Scale, ${ }^{41}$ The Psychiatric Diagnostic Screening Questionnaire, ${ }^{30}$ The Rhode Island Stress and Coping Inventory, ${ }^{31}$ The State-Trait Personality Inventory, ${ }^{32}$ The Brief Symptoms Rating Scale, ${ }^{33}$ The Social Interaction Anxiety Scale, ${ }^{34}$ The Beck Anxiety Scale, ${ }^{35,37}$ Cohen's Perceived Stress Scale, ${ }^{36,42,45,47,48}$ The Depression Anxiety Stress Scale, ${ }^{38,44}$ The Patient Health Questionnaire Anxiety Screening, ${ }^{39}$ The Undergraduate Stress Questionnaire, ${ }^{40}$ The Anxiety Scale of the General Health Questionnaire. ${ }^{46}$

\section{Weight:}

Of the 25 studies included, 13 studies had a design where the researchers weighed the students. ${ }^{25,28,33,35,36,38,41-44,46-48}$ Weight was self-reported by the students in ten studies. ${ }^{26,29-32,34,37,39,40,45}$ Weight was self-reported at baseline in the study conducted by Economos and colleagues, ${ }^{27}$ but was measured using a scale at follow-up. Adams-Campbell and colleagues ${ }^{24}$ did not report on the method that was used to measure weight. 


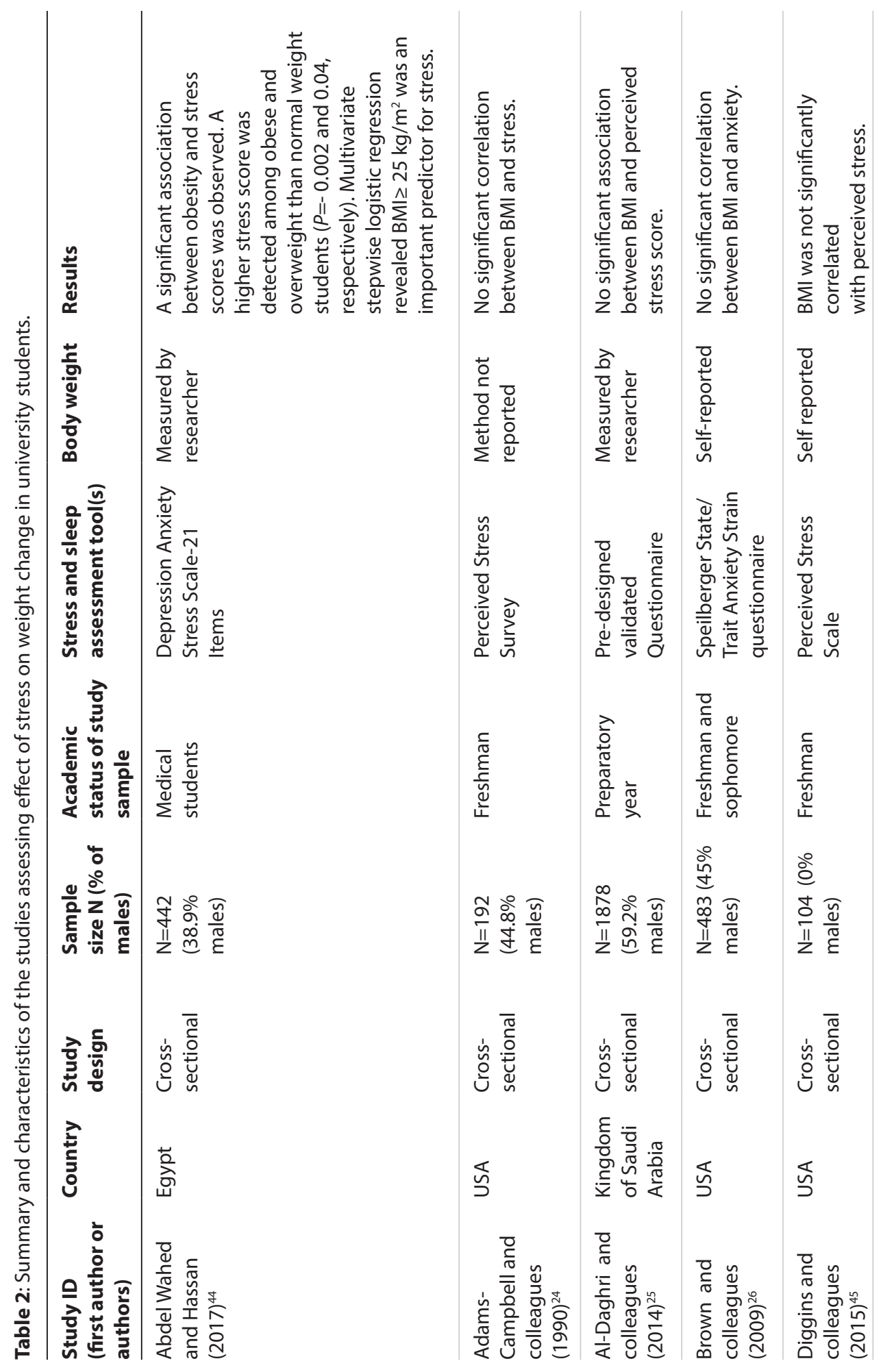




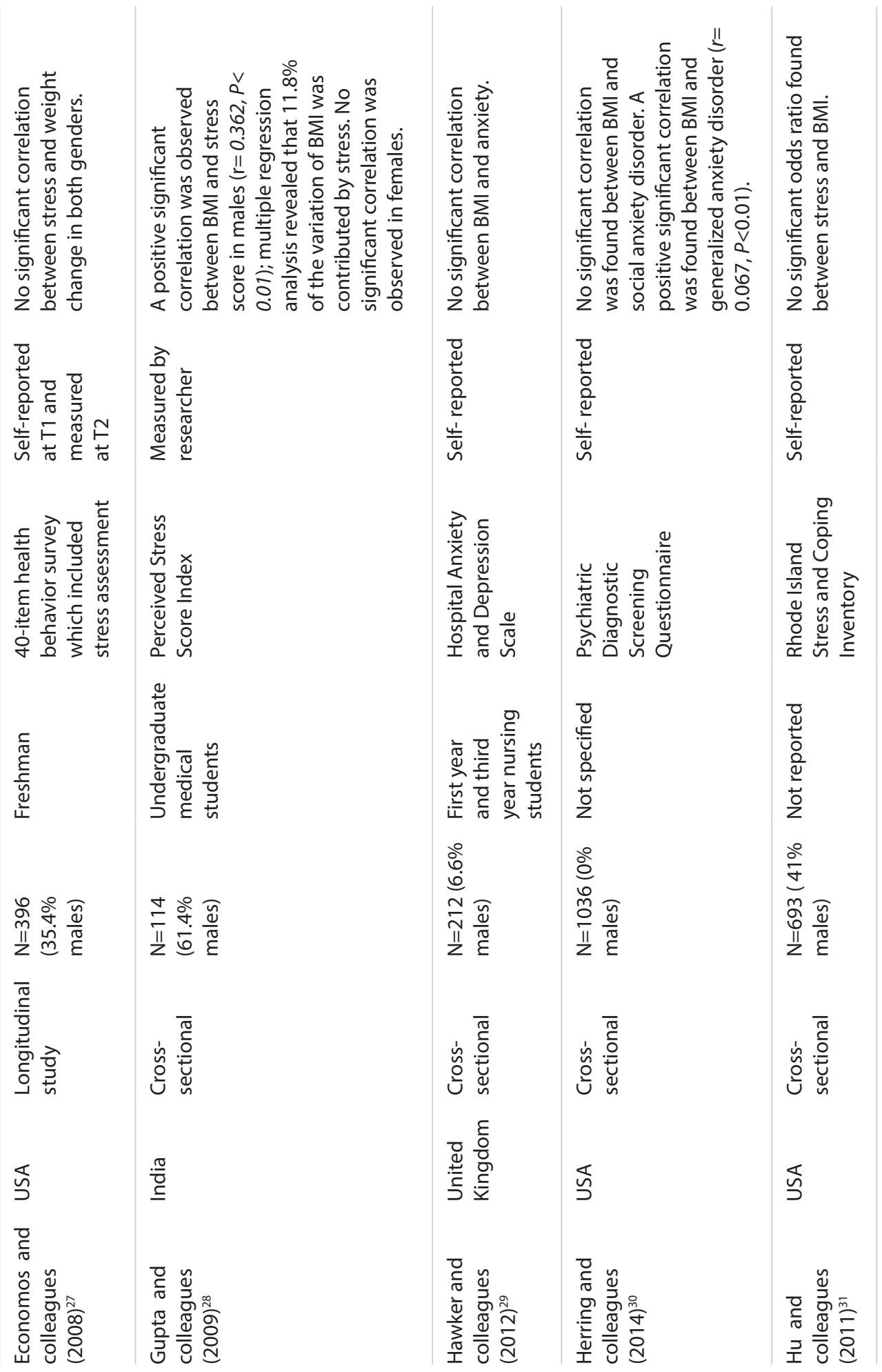



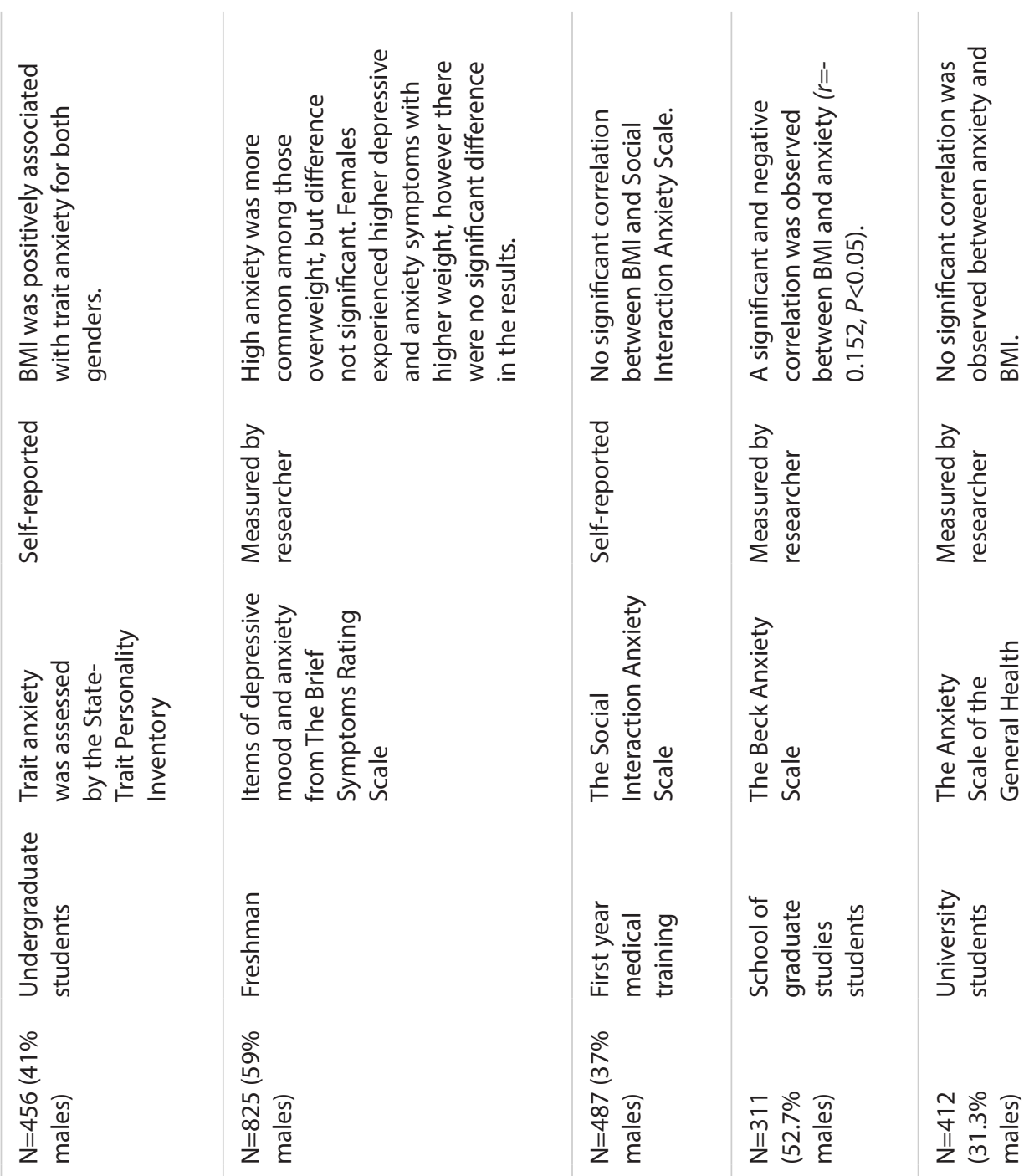

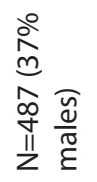
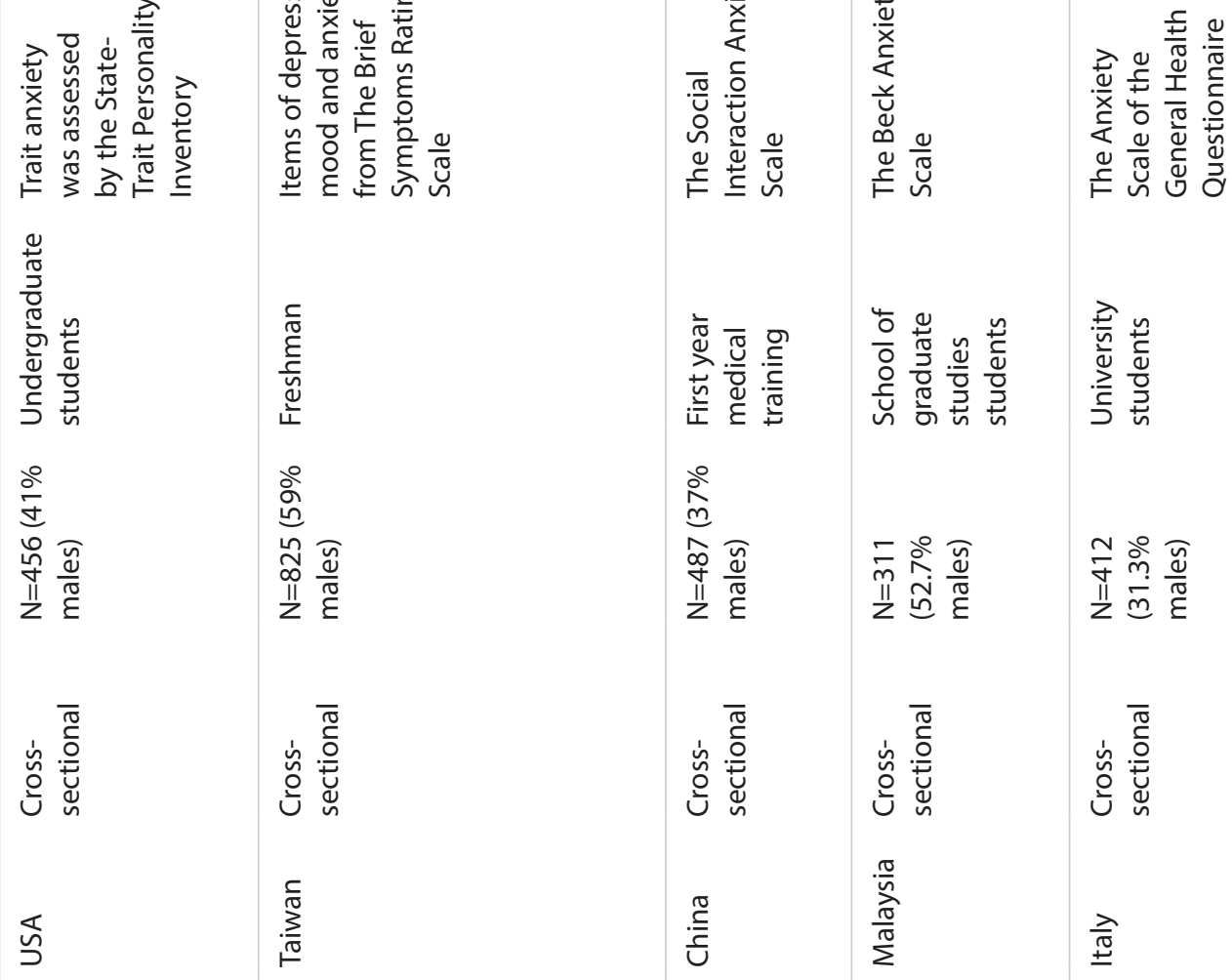

岕.

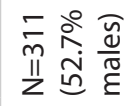

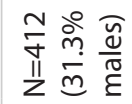
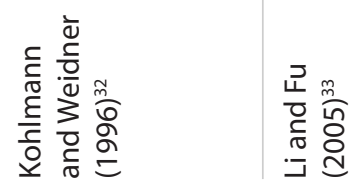

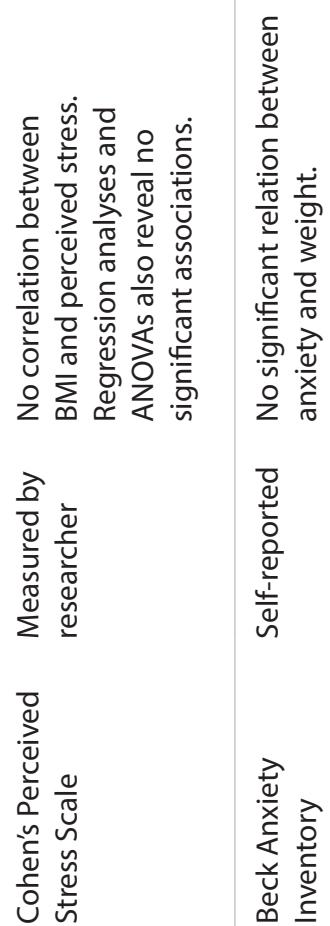

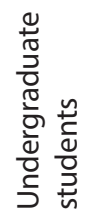

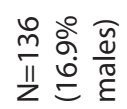

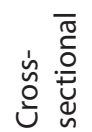

$\frac{\pi}{\frac{\pi}{0}}$

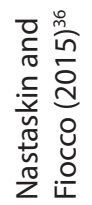

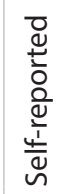

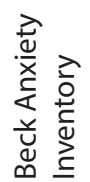

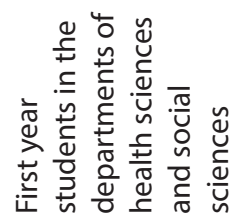

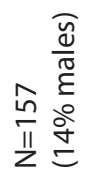

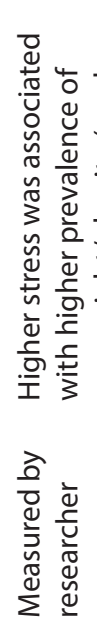

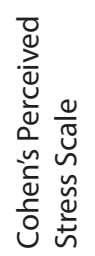

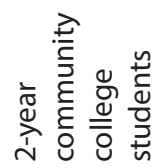

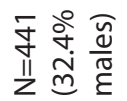

峞

$\stackrel{\nwarrow}{\leftrightharpoons}$

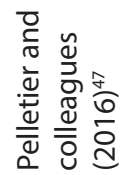

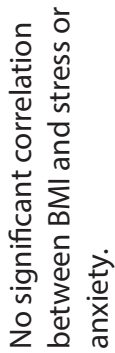

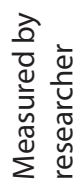

离

$\frac{0}{\frac{0}{0}}$ 凶 产离

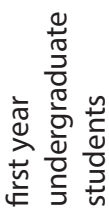

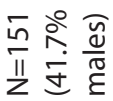
峞

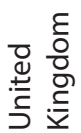

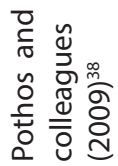




\begin{tabular}{|c|c|c|c|}
\hline 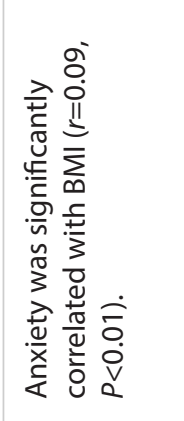 & 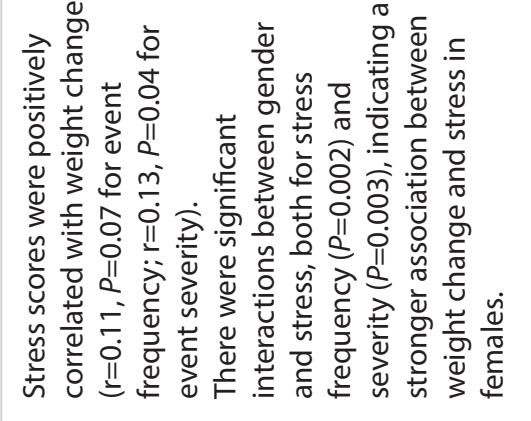 & 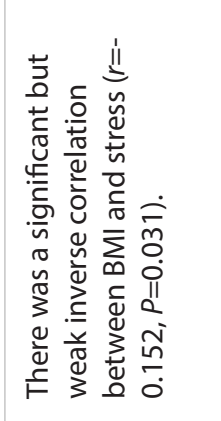 & 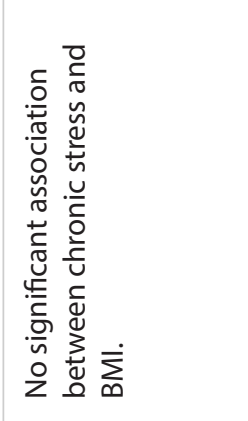 \\
\hline 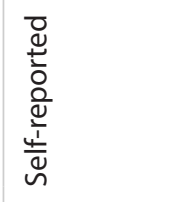 & 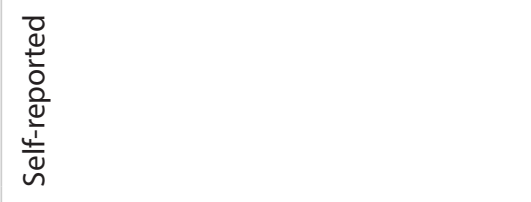 & 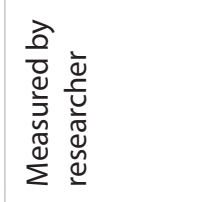 & 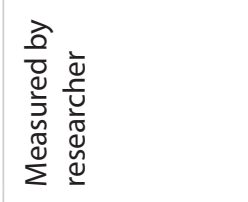 \\
\hline 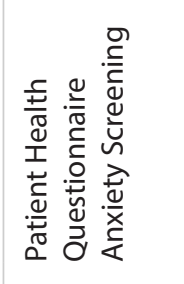 & 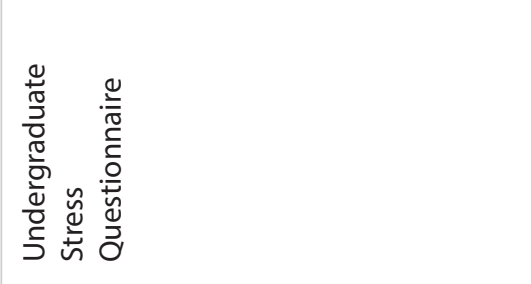 & 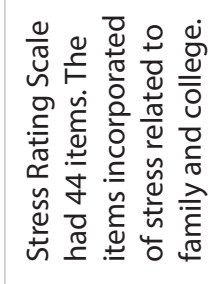 & 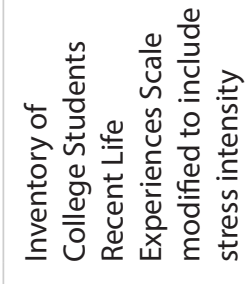 \\
\hline 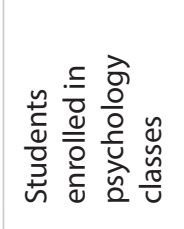 & 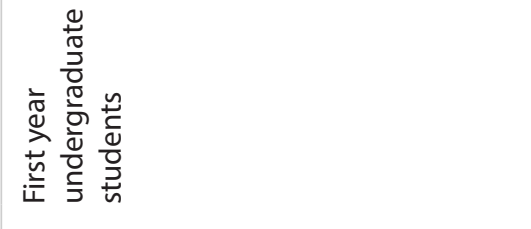 & 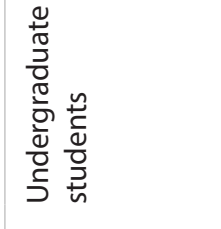 & 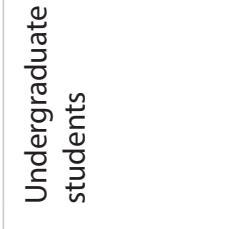 \\
\hline 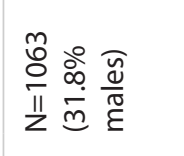 & 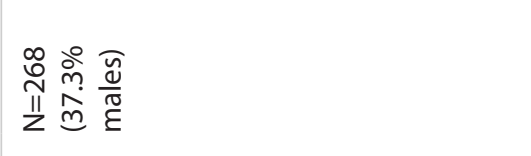 & 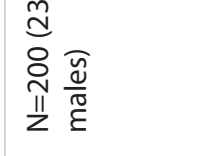 & 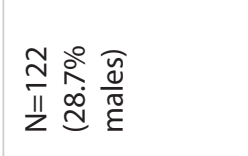 \\
\hline 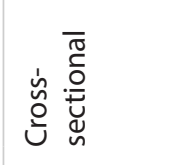 & 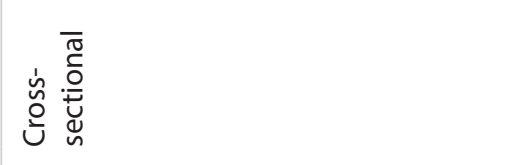 & 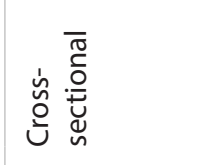 & 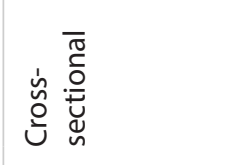 \\
\hline 孚 & $\begin{array}{l}\frac{\sigma}{0} \\
\stackrel{0}{\sigma} \\
\end{array}$ & $\begin{array}{l}\frac{\sqrt{0}}{\bar{c}} \\
\underline{\underline{g}}\end{array}$ & 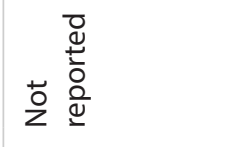 \\
\hline 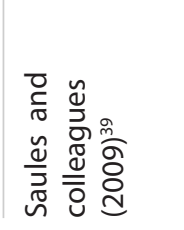 & 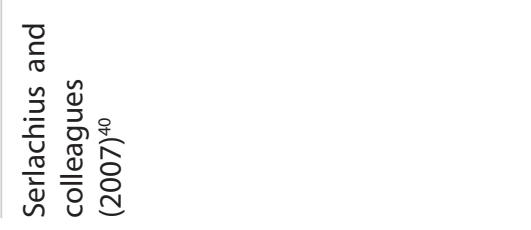 & 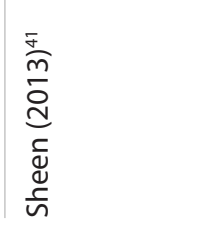 & 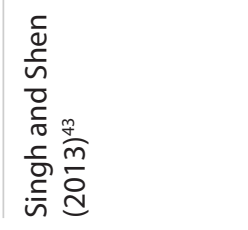 \\
\hline
\end{tabular}




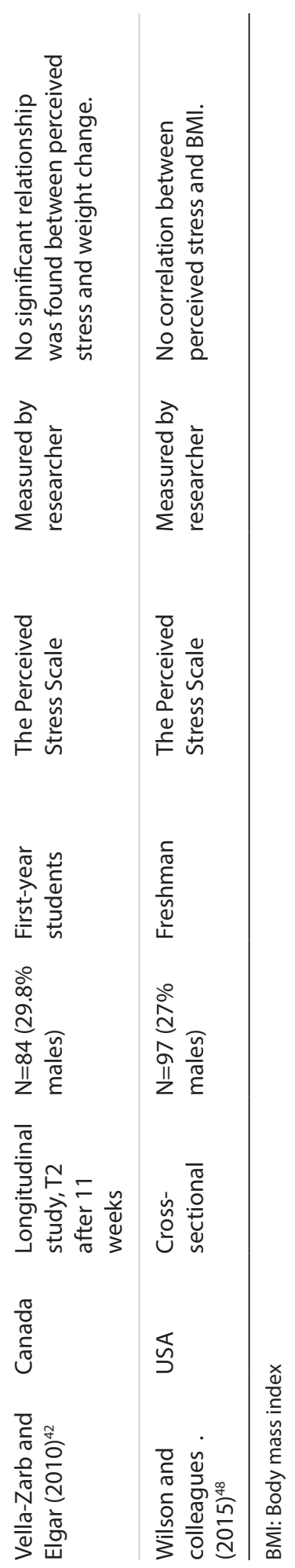




\section{Methodological quality:}

The results of the quality of evidence assessment of the included studies was detailed in table 3 according to the GRADE 4 guidelines. ${ }^{23}$ Five studies provided adequate and appropriate information about eligibility criteria. ${ }^{25,42,43,45,48}$ Twelve studies provided unflawed measurement of exposure and outcome. ${ }^{25,33,35,36,38,41-44,47,48}$ Almost all of the studies failed to adequately control confounding factors with the exception of the study conducted by Mucci and colleagues, ${ }^{46}$ and only two studies had complete follow-up. ${ }^{27,42}$ Only one study had a strong methodological design, as assessed using GRADE 4 criteria, ${ }^{23}$ when compared to the rest of the included studies in this review and the authors found no significant association between stress and weight change. ${ }^{42}$

\section{Population:}

All 25 studies included university students as the sample population. The studies used various age groups, which ranged from students in their freshman year to sophomores and graduate students. Three studies did not specify their student population. ${ }^{30,31,46}$ The sample size of the 25 studies ranged between 84 and 1878 participants.

\section{Setting:}

The studies took place in several countries. Almost half took place in the United States, and the rest were conducted in the United Kingdom, India, Canada, Kingdom of Saudi Arabia, Taiwan, China, Malaysia, Turkey, Egypt and Italy. One study did not report the country. ${ }^{43}$

\section{Outcomes assessed:}

The outcomes assessed included sleep quality and quantity, stress and anxiety levels, and body weight, weight change and/or BMI.

\section{Findings}

\section{Effect of Stress and Anxiety on Weight}

Out of the 25 studies analyzed in this review, 23 were cross-sectional and two were longitudinal. Eight cross-sectional studies found no significant association between stress level and $\mathrm{BMI},{ }^{24,25,31,36,38,43,45,48}$ and the two studies with a longitudinal design also found no significant change in weight as related to stress level. ${ }^{27,42}$ One found a significant association between BMI and stress only for males and not for females, ${ }^{28}$ whereas one study concluded that higher stress levels are associated with a higher prevalence of being overweight/obese; however, this relation was no longer significant after controlling for weight related health behavior. ${ }^{47}$ Another one of the included cross-sectional studies found that higher stress was associated with having a higher weight, ${ }^{44}$ whereas another 
study found that a higher stress score was positively associated with weight change as reported by respondents. ${ }^{40}$ Additionally, one study found BMI to be inversely correlated with stress $(r=-0.152, P=0.031) .{ }^{41}$

As for the studies assessing anxiety, all the studies included in this review were crosssectional studies. Five of the studies revealed a non-significant association between anxiety and BMI. ${ }^{26,29,30,37,46}$ Additionally, one of the studies found no significant relationship between BMI and Social Interaction Anxiety Scale. ${ }^{34}$ One study found a positive association between $\mathrm{BMI}$ and trait anxiety ${ }^{32}$; and one found an inverse correlation between $\mathrm{BMI}$ and anxiety $(r=0.152, P<0.05){ }_{i}^{35}$ whereas, two studies found that higher anxiety was associated with a higher BMI. ${ }^{33,39}$

Stress scores were positively correlated with weight change as reported by Serlachius and colleagues ( $r=0.11, P=0.07$ for event frequency; $r=0.13, P=0.04$ for event severity). In a logistic regression analysis, Serlachius and colleagues observed that stress severity was associated with both a greater risk of weight gain (odds ratio, $O R=1.27,95 \% \mathrm{Cl}, 1.12$ to $1.44, P=0.001)$ and weight loss ( $O R=1.33,1.10$ to $1.61, P=0.003)$, after adjustment for age and gender. Similarly, stress frequency was associated with both a greater risk of weight gain ( $O R=1.40,1.16$ to $1.69, P=0.001$ ) and weight loss ( $O R=1.39,1.05$ to $1.83, P=0.02$ ). These associations did not change after further adjustments. Additionally, there were significant gender by stress interactions, for both stress frequency $(P=0.002)$ and severity $(P=0.003)$, and it was concluded that a stronger association between weight change and stress in women is indicated. ${ }^{40}$

Gupta and colleagues, on the other hand, reported a significant positive correlation between $\mathrm{BMI}$ and stress in males $(r=0.362, P<0.01)$. Multiple regression analysis in males revealed that $11.8 \%$ of variation in $\mathrm{BMI}$ was contributed by stress. In case of females, however, no significant correlation was observed. ${ }^{28}$

One of the studies reported a significant, but weak negative correlation, between BMI and stress $(r=-0.15, P=0.031) .{ }^{41}$ Another study found that higher stress scores were detected among obese and overweight students $\left(P=-0.002\right.$ and 0.04 , respectively). ${ }^{44}$ Pelletier and colleagues found that higher stress levels were associated with a greater prevalence of being overweight and obese (crude prevalence ratio $=1.05 ; 95 \% \mathrm{Cl}, 1.01$ to 1.09 ), however significance was lost after controlling for health risk behaviors. ${ }^{47}$

As for anxiety, a key manifestation of stress, five studies found significant associations between BMI and anxiety. . $30,32,35,39,46$ Herring and colleagues found no significant correlation between $\mathrm{BMI}$ and social anxiety disorder, however a significant positive, but weak, correlation was observed between BMI and generalized anxiety disorder $(r=0.067$, $P<0.01) .{ }^{30}$ Kohlmann and Weidner reported a significant association between BMI and trait anxiety in both men and women ${ }^{32}$; however, it is not clear whether this association was positive or negative. Saules and colleagues observed a significant positive correlation between anxiety and $\mathrm{BMI}(r=0.09, P<0.01) .{ }^{39}$ Mokhtari and colleagues ${ }^{35}$ on the other 
hand reported a significant and negative correlation between BMI and anxiety $(r=-0.152$, $p<0.05)$, suggesting that participants with lower levels of anxiety had higher BMI scores. ${ }^{35}$ Pothos and colleagues reported no significant association between BMI and stress or anxiety in the whole sample, or for males and females separately. ${ }^{38}$ Hawker and colleagues found no significant correlation between $\mathrm{BMI}$ and mental well-being variables and between $\mathrm{BMI}$ and anxiety. ${ }^{29}$

\section{Sleep}

Only one study by Serlachius and colleagues ${ }^{40}$ reported on sleep and found significant decreased sleep quality in university students; however, the study indicated that there was no significant relationship between decreased sleep and weight change. ${ }^{40}$ 
Table 3: Risk of bias summary: review authors' judgements about each risk of bias item for each included study according to Grade guidelines.

\begin{tabular}{|c|c|c|c|c|}
\hline & 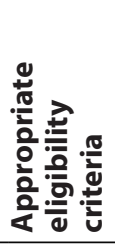 & 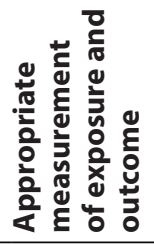 & 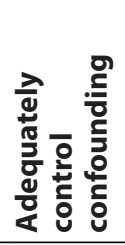 & 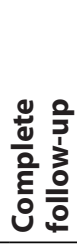 \\
\hline Abdel Wahed and Hassan (2017) & - & + & - & - \\
\hline Adams-Cambell and colleagues (1990) & - & $?$ & - & - \\
\hline Al-Daghri and colleagues (2014) & + & + & - & - \\
\hline Brown and colleagues (2009) & - & $?$ & $?$ & - \\
\hline Diggins and colleagues (2015) & + & - & - & - \\
\hline Economos and colleagues (2008) & $?$ & - & - & + \\
\hline Gasparishvilli and colleagues (2014) & - & + & $?$ & - \\
\hline Gupta and colleagues (2009) & - & - & - & - \\
\hline Hawker and colleagues (2012) & - & $?$ & - & - \\
\hline Helen, and colleagues (2013) & - & $?$ & - & - \\
\hline Herring and colleagues (2014) & - & $?$ & $?$ & - \\
\hline Hu and colleagues (2011) & - & $?$ & - & - \\
\hline Kohlmann and Weidner (1996) & - & - & - & - \\
\hline Li and Fu (2005) & - & + & - & - \\
\hline Liao and colleagues (2010) & - & $?$ & - & - \\
\hline Mokhtari (2015) & $?$ & + & - & - \\
\hline Mucci and colleagues (2016) & - & - & + & - \\
\hline Nastaskin (2015) & - & + & $?$ & - \\
\hline Ozenoglu and colleagues (2013) & - & $?$ & - & - \\
\hline Pelletier and colleagues (2016) & - & + & - & - \\
\hline Pothos and colleagues (2009) & - & + & - & - \\
\hline Saules and colleagues (2008) & - & $?$ & $?$ & - \\
\hline Serlachius and colleagues (2007) & - & - & $?$ & - \\
\hline Sheen (2013) & - & + & - & - \\
\hline Singh and Shen (2013) & + & + & $?$ & - \\
\hline Vella-Zarb and Elgar (2010) & + & + & - & + \\
\hline Wilson and colleagues (2015) & + & + & - & - \\
\hline
\end{tabular}

(+) low risk of bias; criteria met in the study design, (-) high risk of bias; criteria not met in study design, (?) unclear risk of bias; authors failed to report criteria 


\section{Discussion}

This systematic review provides a thorough summary of the literature assessing the relationship between stress, anxiety, and weight status and/or weight change among university students. Overall, we have identified evidence from twenty-five studies suggesting minor, if not negligible, associations between stress and anxiety and weight change during university or college enrollment. A few studies did find an association between stress or anxiety and BMl; however, the results were not consistent, with some reporting a positive association and others reporting an inverse one. Additionally, there is a lack of sufficient literature with appropriate study designs to adequately address the question of this systematic review.

The discrepancy in results from the studies in this review may be due to the difficulty of disentangling the relationship between stress and its hypothesized influence on weight change, which is further compounded by variation in BMI. Boyce and Kujjer ${ }^{49}$ concluded that if students start with a high BMI, they tend to gain more weight than average. Whereas, students who begin with a lower BMI may lose weight secondary to the high stress levels imposed. This double effect would lead to a non-significant relationship when analyzing the total set of data. ${ }^{49}$ Unfortunately, this double effect was not assessed in 24 out of 25 studies included in this review. This effect was first noted in a prospective study assessing the level of stress and weight changes among civil servants, where stress was found to have a differential effect on weight change based on BMI. ${ }^{50}$ There may be additional evidence for this in the findings of Serlachius and colleagues, who found a differential effect of stress on weight change as some students lost weight while others gained at higher stress levels; however, they did not assess whether this differential effect was associated with pre-university BMI. ${ }^{40}$

In addition to high stress and anxiety levels, university students are generally dissatisfied with their sleeping habits ${ }^{51}$ and suffer from sleep disturbances ${ }^{52}$ In the articles that met the inclusion criteria for this systematic review, only one study reported on sleep and found significant decreased sleep quality in university students; however, the study indicated that there was no significant relationship between decreased sleep and weight change. ${ }^{40}$ Scientific evidence however suggests that shortage of sleep does serve as a risk factor for obesity. ${ }^{53}$

This systematic review only included studies that used validated scales for assessing stress and anxiety levels. Although there is evidence to suggest increased stress levels are a risk factor related to adiposity, ${ }^{14}$ this review is unique in that it examined the association of stress and anxiety and body weight among university or college students during their years of study. There were several limitations in this systematic review. In general, the quality of data was weak as apparent from table 3. Almost all the studies meeting the inclusion criteria had a weak study design, used convenience sampling and inappropriate randomization. There were also many different scales used to assess stress. Therefore, 
the methodological limitations of the included studies lower the confidence of the conclusions of this review. Additionally, most of the studies used in this systematic review had a cross-sectional design, which is a major disadvantage. The quality of evidence from cross-sectional studies is weak, lacks follow-up and can only report relationships at one point in time. Another limitation is that many of the studies relied on subjective information about weight given by the students themselves, and thus not objectively measuring study participants can lead to report bias (especially in younger age groups where those with a lower BMI tend to over-report weight as opposed to those who have a higher BMI, who tend to underreport weight). ${ }^{54}$ Moreover, none of the studies in this review included an analysis of body composition; only BMI was reported as a proxy for adiposity. This could lead to a bias when reporting the results of BMI; a higher BMI could sometimes be linked to having more muscle mass, especially in a younger population. ${ }^{55}$ Unfortunately, studies comparing college students to non-college attending young adults are scarce. It is possible that any increase in weight is not necessarily due to university or college enrollment and stress imposed on students, but rather on the increased weight gain that occurs in this age range in general. ${ }^{56}$ Another limitation of the studies in this review is inadequate differentiation between stress and anxiety and at times, the terms were used almost interchangeably. Future research should distinguish between anxiety and stress and assess their effect on weight individually.

This systematic review adds evidence to the existing body of knowledge about the relationship between levels of stress and anxiety and body weight among university students. Although previous studies have reported higher stress and anxiety levels in university and college students as compared to the general population, ${ }^{7}$ this review found no associations between stress/anxiety and weight gain or a higher BMI. Universities need to build the ground for awareness campaigns about weight management and direct students to weight and stress management programs during this critical period of a student's life, irrespective of BMI or weight change. Additional longitudinal studies need to be conducted to critically investigate the changes in weight as related to stress and anxiety levels among university students. 


\section{References}

1. Cohen S, Kessler RC, Gordon LU. Strategies for measuring stress in studies of psychiatric and physical disorders. In: Cohen S, Kessler RC, Gordon LU, editors. Measuring stress: A guide for Health and Social Scientists. Oxford: Oxford University Press; 1995.

2. Saravanan C, Wilks R. Medical Students' Experience of and Reaction to Stress: The Role of Depression and Anxiety. Scientific World J. 2014:1-8.

3. Stallman HM. Psychological distress in university students: A comparison with general population data. Aust Psychol. 2010;45(4):249-257.

4. Campbell RL, Svenson LW, Jarvis GK. Perceived level of stress among university undergraduate students in Edmonton, Canada. Percept Mot Skills. 1992;75(2):552-554.

5. Dyrbye LN, Thomas MR, Shanafelt TD. Systematic review of depression, anxiety, and other indicators of psychological distress among U.S. and Canadian medical students. Acad Med. 2006;81(4):354-373.

6. Galatzer-Levy IR, Bonanno GA. Heterogeneous patterns of stress over the four years of college: associations with anxious attachment and ego-resiliency. J Pers. 2013;81(5):476-486.

7. Kumaraswamy N. Academic Stress, Anxiety and Depression among College Students- A Brief Review. International Review of Social Sciences and Humanities. 5(1):135-143

8. Regehr C, Glancy D, Pitts A. Interventions to reduce stress in university students: a review and meta-analysis. J Affect Disord. 2013;148(1):1-11.

9. Tosevski DL, Milovancevic MP, Gajic SD. Personality and psychopathology of university students. Curr Opin Psychiatry. 2010;23(1):48-52.

10. Lund HG, Reider BD, Whiting AB, Prichard JR. Sleep Patterns and Predictors of Disturbed Sleep in a Large Population of College Students. J Adoles Health.46(2):124-132.

11. Dallman MF, la Fleur SE, Pecoraro NC, Gomez F, Houshyar H, Akana SF. Minireview: glucocorticoids--food intake, abdominal obesity, and wealthy nations in 2004. Endocrinology. 2004;145(6):2633-2638.

12. Groesz LM, McCoy S, Carl J, et al. What is eating you? Stress and the drive to eat. Appetite. 2012;58(2):717-721.

13. Chrousos GP. The role of stress and the hypothalamic-pituitary-adrenal axis in the pathogenesis of the metabolic syndrome: neuro-endocrine and target tissue-related causes. Int J Obes Relat Metab Disord. 2000;24 Suppl 2:S50-55.

14. Wardle J, Chida Y, Gibson EL, Whitaker KL, Steptoe A. Stress and adiposity: a meta-analysis of longitudinal studies. Obesity (Silver Spring). 2011;19(4):771-778.

15. Adam TC, Epel ES. Stress, eating and the reward system. Physiol Behav. 2007;91(4):449-458.

16. $\mathrm{Ng} \mathrm{M}$, Fleming $T$, Robinson $\mathrm{M}$, et al. Global, regional, and national prevalence of overweight and obesity in children and adults during 1980-2013: a systematic analysis for the Global Burden of Disease Study 2013. Lancet. 2014;384(9945):766-781.

17. Mokdad AH, Serdula MK, Dietz WH, Bowman BA, Marks JS, Koplan JP. The spread of the obesity epidemic in the United States, 1991-1998. JAMA. 1999;282(16):1519-1522. 
18. Levitsky DA, Halbmaier CA, Mrdjenovic G. The freshman weight gain: a model for the study of the epidemic of obesity. Int J Obes Relat Metab Disord. 2004;28(11):1435-1442.

19. Vella-Zarb RA, Elgar FJ. The 'freshman 5': a meta-analysis of weight gain in the freshman year of college. J Am Coll Health. 2009;58(2):161-166.

20. Kvaavik E, Tell GS, Klepp KI. Predictors and tracking of body mass index from adolescence into adulthood: follow-up of 18 to 20 years in the Oslo Youth Study. Arch Pediatr Adolesc Med. 2003;157(12):1212-1218.

21. Moher D, Liberati A, Tetzlaff J, Altman DG. Preferred reporting items for systematic reviews and meta-analyses: the PRISMA statement. Int J Surg. 2010;8(5):336-341.

22. Endnote X7 [computer program] Version X7.7. New York, NY: Thomson Reuters; 2016.

23. Guyatt GH, Oxman AD, Vist G, et al. GRADE guidelines: 4. Rating the quality of evidence--study limitations (risk of bias). J Clin Epidemiol. 2011;64(4):407-415.

24. Adams-Campbell LL, Washburn RA, Haile GT. Physical activity, stress, and type A behavior in blacks. J Nah Med Assoc. 1990;82(10):701-705.

25. Al-Daghri NM, Al-Othman A, Al-Attas OS, et al. Stress and cardiometabolic manifestations among Saudi students entering universities: a cross-sectional observational study. BMC Public Health. 2014;14:391.

26. Brown SL, Schiraldi GR, Wrobleski PP. Association of eating behaviors and obesity with psychosocial and familial influences. J Health Educ. 2009;40(2):80-89.

27. Economos CD, Hildebrandt ML, Hyatt RR. College freshman stress and weight change: differences by gender. Am J Health Behav. 2008;32(1):16-25.

28. Gupta S, Ray TG, Saha I. Overweight, obesity and influence of stress on body weight among undergraduate medical students. Indian J Community Med. 2009;34(3):255-257.

29. Hawker CL. Physical activity and mental well-being in student nurses. Nurse Educ Today. 2012;32(3):325-331.

30. Herring MP, O'Connor PJ, Dishman RK. Self-esteem mediates associations of physical activity with anxiety in college women. Med Sci Sports Exerc. 2014;46(10):1990-1998.

31. Hu D, Taylor T, Blow J, Cooper TV. Multiple health behaviors: Patterns and correlates of diet and exercise in a Hispanic college sample. Eat Behav. 2011;12(4):296-301.

32. Kohlmann C-W, Weidner G. Emotional correlates of body weight: The moderating effects of gender and family income. Anxiety Stress Coping. 1996;9(4):357-367.

33. Li YM, Fu CC. Weight, weight perception and psychiatric distress in freshmen at a national university in Hualien county. Tzu Chi Med. 2005;17(3):169-175.

34. Liao Y, Knoesen NP, Castle DJ, et al. Symptoms of disordered eating, body shape, and mood concerns in male and female Chinese medical students. Compr Psychiatry. 2010;51(5):516-523.

35. Mokhtari T, Jamaluddin R, Saad HA. Lifestyle and psychological factors associated with body weight status among university students in Malaysia. Pakistan J Nut. 2015;14(1):18-28.

36. Nastaskin RS, Fiocco AJ. A survey of diet self-efficacy and food intake in students with high and low perceived stress. Nutrition J. 2015;14(1).

37. Ozenoglu A, Kumcagiz $H$, Tokay A, et al. Relationships of body image and eating attitudes with 
sociodemographic, psychologic and nutritional factors in university students attending first classes. Turk Klin TIP BILIM. 2013;33(4):972-980.

38. Pothos EM, Tapper K, Calitri R. Cognitive and behavioral correlates of BMI among male and female undergraduate students. Appetite. 2009;52(3):797-800.

39. Saules KK, Collings AS, Hoodin F, et al. The contributions of weight problem perception, BMI, gender, mood, and smoking status to binge eating among college students. Eat Behav. 2009;10(1):1-9.

40. Serlachius $A$, Hamer M, Wardle J. Stress and weight change in university students in the United Kingdom. Physiol Behav. 2007;92(4):548-553.

41. Sheen H. Blood Pressure, Stress and Body Mass Index (BMI) among Youngsters in South India. International Journal of Nursing Education. 2013;5(1):65-70.

42. Vella-Zarb RA, Elgar FJ. Predicting the 'freshman 15': Environmental and psychological predictors of weight gain in first-year university students. Health Educ J. 2010;69(3):321-332.

43. Singh K, Shen BJ. Abdominal obesity and chronic stress interact to predict blunted cardiovascular reactivity. Int J Psychophysiol. 2013;90(1):73-79.

44. Abdel Wahed WY, Hassan SK. Prevalence and associated factors of stress, anxiety and depression among medical Fayoum University students. Bull Alexandria Fac. 2017;53(1):77-84.

45. Diggins A, Woods-Giscombe C, Waters S. The association of perceived stress, contextualized stress, and emotional eating with body mass index in college-aged Black women. Eat Behav. 2015; 19:188-192.

46. Mucci N, Giorgi G, De Pasquale Ceratti S, Fiz-Perez J, Mucci F, Arcangeli G. Anxiety, StressRelated Factors, and Blood Pressure in Young Adults. Front Psychol. 2016;7:1682.

47. Pelletier JE, Lytle LA, Laska MN. Stress, Health Risk Behaviors, and Weight Status Among Community College Students. Health Educ Behav. 2016;43(2):139-144.

48. Wilson SM, Darling KE, Fahrenkamp AJ, D'Auria AL, Sato AF. Predictors of Emotional Eating During Adolescents'Transition to College: Does Body Mass Index Moderate the Association Between Stress and Emotional Eating? J Am Coll Health. 2015;63(3):163-170.

49. Boyce JA, Kuijer RG. Perceived stress and freshman weight change: the moderating role of baseline body mass index. Physiol Behav. 2015;139:491-496.

50. Kivimaki M, Head J, Ferrie JE, et al. Work stress, weight gain and weight loss: evidence for bidirectional effects of job strain on body mass index in the Whitehall II study. Int J Obes (Lond). 2006;30(6):982-987.

51. Hicks RA, Fernandez C, Pellegrini RJ. Striking changes in the sleep satisfaction of university students over the last two decades. Percep Mot Skills. 2001;93(3):660.

52. Schlarb AA, Classen M, Grunwald J, Vogele C. Sleep disturbances and mental strain in university students: results from an online survey in Luxembourg and Germany. Int J Ment Health Syst. 2017;11:24.

53. Patel SR, Hu FB. Short sleep duration and weight gain: a systematic review. Obesity (Silver Spring).2008;16(3):643-653.

54. Stommel M, Schoenborn CA. Accuracy and usefulness of BMI measures based on self- 
reported weight and height: findings from the NHANES \& NHIS 2001-2006. BMC Public Health. 2009;9:421.

55. Nevill AM, Stewart AD, Olds T, Holder R. Relationship between adiposity and body size reveals limitations of BMI. Am J Phys Anthropol. 2006;129(1):151-156.

56. Zagorsky JL, Smith PK. The Freshman 15: A critical Time for Obesity Intervention or Media Myth? Soc Sci Q. 2011;92(5):1389-1407. 


\section{CHAPTER}

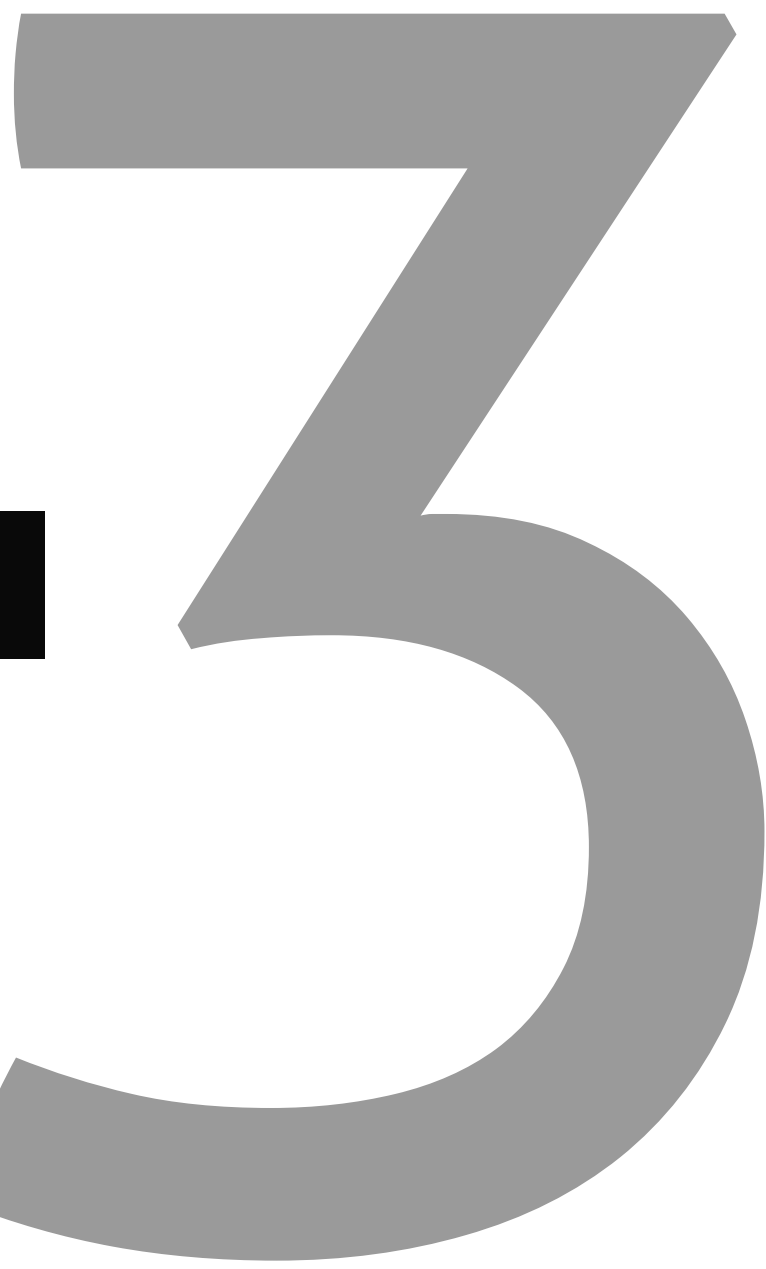




\section{Association between $\beta$-amino- isobutyric acid and cardiometabolic risk factors: A preliminary study}

Suzan A. Haidar, Mirey Karavetian, Nanne K. de Vries, Alessandro Laviano, Mohammad Rached 


\section{Abstract \\ Association between $\boldsymbol{\beta}$-amino-isobutyric acid and cardiometabolic risk factors: A preliminary study}

\section{Introduction:}

Physical activity protects against chronic diseases. Preclinical studies suggest that circulating levels of the myokine $\beta$-amino-isobutyric acid (BAIBA) may prevent obesity and improve cardiometabolic health. We aimed at assessing whether serum BAIBA is associated with physical activity, markers of cardiometabolic risk, and gender differences among young individuals.

\section{Methods:}

A cross-sectional study was conducted on 80 university students. Anthropometry, blood pressure, lipid profile, fasting blood glucose (FBS), C-reactive protein, cortisol and physical activity (PA) were measured and analyzed against serum BAIBA levels.

\section{Results:}

Average BAIBA levels were 1.57 $\pm 0.61 \square$ M. Males had significantly larger waist $(86.0 \pm 9.6$ $\mathrm{cm})$ and neck circumferences $(38.6 \pm 2.5 \mathrm{~cm})$, systolic and diastolic blood pressure $(124.9 \pm 11.7 \mathrm{mmHg}$ and $77.9 \pm 9.9 \mathrm{mmHg}$, respectively), FBS $(84.6 \pm 7.5 \mathrm{mg} / \mathrm{dl})$, cortisol $(594.8 \pm 158.9 \mathrm{nmol} / \mathrm{L})$ and PA levels than females. They also had significantly lower highdensity lipoprotein $(46.9 \pm 7.3 \mathrm{mg} / \mathrm{dl})$. BAIBA concentrations in males and females were not significantly different. No significant association was found between BAIBA concentrations and nutritional, metabolic and functional parameters, except for diastolic blood pressure $(D B P)$ in males $(r=-0.35 ; P=0.03)$.

\section{Conclusions:}

In healthy, young individuals, serum BAIBA levels were not related to nutritional status, metabolic status, and physical activity, but were inversely related to DBP in males only.

Key words: BAIBA, physical activity, students, blood pressure, BMI 


\section{Introduction}

Despite intensive preventive campaigns, cardiovascular diseases remain among the leading causes of death and disability particularly in the western world. ${ }^{1}$ Unhealthy lifestyles limit the efficacy of prevention strategies by favoring the development of metabolic and vascular complications. Indeed, obesity and physical inactivity predispose to cardiovascular diseases and represent negative prognostic factors. Remarkably, obesity prevalence continues to escalate in both developed and developing countries. ${ }^{2,3}$ High body mass index (BMI) accounted for 4.4 million deaths and more than $5 \%$ of global disability. ${ }^{4}$ Consequently, overweight and obesity are also impinging on healthcare costs, by contributing to both direct and indirect costs..$^{5-8}$ This clinical and socio-economic alarming scenario recommends the development of new strategies to tackle the metabolic and vascular complications associated with unhealthy lifestyles.

Physical activity has consistently proven to protect against the onset of chronic diseases, independent of weight loss. Therefore, particular attention has been recently given to skeletal muscle as an endocrine organ modulating human metabolism. ${ }^{9} \beta$-aminoisobutyric acid (BAIBA) is a myokine produced in response to muscle contraction and the consequent breakdown of valine and thymine. BAIBA increases the expression of brown adipocyte-specific genes in white adipose tissue and fatty acid $\beta$-oxidation in hepatocytes both in vitro and in vivo. ${ }^{10}$ In mice, higher BAIBA levels are associated with improved glucose homeostasis, suppressed inflammation, increased fatty acid oxidation and decreased weight gain. ${ }^{10,11}$ In humans, plasma BAIBA concentrations parallel the levels of physical exercise. ${ }^{10}$ In subjects participating to the Framingham Heart Study, BAIBA levels were inversely correlated with fasting glucose, insulin, insulin resistance, triglycerides, total cholesterol, and BMI. ${ }^{10}$ Therefore, it has been proposed that BAIBA may play a role in the exercise-induced protection against the metabolic syndrome. ${ }^{10} \mathrm{However}$, the literature assessing BAIBA levels and its influence on human health is scarce and preliminary.

In the present study, we therefore explored whether an association exists between serum BAIBA levels and cardiometabolic risk factors in healthy young individuals at risk of developing cardiovascular disease, and whether gender has an influence on BAIBA levels.

\section{Materials and Methods}

\section{Sampling}

Lebanon' population is at high risk of developing cardiovascular diseases. ${ }^{12}$. Purposive sampling was used to recruit students from both rural and urban areas to provide both geographical diversity and to include students from all socioeconomic levels. After which, the students, were informed about the aims and methods of the study and were invited to participate via e-mail and through classroom visits by the research team. Inclusion criteria 
were: i) first semester enrollment to the university, ii) free of diseases (by questioning the students about their medical history), and iii) not pregnant. Interested participants not meeting the inclusion criteria were not considered for the study. Eighty students met the inclusion criteria and signed the informed consent. They were informed about the right to withdraw from the study at any time. Ethical approval for this study was obtained from Lebanese International University's Committee on Research Ethics (CRE). (Case number: LIUCRE-1411172.)

\section{Data and blood collection}

Data collection was conducted at the nutrition clinics of the students' home campus. Students were asked to fast for 12-hours before blood collection.

\section{Blood pressure measurement}

Blood pressure (BP) was measured by trained research assistants, using a standardized mercury sphygmomanometer (ALPK2, Japan) in the seated position after 5 minutes of rest, without prior smoking and exercise on that day. Two consecutive readings of systolic blood pressure (SBP) and diastolic blood pressure (DBP) were taken on the same arm within a two-minute time interval. The mean of the two measures was used for analysis. ${ }^{13}$ Blood sample was drawn from students by a licensed phlebotomist and analyzed at an accredited laboratory. Elevated SBP was defined as blood pressure equal to or above 120 $\mathrm{mmHg}^{13}$, whereas elevated was defined as blood pressure equal to or above $80 \mathrm{mmHg}^{13}$.

\section{Anthropometrics}

Trained licensed dietitians collected the students' anthropometric data. Height $(\mathrm{cm})$ was measured to the nearest $0.1 \mathrm{~cm}$, using a portable stadiometer (ADE stadiometer, Germany), without shoes. Weight (kg), was taken to the nearest $100 \mathrm{~g}$ using a calibrated beam scale (Detecto,USA), without shoes and with light clothing. Waist circumference $(\mathrm{WC} ; \mathrm{cm})$ was measured at the mid-point, half-way between the right iliac crest and the lower costal region ${ }^{14}$ and neck circumference $(\mathrm{NC} ; \mathrm{cm}$ ) measured the midway of the neck, between mid-cervical spine and mid anterior neck. ${ }^{15}$ Waist and neck circumferences were measured to the nearest $0.1 \mathrm{~cm}$, using Accugirth measuring tapes.

\section{Exercise}

Exercise levels were measured using the International Physical Activity Questionnaire (IPAQ)- short form ${ }^{16}$, a validated tool consisting of seven questions assessing duration, frequency and intensity of physical activity performed in the past 7 days. The Metabolic Equivalent of Task (MET) were calculated by multiplying the total minutes spent in the corresponding activity by the frequency (i.e., days) and the constants of 3.3, 4.0 and 8.0 for light, moderate and vigorous activity respectively. The total MET value was computed by summing up the respective MET values of all activities that were done in bouts longer 
than 10 minutes in duration. Physical activity level was categorized as low when MET value was $<600$, moderate when MET value was between 600-2999, and high when MET value was $\geq 3000 .^{16}$

\section{Biochemical markers}

Blood was collected between 7:00 am and 10:00 am and samples were then transported to an accredited laboratory using a thermally insulated box. Serum was analyzed for BAIBA $(\mu \mathrm{M} / \mathrm{mL})$ total cholesterol $(\mathrm{mg} / \mathrm{dL}), \mathrm{HDL}$-cholesterol (HDL-C; $\mathrm{mg} / \mathrm{dL})$, triglyceride (TG; $\mathrm{mg} /$ $\mathrm{dL}$ ), high-sensitivity C-reactive protein (CRP; $\mathrm{mg} / \mathrm{L})$, cortisol ( $\mathrm{nmol} / \mathrm{L})$ and fasting blood glucose (FBG; mg/dL) concentrations and LDL-cholesterol (LDL-C; mg/dL) levels were calculated only if triglyceride levels were below $400 \mathrm{mg} / \mathrm{dL}$. BAIBA levels were analyzed using liquid chromatography-tandem mass spectrometry and verified against a standard. The analyses of total cholesterol, LDL-C, HDL-C, TG, CRP and FBG concentrations were performed using the Cobas C111 automated biochemical analyzer (Roche Diagnostics, Indianapolis, IN, USA) based on spectrophotometric principles. Serum cortisol ( $\mathrm{nmol} / \mathrm{L}$ ) morning level was measured using Cobas e411 immunoassay automated analyzer (Roche Diagnostics, Indianapolis, IN, USA) based on electrochemiluminescence (ECLIA) principle.

\section{Risk Factor Cut-offs}

BMl categories were defined as $<18.5,18.5-24.99,25-29.9$ and $>30 \mathrm{~kg} / \mathrm{m}^{2}$ for underweight, normal, overweight and obese, respectively ${ }^{17}$, impaired FBG as $100-125 \mathrm{mg} / \mathrm{dL}^{18}$, low HDL as less than $40 \mathrm{mg} / \mathrm{dL}$ in males and less than $50 \mathrm{mg} / \mathrm{dL}$ in females (Roche kit, USA), high LDL as equal to or above $130 \mathrm{mg} / \mathrm{dL}$ ), , high total cholesterol as equal to or above $200 \mathrm{mg} /$ $\mathrm{dL}$ (Roche kit, USA), high TG as equal to or above $150 \mathrm{mg} / \mathrm{dL}$, elevated waist circumference as equal to or above $94 \mathrm{~cm}$ in males and equal to or above $80 \mathrm{~cm}$ in females ${ }^{19}$, elevated CRP as above $5 \mathrm{mg} / \mathrm{dL}$ (Roche kit, USA) and elevated cortisol as above $536 \mathrm{nmol} / \mathrm{l}$ (Roche kit, USA).

\section{Data analyses}

Statistical analyses were conducted using Statistical Package for Social Sciences (SPSS) version 21.0, and a $p$-value $<0.05$ was considered statistically significant. Descriptive analyses were performed to summarize participants' characteristics. Independent-samples T-test was used for continuous variables following a normal distribution, Mann-Whitney $\mathrm{U}$ test for non-normally distributed continuous data, Chi-square test for categorical variables, and Fisher's Exact test for categorical variables, where the expected count is less than 5. Using Spearman's rho, correlation coefficients were estimated for the total sample and separately for each variable. 


\section{Results}

Eighty freshman students ( $55 \%$ females) participated in this study. Their characteristics are reported in Table 1. Males had significantly larger waist and neck circumferences, as well as higher SBP, DBP, FBG, cortisol and physical activity level than females. However, $\mathrm{HDL}$ were significantly lower in males than in females. Males had lower BAIBA levels than females $(1.43 \pm 0.56 \mu \mathrm{M}$ vs $1.68 \pm 0.63 \mu \mathrm{M}$, respectively), but this difference did not reach significance. 
Table 1: Characteristics of study participants and differences between genders $(n=80)[$ mean $\pm S D]$

\begin{tabular}{|c|c|c|c|c|}
\hline & $\begin{array}{l}\text { Total }(n=80) \\
\text { Mean } \pm \text { SD }\end{array}$ & $\begin{array}{l}\text { Males }(n=36) \\
\text { Mean } \pm \text { SD }\end{array}$ & $\begin{array}{l}\text { Female }(n=44) \\
\text { Mean } \pm \text { SD }\end{array}$ & p-value \\
\hline Age (years) & $19.3 \pm 2.04$ & $19.5 \pm 1.57$ & $19.14 \pm 2.34$ & 0.43 \\
\hline BMI $\left(\mathrm{kg} / \mathrm{m}^{2}\right)$ & $23.74 \pm 4.49$ & $24.20 \pm 4.23$ & $23.37 \pm 4.70$ & 0.41 \\
\hline WC (cm) & $83.16 \pm 11.14$ & $86.01 \pm 9.67$ & $80.83 \pm 11.81$ & 0.03 \\
\hline $\mathrm{NC}(\mathrm{cm})$ & $36.53 \pm 3.34$ & $38.61 \pm 2.56$ & $34.82 \pm 2.91$ & $<0.001$ \\
\hline SBP $(\mathrm{mmHg})$ & $117.51 \pm 12.67$ & $124.97 \pm 11.71$ & $111.41 \pm 9.93$ & $<0.001$ \\
\hline $\mathrm{DBP}(\mathrm{mmHg})$ & $72.33 \pm 9.79$ & $77.96 \pm 9.94$ & $67.73 \pm 6.89$ & $<0.001$ \\
\hline BAIBA $(\mu \mathrm{M})$ & $1.57 \pm 0.61$ & $1.43 \pm 0.56$ & $1.68 \pm 0.63$ & 0.07 \\
\hline $\begin{array}{l}\text { Fasting Blood Glucose } \\
\text { (FBG) (mg/dL) }\end{array}$ & $82.09 \pm 7.49$ & $84.64 \pm 7.56$ & $80.00 \pm 6.83$ & 0.005 \\
\hline Total cholesterol (mg/dL) & $158.71 \pm 27.13$ & $156.89 \pm 28.03$ & $160.20 \pm 26.60$ & 0.59 \\
\hline LDL cholesterol (mg/dL) & $93.76 \pm 27.91$ & $94.97 \pm 26.84$ & $92.77 \pm 29.03$ & 0.72 \\
\hline HDL cholesterol (mg/dL) & $51.79 \pm 11.70$ & $46.92 \pm 7.35$ & $55.77 \pm 13.09$ & $<0.001$ \\
\hline Triglycerides (mg/dL) & $76.93 \pm 31.76$ & $82.11 \pm 33.10$ & $72.68 \pm 30.34$ & 0.18 \\
\hline $\mathrm{CRP}(\mathrm{mg} / \mathrm{dL})$ & $2.46 \pm 3.35$ & $2.80 \pm 4.06$ & $2.1924 \pm 2.65$ & 0.41 \\
\hline Cortisol (nmol/L) & $533.12 \pm 192.38$ & $594.88 \pm 158.99$ & $482.60 \pm 204.00$ & 0.009 \\
\hline $\begin{array}{l}\text { Physical activity level } \\
\text { (METs) }\end{array}$ & $2011.4 \pm 2623$ & $2852.9 \pm 2886.2$ & $1322.8 \pm 2186.7$ & 0.009 \\
\hline
\end{tabular}

Data are expressed as mean \pm SD.

BMI: body mass index; WC: waist circumference, NC: neck circumference; SBP: systolic blood pressure; DBP: diastolic blood pressure; BAIBA: $\beta$-aminoisobutyric acid; LDL: low density lipoprotein, HDL: high density lipoprotein; CRP: C-reactive protein; SD: standard deviation, Mets: Metabolic equivalents of task. 


\section{Metabolic Syndrome Components Behavior}

The prevalence of the metabolic risk factors, and their gender-related distribution are reported in Table 2. Approximately one third of the sample was overweight or obese and had elevated waist circumference. Overall, SBP was above normal in approximately half of the sample, and DBP in 25\%. Males had significantly higher SBP and DBP than females. One student out of four had lower than normal HDL cholesterol, with no significant difference between the two genders. Additionally, $40 \%$ of participants had high cortisol levels, and males had statistically higher values than females. Impaired fasting blood glucose, elevated triglycerides, total cholesterol, LDL cholesterol and CRP were found in a small proportion of students (i.e., $2.5 \%, 2.5 \%, 5.0 \%, 10.0 \%$, and $12.5 \%$ respectively), with no significant difference between the genders. As for exercise, more than one third of students had low levels of physical activity whereas $40 \%$ exercised moderately and $22.5 \%$ had high levels of exercise. As shown in Table 2, females had significantly lower levels of physical activity when compared with males $(p<0.001)$. 
Table 2: Prevalence of factors for metabolic risk in the population studied $(n=80)$, and genderrelated distribution (\%)

\begin{tabular}{|c|c|c|c|c|c|}
\hline & & $\begin{array}{l}\text { Total } \\
\% \text { (n) }\end{array}$ & $\begin{array}{l}\text { Males } \\
\% \text { (n) }\end{array}$ & $\begin{array}{l}\text { Females } \\
\% \text { (n) }\end{array}$ & p-value \\
\hline \multirow[t]{4}{*}{ BMI $\left(\mathrm{kg} / \mathrm{m}^{2}\right)$} & Underweight & $6.3(5)$ & $0.0(0)$ & $11.4(5)$ & \multirow[t]{4}{*}{0.20} \\
\hline & $\begin{array}{l}\text { Normal } \\
\text { weight }\end{array}$ & $62.5(50)$ & $69.4(25)$ & $56.8(25)$ & \\
\hline & Overweight & $22.5(18)$ & $22.2(8)$ & $22.7(10)$ & \\
\hline & Obese & $8.8(7)$ & $8.3(3)$ & $9.1(4)$ & \\
\hline \multirow{2}{*}{$\begin{array}{l}\text { Waist circumference } \\
(\mathrm{cm})\end{array}$} & Normal & $63.8(51)$ & $86.1(31)$ & $45.5(20)$ & \multirow[t]{2}{*}{$<0.001$} \\
\hline & Elevated & $36.3(29)$ & $13.9(5)$ & $54.5(24)$ & \\
\hline \multirow[t]{4}{*}{$\mathrm{SBP}(\mathrm{mmHg})$} & Normal & $53.8(43)$ & $33.3(12)$ & $70.5(31)$ & \multirow[t]{4}{*}{$<0.001$} \\
\hline & $\begin{array}{l}\text { Pre- } \\
\text { Hypertensive }\end{array}$ & $41.3(33)$ & $55.6(20)$ & $29.5(12)$ & \\
\hline & Stage 1 SBP & $5.0(4)$ & $11.1(4)$ & $0.0(0)$ & \\
\hline & Stage 2 SBP & $0.0(0)$ & $0.0(0)$ & $0.0(0)$ & \\
\hline \multirow[t]{4}{*}{$\mathrm{DBP}(\mathrm{mmHg})$} & Normal & $75.0(60)$ & $50.0(18)$ & $95.5(42)$ & \multirow[t]{4}{*}{$<0.001$} \\
\hline & $\begin{array}{l}\text { Pre- } \\
\text { Hypertensive }\end{array}$ & $18.8(15)$ & $36.1(13)$ & $4.5(2)$ & \\
\hline & Stage 1 DBP & $5.0(4)$ & $11.1(4)$ & $0.0(0)$ & \\
\hline & Stage 2 DBP & $1.3(1)$ & $2.8(1)$ & $0.0(0)$ & \\
\hline \multirow[t]{2}{*}{$\mathrm{FBG}(\mathrm{mg} / \mathrm{dL})$} & Normal & 97.5 (78) & $97.2(35)$ & $97.7(43)$ & \multirow[t]{2}{*}{1.00} \\
\hline & Impaired & $2.5(2)$ & $2.8(1)$ & $2.3(1)$ & \\
\hline \multirow[t]{2}{*}{ Triglycerides (mg/dL) } & Normal & $97.5(78)$ & $97.2(35)$ & 97.7 (43) & \multirow[t]{2}{*}{1.00} \\
\hline & Elevated & $2.5(2)$ & $2.8(1)$ & $2.3(1)$ & \\
\hline \multirow{2}{*}{$\begin{array}{l}\text { Total Cholesterol } \\
(\mathrm{mg} / \mathrm{dL})\end{array}$} & Desirable & $95.0(76)$ & $94.4(34)$ & $95.5(42)$ & \multirow[t]{2}{*}{1.00} \\
\hline & Elevated & $5.0(4)$ & $5.6(2)$ & $4.5(2)$ & \\
\hline \multirow{3}{*}{$\begin{array}{l}\text { LDL cholesterol } \\
(\mathrm{mg} / \mathrm{dL})\end{array}$} & Optimal & $55.0(44)$ & $47.2(17)$ & $61.4(27)$ & \multirow[t]{3}{*}{0.43} \\
\hline & Near optimal & $35.0(28)$ & $41.7(15)$ & $29.5(13)$ & \\
\hline & High & $10.0(8)$ & $11.1(4)$ & $9.1(4)$ & \\
\hline \multirow{2}{*}{$\begin{array}{l}\text { HDL cholesterol } \\
(\mathrm{mg} / \mathrm{dL})\end{array}$} & Low & $25.0(20)$ & $16.7(6)$ & $31.8(14)$ & \multirow[t]{2}{*}{0.19} \\
\hline & Normal & $75.0(60)$ & $83.3(30)$ & $68.2(30)$ & \\
\hline \multirow[t]{2}{*}{ CRP (mg/dL) } & Normal & $87.5(70)$ & $88.9(32)$ & $86.4(38)$ & \multirow[t]{2}{*}{1.00} \\
\hline & High & $12.5(10)$ & $11.1(4)$ & $13.6(6)$ & \\
\hline \multirow[t]{2}{*}{ Cortisol (nmol/L) } & Normal & $60.0(48)$ & $41.7(15)$ & $75.0(33)$ & \multirow[t]{2}{*}{0.003} \\
\hline & High & $40.0(32)$ & $58.3(21)$ & $25.0(11)$ & \\
\hline \multirow[t]{3}{*}{ Physical activity level } & Low & $37.5(30)$ & $19.4(7)$ & $52.3(23)$ & \multirow[t]{3}{*}{$<0.001$} \\
\hline & Moderate & $40(32)$ & $41.7(15)$ & $38.6(17)$ & \\
\hline & High & $22.5(18)$ & $38.9(14)$ & $9.1(4)$ & \\
\hline
\end{tabular}

BMI: body mass index; SBP: systolic blood pressure; DBP: diastolic blood pressure; FBG: fasting blood glucose; LDL: low density lipoprotein, HDL: high density lipoprotein; CRP: C-reactive protein. Data are expressed as mean \pm SD. 
No significant association between BAIBA circulating levels and study parameters was found. In the gender-based subgroup analysis (Table 3), BAIBA levels were found to be significantly and inversely correlated with DBP only in males $(r=-0.35 ; P=0.03)$.

Table 3: Correlation between BAIBA and study variables in both genders

\begin{tabular}{|c|c|c|c|c|}
\hline & \multicolumn{4}{|c|}{ BAIBA } \\
\hline & \multicolumn{2}{|c|}{ Males $(\mathrm{N}=36)$} & \multicolumn{2}{|c|}{ Females $(n=44)$} \\
\hline & $\mathbf{r}$ & p-value & $\mathbf{r}$ & p-value \\
\hline$\overline{\text { BMI }}$ & -0.26 & 0.12 & 0.02 & 0.86 \\
\hline Neck circumference & 0.09 & 0.57 & -0.10 & 0.50 \\
\hline Waist circumference & -0.07 & 0.67 & 0.16 & 0.91 \\
\hline SBP & -0.24 & 0.15 & 0.11 & 0.45 \\
\hline DBP & -0.35 & $0.03^{*}$ & 0.09 & 0.53 \\
\hline FBG & -0.21 & 0.20 & 0.20 & 0.19 \\
\hline LDL cholesterol & 0.001 & 0.99 & 0.003 & 0.98 \\
\hline HDL cholesterol & 0.12 & 0.46 & -0.11 & 0.45 \\
\hline Total cholesterol & -0.10 & 0.53 & -0.01 & 0.92 \\
\hline Triglycerides & -0.21 & 0.21 & -0.09 & 0.53 \\
\hline CRP & -0.11 & 0.51 & -0.01 & 0.91 \\
\hline Cortisol & 0.18 & 0.27 & 0.23 & 0.11 \\
\hline Physical activity & 0.08 & 0.62 & -0.03 & 0.84 \\
\hline
\end{tabular}

*Indicates a statistically significant correlation using Spearman's rho BMI: body mass index; SBP: systolic blood pressure; DBP: diastolic blood pressure; FBG: fasting blood glucose; LDL: low density lipoprotein, HDL: high density lipoprotein; CRP: C-reactive protein.

Mean BAIBA concentration in males with high DBP (>=80 mmHg) was $0.94 \pm 0.25(\mu \mathrm{M}$; $\mathrm{n}=5)$ compared with $1.61 \pm 0.60(\mu \mathrm{M})$ among those with $\mathrm{DBP}<80 \mathrm{mmHg}(\mathrm{n}=31)$. 


\section{Discussion}

The present study investigated for the first time the possible association between BAIBA circulating levels and cardiometabolic risk factors in healthy young individuals living in an obesogenic environment. In fact, a high prevalence of obesity, metabolic syndrome and cardiovascular disease has been reported in Lebanon. ${ }^{20}$ Our results suggest that BAIBA concentrations in healthy, young individuals are not associated to the presence of cardiometabolic risk factors, as inferred by the lack of significant differences between males and females, and physical activity levels. However, our study reveals that in males BAIBA circulating levels are inversely related to DBP, which suggests a protective role for this myokine on blood vessels, and may offer a therapeutic target in diastolic hypertension. The biological link in males of the inverse relationship between circulating BAIBA levels and DBP remains unclear, but autonomic and metabolic factors could be proposed. ${ }^{21}$ Unfortunately, the cross-sectional design of our study does not allow to assess whether the reduction of BAIBA levels triggers or is secondary to raising diastolic blood pressure. Unexpectedly, we could not observe correlation nor association between BAIBA levels and physical activity. However the IPAQ questionnaire does not calculate physical activity in leisure time and henceone can infer this is the protective physical activity dominion, although this was not investigated. Our results confirm previous data by Morales et al., who could not observe an increase of BAIBA levels following aerobic exercise ${ }^{22}$, but are in contrast with Roberts et al. who reported a significant increase ( $+17 \%)$ of BAIBA levels in a sedentary population undergoing a supervised 20 -week endurance training program. ${ }^{10}$ To reconcile this contrasting evidence, it could be postulated that physical activity and structured physical exercise could differently induce BAIBA synthesis. Alternatively, but not mutually exclusive, it could be postulated that aerobic vs resistance exercise could exert a different effect on muscle metabolism. Larger studies allowing for relevant stratification of patients according to the type and level of activity/exercise could help in better understand the inducing factors of BAIBA synthesis. Based on the available literature and our present results, it could be hypothesized that muscle building per se may not be relevant for BAIBA synthesis, since we could not observe any significant difference between males and females, whose muscularity is significantly different. Also, it can be postulated that ongoing and prolonged physical activity/exercise aiming at improving metabolism rather than building muscle mass is key to raise BAIBA concentrations.

We could not observe any association between BAIBA levels and BMI nor waist circumference. In this light, our results support the Framingham heart study, although it should be acknowledged that a non-significant trend was then observed. ${ }^{10}$ More contrasting evidence on the relationship between BAIBA levels and anthropometry are available. Rietman et al. studied healthy individuals and reported no correlation between waist circumference and BAIBA, but a significant negative association between BAIBA and subcutaneous fat. ${ }^{23}$ In contrast, Molfino and colleagues studied hemodialyzed 
patients, but could not find any association between BAIBA levels and BMI nor with body composition parameters. ${ }^{24}$ The interpretation of human data so far available appears more complex than in preclinical modes, in which BAIBA levels are consistently related to nutritional parameters. ${ }^{25}$ When devising future clinical research, inclusion of body composition analysis appears key to appreciate the potential role of BAIBA as surrogate marker of healthy muscle metabolism influencing overall homeostasis rather than a quantitative index of muscularity and level of physical activity/exercise.

In our group of healthy and young students, circulating BAIBA concentrations were significantly and inversely related to DBP in males. This clinical relevance of this finding is highlighted by the evidence that a DBP increase of $10 \mathrm{mmHg}$ doubles mortality from stroke and ischemic heart disease. ${ }^{26}$ More importantly, this relationship was not influenced by different levels of physical activity, suggesting a constitutive, non-inducible link between BAIBA and DBP. Thus, the BAIBA pathway could represent an early marker for diastolic hypertension and a suitable therapeutic target.

We acknowledge that our study has limitations. First, its cross-sectional design makes it difficult to draw casual inferences and identify confounders. Second, sample size was relatively small and it was not possible to conduct a power analysis prior to the study to determine the appropriate number of students that needed to be recruited since clinical research assessing BAIBA levels is still preliminary and baseline values have not been consistently published. Finally, our study assessed only university students, who are young and almost invariably healthy. It is very difficult to find differences between healthy youth, in a relatively short time, interacting with cardiometabolic risk factors, with only $30 \%$ being overweight and obese. This may not allow translate our results to older populations with higher cardio metabolic risk. Additionally, body composition parameters were not assessed, although waist circumference was taken.

\section{Conclusions}

BAIBA concentrations in young and healthy individuals are not associated with BMI, waist circumference and other factors of cardiometabolic risk, but they showed a negative correlation with DBP in males only. This is in contrast with previous and mainly preclinical studies, and suggests that BAIBA may potentially protect against obesity and its comorbidities only under specific condition. 


\section{References}

1. Murray CJ, Barber RM, Foreman KJ, et al. Global, regional, and national disability-adjusted life years (DALYs) for 306 diseases and injuries and healthy life expectancy (HALE) for 188 countries, 1990-2013: quantifying the epidemiological transition. Lancet (London, England). 2015;386(10009):2145-2191.

2. $\mathrm{Ng} \mathrm{M}$, Fleming $\mathrm{T}$, Robinson $\mathrm{M}$, et al. Global, regional, and national prevalence of overweight and obesity in children and adults during 1980-2013: a systematic analysis for the Global Burden of Disease Study 2013. Lancet (London, England). 2014;384(9945):766-781.

3. Finucane MM, Stevens GA, Cowan MJ, et al. National, regional, and global trends in body-mass index since 1980: systematic analysis of health examination surveys and epidemiological studies with 960 country-years and 9.1 million participants. Lancet (London, England). 2011;377(9765):557-567.

4. Forouzanfar $\mathrm{MH}$, Alexander $\mathrm{L}$, Anderson $\mathrm{HR}$, et al. Global, regional, and national comparative risk assessment of 79 behavioural, environmental and occupational, and metabolic risks or clusters of risks in 188 countries, 1990-2013: a systematic analysis for the Global Burden of Disease Study 2013. Lancet (London, England). 2015;386(10010):2287-2323.

5. Visscher TL, Seidell JC. The public health impact of obesity. Annu Rev Public Health. 2001;22:355-375.

6. Taylor VH, Forhan M, Vigod SN, Mclntyre RS, Morrison KM. The impact of obesity on quality of life. Best Pract Res Clin Endocrinol Metab. 2013;27(2):139-146.

7. Blackstone RP. Obesity: the medical practitioner's essential guide. New York: Springer Scientific; 2016.

8. Lehnert T, Sonntag D, Konnopka A, Riedel-Heller S, Konig HH. Economic costs of overweight and obesity. Best practice \& research. Clinical endocrinology \& metabolism. 2013;27(2):105-115.

9. Bostrom P, Wu J, Jedrychowski MP, et al. A PGC1-alpha-dependent myokine that drives brownfat-like development of white fat and thermogenesis. Nature. 2012;481(7382):463-468.

10. Roberts LD, Bostrom P, O'Sullivan JF, et al. beta-Aminoisobutyric acid induces browning of white fat and hepatic beta-oxidation and is inversely correlated with cardiometabolic risk factors. Cell Metab. 2014;19(1):96-108.

11. Jung TW, Hwang HJ, Hong HC, Yoo HJ, Baik SH, Choi KM. BAIBA attenuates insulin resistance and inflammation induced by palmitate or a high fat diet via an AMPK-PPARdelta-dependent pathway in mice. Diabetologia. 2015;58(9):2096-2105.

12. Zeidan RK, Farah R, Chahine MN, et al. Prevalence and correlates of coronary heart disease: first population-based study in Lebanon. Vasc Health Risk Manag. 2016;12:75-84.

13. Pickering TG, Hall JE, Appel LJ, et al. Recommendations for blood pressure measurement in humans and experimental animals: part 1: blood pressure measurement in humans: a statement for professionals from the Subcommittee of Professional and Public Education of the American Heart Association Council on High Blood Pressure Research. Circulation. 2005;111(5):697-716. 
14. Van der Kooy K, Seidell JC. Techniques for the measurement of visceral fat: a practical guide. Int J Obes Relat Metab Disord. 1993;17(4):187-196.

15. Aswathappa J, Garg S, Kutty K, Shankar V. Neck circumference as an anthropometric measure of obesity in diabetics. N Am J Med Sci. 2013;5(1):28-31.

16. Craig $C L$, Marshall $A L$, Sjostrom $M$, et al. International physical activity questionnaire: 12-country reliability and validity. Med Sci Sports Exerc. 2003;35(8):1381-1395.

17. World Health Organization.Report of WHO consultaion on obesity. Obesity: preventing and managing the global epidemic. Geneva: World Health Organization, 2000.

18. Nathan DM, Davidson MB, DeFronzo RA, et al. Impaired Fasting Glucose and Impaired Glucose Tolerance. Implications for care. 2007;30(3):753-759.

19. Alberti KG, Eckel RH, Grundy SM, et al. Harmonizing the metabolic syndrome: a joint interim statement of the International Diabetes Federation Task Force on Epidemiology and Prevention; National Heart, Lung, and Blood Institute; American Heart Association; World Heart Federation; International Atherosclerosis Society; and International Association for the Study of Obesity. Circulation. 2009;120(16):1640-1645.

20. Sibai A-M, Obeid O, Batal M, Adra N, Khoury DE, Hwalla N. Prevalence and correlates of metabolic syndrome in an adult Lebanese population. CVD Prev Control. 2008;3(2):83-90.

21. Gaudreault V, Despres JP, Rheaume C, et al. Exercise-induced exaggerated blood pressure response in men with the metabolic syndrome: the role of the autonomous nervous system. Blood Press Monit. 2013;18(5):252-258.

22. Morales FE, Forsse JS, Andre TL, et al. BAIBA Does Not Regulate UCP-3 Expression in Human Skeletal Muscle as a Response to Aerobic Exercise. J Am Coll Nut. 2017;36(3):200-209.

23. Rietman A, Stanley TL, Clish C, et al. Associations between plasma branched-chain amino acids, beta-aminoisobutyric acid and body composition. J Nutr Sci. 2016;5:e6.

24. Molfino A, Amabile MI, Ammann T, et al. The metabolite beta-aminoisobutyric acid and physical inactivity among hemodialysis patients. Nutrition. 2017;34:101-107.

25. Begriche K, Massart J, Abbey-Toby A, Igoudjil A, Letteron P, Fromenty B. Beta-aminoisobutyric acid prevents diet-induced obesity in mice with partial leptin deficiency. Obesity (Silver Spring, Md.). 2008;16(9):2053-2067.

26. National High Blood Pressure Education P. The Seventh Report of the Joint National Committee on Prevention, Detection, Evaluation, and Treatment of High Blood Pressure. Bethesda (MD): National Heart, Lung, and Blood Institute (US); 2004. 
CHAPTER

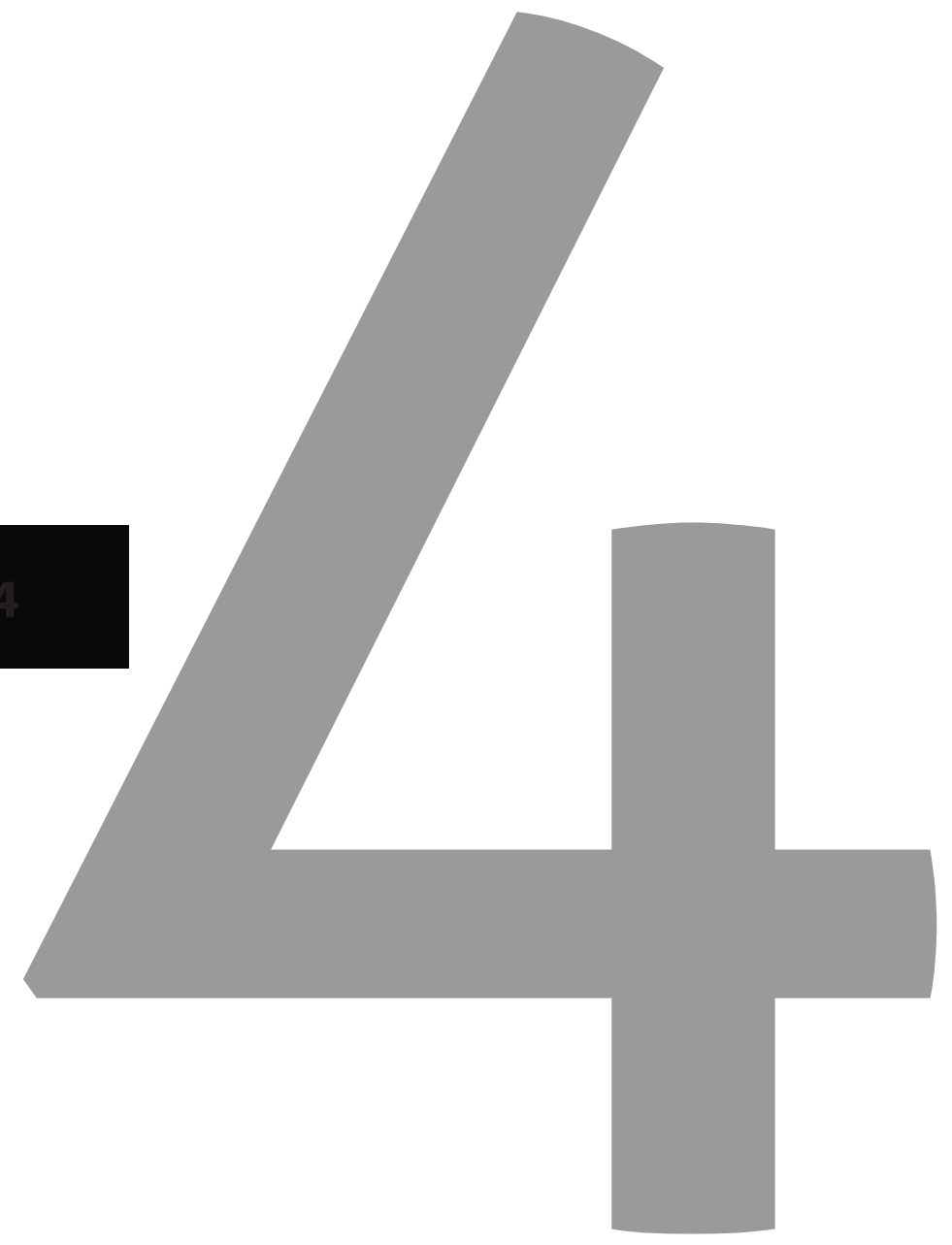




\section{University Lebanese students are not immune to the metabolic syndrome}

Suzan A. Haidar, Mirey Karavetian, Hadia Rashwan, Nanne K. de Vries 


\section{Abstract}

\section{Lebanese students are not immune to the metabolic syndrome}

\section{Background:}

The Metabolic syndrome (MetS) is a disorder characterized by a cluster of symptoms, which increases risk of developing cardiovascular disease and diabetes.

\section{Objective:}

To estimate the prevalence rate of the MetS and identify its predisposing risk factors in Lebanese university students.

\section{Methods:}

Using cluster based randomization, 266 students were recruited to participate in a crosssectional study at a local University. Anthropometric measurements, biochemical data and blood pressure were collected. Students filled out the following questionnaires: demographics, lifestyle habits, beverage consumption, International Physical Activity Questionnaire, Pittsburgh Sleep Quality Index and the Perceived Stress Questionnaire. MetS was diagnosed based on the criteria of the International Diabetes Federation.

\section{Results:}

The prevalence of MetS in the sample population was found to be $6.4 \%$. Furthermore, $65 \%$ of the sample had low HDL-C levels $(53.10 \pm 13.06 \mathrm{mg} / \mathrm{dl})$ and approximately $52 \%$ had a high waist circumference $(85.67 \pm 11.45 \mathrm{~cm})$. Neither lifestyle habits, beverage consumption, physical activity level, sleep quality nor increased stress were associated with increased risk of developing MetS. Age was significantly associated with higher odds of developing the MetS (aOR=1.15, 95\%Cl: 1.03-1.29).

\section{Conclusion:}

Metabolic syndrome is a cause of concern among Lebanese students which highlights the need for prevention programs to decrease future health risks.

Keywords: Metabolic syndrome; university students; Stress, Sleep, Diet, Physical activity, cardiovascular diseases 


\section{Introduction}

The metabolic syndrome (MetS) is a cluster of conditions, defined by the International Diabetes Federation (IDF) [1] as having central obesity, along with two or more of the following abnormalities: elevated blood pressure (BP), fasting blood glucose (FBG), triglycerides and reduced high-density lipoprotein (HDL)-cholesterol. The clinical implication of the MetS relates to its ability to predict cardiovascular morbidity and mortality, type II diabetes and all-cause mortality[2-4]. Furthermore, the MetS is associated with high utilization of health resources and costs [5].

While existing research on the MetS has primarily focused on older adults, recent studies are showing a particular interest in exploring its prevalence in university and college students [6-8]. Traditionally, university students are thought to be young and healthy and are consequently a population that is overlooked by public health professionals for primary prevention for chronic diseases [9]. Yet, the international literature is increasingly revealing that university students are a vulnerable population, and a growing body of evidence has uncovered a cluster of metabolic and lifestyle risk factors in this population $[10,11]$. These factors include, but are not limited to being overweight and obese [12], consuming unhealthy diets [13], lack of physical activity [14], sleep deprivation [15] and high stress levels [16]. Moreover, some university students lack adequate self-regulatory skills enabling them to maintain healthy behaviors in the college environment [17] and face numerous interpersonal and environmental barriers to weight management and consuming healthy diets [18-20]. This is unfortunate since poor health habits and chronic disease risk factors, which are established during youth, are likely to persist into adulthood, negatively affecting the future health of individuals and populations [21, 22].

Lebanon is a small Mediterranean country and like other developing countries, has been experiencing the nutrition transition [23]. More than half of the adult population in the country exhibits one component of the MetS [24] and prevalence of fulminant MetS is estimated to be approximately 34.6\% [25]. While previous studies carried out among university students in Lebanon generated alarming results, such as adoption of a westernized diet [26, 27], physical inactivity ranging from 40\% [28] to 74\% [29], and rates of overweight and obesity generally being above $20 \%[26,27]$. More specifically, in the under 20 age group, $33.1 \%$ of Lebanese males and $29.8 \%$ of Lebanese females were found to be overweight and $15.9 \%$ of males and $12.5 \%$ of females were obese [30]. Unfortunately, little is known about the extent of metabolic abnormalities and their predictors in this population.

Given these findings, the objective of this study is to quantify the metabolic syndrome prevalence and its individual components using the International Diabetes Federation (IDF) [1] definition in addition to exploring their predictors, in a sample of Lebanese university students. 


\section{Methods}

Using the two stage sampling method, five campuses from various geographical locations in Lebanon were selected at random to harbor the study. Students were contacted via mass email and invited to participate in data collection. Eligibility criteria included: (1) enrollment in the university, (2) free of chronic disease, (3) not pregnant, (4) not taking medication. Students were excluded from the study if they were sick at the time of the study, suffered from chronic diseases, not having fasted (as required, see below) and not meeting the inclusion criteria. The students were informed about the objectives and methodology of the study, and about their right to withdraw from it at any time. Ethical approval was obtained from the University's Committee on Research Ethics (CRE) (case number: LIUCRE-141117-2)

\section{Data collection}

Eligible students were asked to attend the nutrition clinics at their home campus for data collection after a 12-hour fast. Data was collected using face to face interviews which took between 30 and 50 minutes.

Anthropometry and blood pressure (BP): parameters were collected by trained dietitians using standardized techniques and calibrated equipment. Height $(\mathrm{cm})$ was measured using a portable stadiometer (ADE, Germany) to the nearest $0.1 \mathrm{~cm}$, without shoes, with the subject stretching to the maximum height and the head positioned in the Frankfort plane. Weight $(\mathrm{kg})$ was measured to the nearest $100 \mathrm{~g}$ using a beam scale, without shoes and with participant wearing light clothes. Body mass index (BMI) which is the ratio of weight $(\mathrm{kg})$ and height squared $\left(\mathrm{m}^{2}\right)$ was calculated. Waist circumference (cm) was measured to the nearest $0.1 \mathrm{~cm}$ at the mid-point, half-way between the right iliac crest and the lower costal region using an Accugirth measuring tape [31]. BP was measured using a standardized mercury sphygmomanometer in seated position after a 5-minute resting period, without prior smoking or exercise [32]. Two consecutive readings were taken on the same arm, and the mean of the two measures was used for analysis. The cutoff values for all measurements were according to IDF criteria [1] (table 1).

Blood collection and analysis: a 5-ml blood sample was drawn by a licensed phlebotomist into a sterile serum separator tube with clot activator. Blood samples were then transported to an accredited laboratory using a thermally insulated box and were centrifuged and analyzed immediately after separation. Serum was analyzed for total cholesterol (mg/dl), LDL-cholesterol (LDL-C) mg/dl, HDL-C mg/dl, triglycerides (mg/dl) and fasting blood glucose (FBG) (mg/dl) concentrations. The analyses were performed using the Cobas $\mathrm{C} 111$ automated biochemical analyser (Roche Diagnostics, Indianapolis, IN, USA) based on spectrophotometric principles. After blood collection, the students were served a light breakfast. 
Table 1. Diagnostic Criteria for Metabolic Syndrome according to the IDF(1)

Risk Factors Criteria

Abdominal obesity

Waist circumference $\geq 94 \mathrm{~cm}$ in men and $\geq 80 \mathrm{~cm}$ in women

In addition to $\mathbf{2}$ or more of the following:

\begin{tabular}{ll} 
Hypertension & $\geq 130 \mathrm{~mm} \mathrm{Hg}$ systolic or $\geq 85 \mathrm{~mm} \mathrm{Hg}$ diastolic \\
\hline Hyperglycemia & $\geq 100 \mathrm{mg} / \mathrm{dl}$ \\
\hline Hypertriglyceridemia & $\geq 150 \mathrm{mg} / \mathrm{dl}$ \\
\hline Low HDL-C & $<40 \mathrm{mg} / \mathrm{dl}$ in men and $<50 \mathrm{mg} / \mathrm{dl}$ in women
\end{tabular}

HDL-C: High Density Lipoprotein- Cholesterol

\section{Questionnaires}

The students were then asked to fill a series of questionnaires:

1 Demographics and lifestyle habits questionnaire, adapted from Levitsky et al., (2004) [13], included 10 open-ended questions that focused on quantifying the number of meals consumed daily, meals consumed outside the home, smoking status, alcohol consumption. The questionnaire also included questions about year of university enrollment and living arrangements.

2 Beverage consumption was assessed using a Food Frequency Questionnaire (FFQ), adapted from Batal et al., (2007) [33]. This is a culturally validated semiquantitative FFQ which includes beverage consumption such as soft drinks and diet soft drinks.

3 The International Physical Activity Questionnaire (IPAQ) (2014) [34], short form, is a validated tool used to measure level of exercise and consists of seven questions assessing duration and frequency of light, moderate and vigorous physical activity completed in the past week. The Metabolic Equivalent of Tasks (METs) was calculated by multiplying the total minutes spent in the corresponding activity with the frequency (days) and the constants of 3.3, 4.0 and 8.0 for light, moderate and vigorous activity respectively. The total MET value was computed by summing up the respective MET values for all activities that were done in bouts that were longer than 10 minutes in duration.

4 The Pittsburgh Sleep Quality Index (PSQI), (2014) [35], developed by Buysse et al (1989): a 9-item questionnaire that includes four questions assessing the duration (hours) of sleep, duration needed to fall asleep, time needed to wake up and awake time spent in bed; in addition five other questions addressing the 
reasons for troubled sleep. Answers were converted to a total score using an algorithm adapted from the developers of the questionnaire, where higher scores indicated poor sleep quality

5 The Perceived Stress Questionnaire [36]: a ten-item questionnaire measuring stress levels in the previous month. Answers followed a 5-point scale with frequencies ranging from never to very often. Total score ranged between 0 to 40, where higher scores indicated increased stress levels and where no cut-offs have been predefined;

All questionnaires were available in both English and Arabic. All questionnaires were back translated into both languages to ensure accuracy. The respondents were able to choose their language of preference when filling out the questionnaires. All instruments were pilot-tested for validation in a sample of students before the study was conducted, the results of which were not included in the analysis.

\section{Statistical analysis}

Means with standard deviations, and frequencies were computed for continuous and categorical variables, respectively. We followed the IDF definition [1] for diagnosing the MetS (Table 1). Body mass index (BMI) was calculated as the ratio of weight $(\mathrm{kg})$ to square of height $(\mathrm{m})$. Overweight and obesity were defined as BMI $\geq 25 \mathrm{~kg} / \mathrm{m}^{2}$ and $\geq 30$ $\mathrm{kg} / \mathrm{m}^{2}$, respectively [37]. To identify the predictors of metabolic abnormalities, separate multiple logistic regression analysis was carried out for the MetS, abdominal obesity, hypertension, low HDL-C as the dependent variables. These abnormalities were chosen as their prevalence exceeded $10 \%$ in the study sample. As a first step, the dependent variables were cross-tabulated against the covariates consisting of: age, gender, smoking status, physical activity level, sleep quality, stress score, soft drink and diet soft drink consumption; those with a $\mathrm{p}$-value $<0.2$ were entered into the regression model. Odds ratios (ORs) and their $95 \%$ confidence intervals (Cls) were calculated. Statistical analysis was conducted using Stata ${ }^{\circledR}$ release 14 . A p-value $<0.05$ indicated statistical significance.

\section{Results}

In total, 266 students consented to participate. One third of the participants were males (33.5\%), the majority of the participants (87.5\%) lived with their families and most of the students $(70.3 \%)$ were unemployed at the time of the assessment. Around one quarter (24.4\%) of the sample were smokers and only $15.8 \%$ engaged in vigorous levels of physical activity on a weekly basis (Table 2). The mean BMI of the participants was at the upper margin of the normal range $\left(24.13 \mathrm{~kg} / \mathrm{m}^{2}\right)$. Finally, the mean stress score of the participants was 19.64 out of a total possible 40 points (higher scores indicating more stress) and the average sleep score was 6.65, where a score above five indicated poor sleep quality (table 3). 
Table 2. Participant Characteristics (categorical data) $(n=266)$

\begin{tabular}{cl}
\hline & N (\%) \\
\hline Gender & $177(66.5)$ \\
\hline Female & \\
\hline Social status & $253(95.1)$ \\
\hline Single & $12(4.5)$ \\
\hline Married & $1(0.4)$ \\
\hline Divorced & \\
\hline Weekly PAL* & $110(41.5)$ \\
\hline Light PAL & $113(42.6)$ \\
\hline Moderate PAL & $42(15.8)$ \\
\hline Vigorous PAL & $185(70.3)$ \\
\hline Employment* & $48(18.3)$ \\
\hline Unemployed & $30(11.4)$ \\
\hline Employed, part-timer & \\
\hline Employed, full-timer & $201(75.6)$ \\
\hline Smoking status &
\end{tabular}

Table 3. Participant Characteristics (continuous data) $(n=266)$

\begin{tabular}{ll}
\hline & Mean (SD) \\
\hline Age, years & $20.56(3.07)$ \\
\hline BMI (kg/m2) & $24.13(4.57)$ \\
\hline Waist circumference (cm) & $85.67(11.45)$ \\
\hline \multicolumn{1}{c}{ Men } & $89.51(11.34)$ \\
\hline \multicolumn{1}{|c}{ Women } & $83.74(11.04)$ \\
\hline Total cholesterol (mg/dl) & $162.93(30.78)$ \\
\hline LDL-C (mg/dl) & $94.64(29.39)$ \\
\hline HDL-C (mg/dl) & $53.10(13.06)$ \\
\hline \multicolumn{1}{c}{ Men } & $45.18(9.27)$ \\
\hline Wystolic blood pressure (mmHg) & $57.08(12.90)$ \\
\hline Diastolic blood pressure (mmHg) & $113.5(15.4)$ \\
\hline Fasting blood glucose (mg/dl) & $70.8(10.7)$ \\
\hline Fasting triglycerides (mg/dl) & $82.60(13.10)$ \\
\hline Stress score (Max 40) & $81.73(41.29)$ \\
\hline Sleep quality (>5 poor quality) & $19.64(6.18)$ \\
\hline
\end{tabular}

BMI: Body mass index FBG: LDL: Iow density lipoprotein, HDL: high density lipoprotein;

Waist circumference $\geq 80 \mathrm{~cm}$ for females and $\geq 90 \mathrm{~cm}$ for males; FBG above $100 \mathrm{mg} / \mathrm{dL}$, Blood pressure $\geq 130 \mathrm{~mm}$ $\mathrm{Hg}$ systolic or $\geq 85 \mathrm{~mm} \mathrm{Hg}$ diastolic; Triglycerides $\geq 150 \mathrm{mg} / \mathrm{dL}$ low HDL as $<40 \mathrm{mg} / \mathrm{dL}$ in males and $<50 \mathrm{mg} / \mathrm{dL}$ in females are considered metabolic abnormalities used for metabolic syndrome diagnosis. high LDL as $>=130$ $\mathrm{mg} / \mathrm{dL}$ (Roche kit, USA), high total cholesterol as $>=200 \mathrm{mg} / \mathrm{dL}$ (Roche kit, USA),. Data are expressed as mean (SD). *Valid percentages are reported 
Metabolic abnormalities were assessed in the study population (Table 4). Out of the total sample, only $10.5 \%$ were free of metabolic abnormality. Around half of the participants (45.9\%) had only one abnormality related to MetS, more than one third (37.2\%) had two, $5.3 \%$ had three and $1.1 \%$ had four abnormalities. Therefore, according to the IDF criteria, $6.4 \%$ of the sample suffered from metabolic syndrome.

The most common abnormality was low HDL-C (65.0\%), followed by elevated waist circumference $(51.9 \%)$. The least identified abnormality was elevated blood glucose (1.1\%).

Table 4. Prevalence of Metabolic Abnormalities among University Students ( $n=266$ )

\begin{tabular}{lll}
\hline & & $\mathbf{N}(\%)$ \\
\hline Waist circumference & Elevated & $138(51.9)$ \\
\hline Blood pressure & Elevated & $45(16.9)$ \\
\hline Blood glucose & Elevated & $3(1.1)$ \\
\hline Triglycerides & Elevated & $15(5.6)$ \\
\hline HDL-C & Low & $173(65.0)$ \\
\hline Metabolic syndrome & Present & $17(6.4)$ \\
\hline
\end{tabular}

Cut of points were according to IDF standards detailed in Table 1

HDL-C: High Density Lipoprotein- Cholesterol

Table 5 displays the predictors of each metabolic abnormality with a prevalence higher than $10 \%$. Age was significantly associated with higher odds of having an elevated waist circumference (aOR=1.17, 95\% Cl: 1.05-1.30). Moreover, female gender was associated with more than three times higher odds of developing this abnormality $(\mathrm{aOR}=3.56$, 95\%Cl: 1.89-6.72). In contrast, female gender was coupled with lower odds of having elevated blood pressure ( $\mathrm{aOR}=0.08,95 \% \mathrm{Cl}$ : 0.03-0.20). Also, being employed was linked to lower odds of having hypertension, especially among part-timers ( $\mathrm{aOR}=0.15,95 \% \mathrm{Cl}$ : 0.04 0.59). Interestingly, increased stress was significantly associated with slightly decreased odds of having low HDL-C ( $\mathrm{aOR}=0.95,95 \% \mathrm{Cl}$ : 0.91-0.99). Finally, age was the only variable significantly associated with higher odds of developing the metabolic syndrome (aOR=1.15, 95\%Cl: 1.03-1.29). 
Table 5. Predictors of Each Metabolic Abnormality among University Students

\begin{tabular}{|c|c|c|c|c|c|}
\hline \multirow{2}{*}{ Predictor* } & \multirow{2}{*}{ aOR } & \multirow{2}{*}{ SE } & \multicolumn{2}{|c|}{ 95.0\% Confidence Interval } & \multirow{2}{*}{ p-value } \\
\hline & & & Lowe & d Upper Bound & \\
\hline \multicolumn{6}{|l|}{ Elevated waist circumference ${ }^{a}$} \\
\hline Age & 1.17 & 0.06 & 1.05 & 1.30 & $0.005^{*}$ \\
\hline Gender (ref=male) & - & - & - & - & - \\
\hline Female & 3.56 & 1.15 & 1.89 & 6.72 & $<0.001^{*}$ \\
\hline Weekly soft drink consumption & 0.89 & 0.16 & 0.62 & 1.27 & 0.51 \\
\hline $\begin{array}{l}\text { Weekly diet soft drink } \\
\text { consumption }\end{array}$ & 1.43 & 0.56 & 0.66 & 3.09 & 0.36 \\
\hline Stress score & 1.02 & 0.03 & 0.97 & 1.07 & 0.45 \\
\hline Sleep quality & 1.06 & 0.05 & 0.97 & 1.16 & 0.19 \\
\hline PAL (ref=light PAL) & - & - & - & - & 0.72 \\
\hline Moderate PAL & 0.92 & 0.27 & 0.51 & 1.64 & 0.77 \\
\hline Vigorous PAL & 0.85 & 0.37 & 0.37 & 1.97 & 0.70 \\
\hline \multicolumn{6}{|l|}{ Elevated blood pressure ${ }^{b}$} \\
\hline Gender (ref=male) & - & - & - & - & - \\
\hline Female & 0.08 & 0.04 & 0.03 & 0.20 & $<0.001^{*}$ \\
\hline $\begin{array}{l}\text { Employment status } \\
\text { (ref=unemployed) }\end{array}$ & - & - & - & - & $0.001^{*}$ \\
\hline Employed, part time & 0.15 & 0.11 & 0.04 & 0.59 & $0.007^{*}$ \\
\hline Employed, full time & 0.48 & 0.27 & 0.16 & 1.45 & 0.19 \\
\hline Smoking status (ref=no smoking) & & - & - & - & - \\
\hline Smoker & 1.11 & 0.48 & 0.48 & 2.60 & 0.81 \\
\hline Weekly soft drink consumption & 1.33 & 0.27 & 0.90 & 1.97 & 0.16 \\
\hline Stress score & 0.99 & 0.03 & 0.93 & 1.06 & 0.75 \\
\hline PAL (ref=light PAL) & - & - & - & - & 0.83 \\
\hline Moderate PAL & 1.15 & 0.51 & 0.49 & 2.74 & 0.74 \\
\hline Vigorous PAL & 1.05 & 0.57 & 0.36 & 3.06 & 0.93 \\
\hline \multicolumn{6}{|l|}{ Low HDL-Cc } \\
\hline Stress score & 0.95 & 0.02 & 0.91 & 0.99 & $0.012^{*}$ \\
\hline \multicolumn{6}{|l|}{ Metabolic Syndromed } \\
\hline Age & 1.15 & 0.07 & 1.03 & 1.29 & $0.012^{*}$ \\
\hline Gender (ref=male) & - & - & - & - & - \\
\hline Female & 0.41 & 0.21 & 0.15 & 1.14 & 0.087 \\
\hline
\end{tabular}

aOR: Adjusted Odds Ratio; SE: Standard Error; PAL: Physical Activity Level; HDL-C: High Density LipoproteinCholesterol

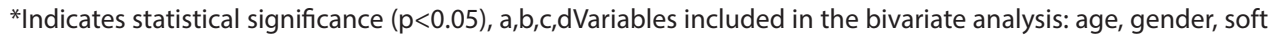
drink, diet soft drink, stress score, sleep quality, physical activity level; those with $p<0.2$ were included in the multivariate analysis. Metabolic abnormalities included when prevalence was higher than $10 \%$. 


\section{Discussion}

There is scarce data on metabolic syndrome and related chronic diseases among university students in Lebanon, probably because students are often considered to be protected by their young age. Therefore, the present study aimed to determine the prevalence and determinants of metabolic syndrome in this overlooked population, in a country with growing rates of both obesity [38] and cardiovascular disease (CVD) [39]. Using the IDF criteria, we found that the overall prevalence of MetS to be $6.4 \%$ in the student sample. Furthermore, individual components of the MetS were considerably high, as half of the sample had one abnormality and more than a third had two abnormalities. Low HDL-C levels were the most detected abnormality followed by an elevated waist circumference. The above findings are alarming at such a young age and may be the cause of high rates of cardiovascular disease in the adult Lebanese population.

The MetS prevalence rate calculated in this study is comparable to the rate reported by Dhaheri et al (2016) [40] among female college students in the United Arab Emirates (6.8\%). However, university students in the Kingdom of Saudi Arabia [41] and female adolescents in Kuwait [42] had slightly higher prevalence rates, $7.8 \%$ and $14.8 \%$ respectively. Our calculated prevalence rate is also close to those of students in the United States, where Ford and colleagues found the rate to be $6.7 \%$ among $20-29$ year olds [43] and almost identical to results from a study conducted by Dalleck \& Kjelland (2012) [7] who found the prevalence to be $6.8 \%$. However the literature has exhibited much variability in terms of prevalence estimation with some rates ranging from from $0.3 \%[6]$ to others reaching $10 \%$ [44] in the United States. The rate of MetS, calculated in this study is higher than that reported in many countries worldwide. For example, $1.7 \%$ of Brazilian university students [45] and $4.6 \%$ of students in Taiwan suffered from the MetS [46]. A similar study conducted on university students in Lebanon found the prevalence to be 5.2\% [47]; however, different criteria for diagnosis was used. The variability could be due to the criteria used to identify MetS, the variability due to race and ethnicity and the study design $[6,40]$.

Our finding that low HDL-C levels were the most common abnormality in the student population has been reported in several studies among university students [48] in adult Arab Americans [49] and in Lebanese adolescents, where 96.2\% had low HDL-C levels [38]. It is worthy to note that low HDL-C levels have been associated with a Western dietary pattern characterized by high consumption of fatty foods and processed meats [50], which is more commonly consumed among younger Lebanese individuals [50]. Since decreased levels of HDL cholesterol are a risk factor for MetS and are an independent risk factor for CVD [51] regular health checks and lipid profile screening should be introduced early on. Furthermore, health promotion interventions should be implemented among Lebanese collegians to help students alter unhealthy lifestyle behaviors that may be contributing to the low HDL levels and thus increased risk of MetS and CVD.

The second most common abnormality detected in our sample was increased waist 
circumference for which females had a higher risk. This finding was also reported by Yahia and colleagues (2017) [6] and was unexpected since females tend to be more self-conscious and concerned with body image [52]. This should be further explored in future studies as it is well known that a high waist circumference is a riskfactor for MetS and consequently cardiovascular disease [53]. Additionally, Lebanese specific cut-off values for waist circumference should be researched as previous studies have found that ethnic variation exists [54].

A noteworthy finding in our study is that age was associated with an increased risk of MetS, despite the young age of our sample population, indicating that even a slight age increase may significantly increase the risk of MetS. This finding has also been reported in a Finnish study conducted among young adults in the 24-39 age bracket [55].

This study had several strengths. First, anthropometric data collection was conducted by trained dietitians. Second, validated questionnaires were used for data collection and which were pilot tested before use. Furthermore, although only one university was used for recruitment, the university had several campuses in several geographical locations and students from all socioeconomic levels so the sample was somewhat representative of college students across Lebanon

However, this study had several limitations, one of which is its cross-sectional design that does not allow causal inferences. Additionally there was an overrepresentation of female participants, which is a common finding in university based studies [56, 57]. Furthermore, self-selection bias was an additional limitation, as students who are more healthy tend to participate more readily in health oriented studies and this could underestimate the prevalence rate reported. The current study was also conducted at only one university so generalizability of results is limited. Additionally, waist circumference cut-off points used are not Lebanese specific, as those have still not been identified, and thus European standards were used as per IDF guidelines [1]. Furthermore, most of the students still lived at home and did not consume alcohol, so analysis for these variables was not possible.

\section{Conclusion}

This study reveals a high vulnerability of university students to the MetS and an alarming prevalence of its individual components, most noteworthy low HDL levels and increased waist circumference. This raises the need for increased awareness of the problem among both college health care providers and students alike to dispel the myth that young age is protective against chronic diseases. Furthermore, routine screening for primary prevention among students enrolled in colleges and universities is necessary, as postsecondary institutions are ideal hubs to reach out to collegians. Moreover, our findings can assist to inform future interventions to target at risk collegians. Finally, future studies should focus on recruiting a more representative sample, of equal distribution in gender to better understand the causes of the problem. 


\section{References}

1. Alberti KG, Eckel RH, Grundy SM, Zimmet PZ, Cleeman Jl, Donato KA, et al. Harmonizing the metabolic syndrome: a joint interim statement of the International Diabetes Federation Task Force on Epidemiology and Prevention; National Heart, Lung, and Blood Institute; American Heart Association; World Heart Federation; International Atherosclerosis Society; and International Association for the Study of Obesity. Circulation. 2009;120(16):1640-5.

2. Ford ES. Risks for All-Cause Mortality, Cardiovascular Disease, and Diabetes Associated With the Metabolic Syndrome. A summary of the evidence. Diabetes Care 2005;28(7):1769-78.

3. Malik S, Wong ND, Franklin SS, Kamath TV, L'Italien GJ, Pio JR, et al. Impact of the Metabolic Syndrome on Mortality From Coronary Heart Disease, Cardiovascular Disease, and All Causes in United States Adults. Circulation 2004;110(10):1245-50.

4. Kaur J. A Comprehensive Review on Metabolic Syndrome. Cardiol Res and Practice 2014;2014:943162.

5. Boudreau DM, Malone DC, Raebel MA, Fishman PA, Nichols GA, Feldstein AC, et al. Health care utilization and costs by metabolic syndrome risk factors. Metab Syndr Relat Disord. 2009;7(4):305-14.

6. Yahia N, Brown CA, Snyder E, Cumper S, Langolf A, Trayer C, et al. Prevalence of Metabolic Syndrome and Its Individual Components Among Midwestern University Students. J community Health 2017;42(4):674-87.

7. Dalleck LC, Kjelland EM. The prevalence of metabolic syndrome and metabolic syndrome risk factors in college-aged students. Am J Health Promot 2012;27(1):37-42.

8. Morrell JS, Lofgren IE, Burke JD, Reilly RA. Metabolic Syndrome, Obesity, and Related Risk Factors Among College Men and Women. J Am Coll Health 2012;60(1):82-9.

9. Nelson MC, Story M, Larson NI, Neumark-Sztainer D, Lytle LA. Emerging Adulthood and College-aged Youth: An Overlooked Age for Weight-related Behavior Change. Obesity 2008;16(10):2205-11.

10. Huang TT-K, Kempf AM, Strother ML, Li C, Lee RE, Harris KJ, et al. Overweight and Components of the Metabolic Syndrome in College Students. Diabetes Care. 2004;27(12):3000-1.

11. Moreno-Gomez C, Romaguera-Bosch D, Tauler-Riera P, Bennasar-Veny M, Pericas-Beltran J, Martinez-Andreu S, et al. Clustering of lifestyle factors in Spanish university students: the relationship between smoking, alcohol consumption, physical activity and diet quality. Public Health Nutr 2012;15(11):2131-9.

12. Lowry R, Galuska DA, Fulton JE, Wechsler H, Kann L, Collins JL. Physical activity, food choice, and weight management goals and practices among U.S. college students. Am J Prev Med. 2000;18(1):18-27.

13. Levitsky DA, Halbmaier CA, Mrdjenovic G. The freshman weight gain: a model for the study of the epidemic of obesity. Int J Obes Relat Metab Disord 2004;28(11):1435-42.

14. Huang TTK, Harris KJ, Lee RE, Nazir N, Born W, Kaur H. Assessing Overweight, Obesity, Diet, and Physical Activity in College Students. J Am Coll Health 2003;52(2):83-6. 
15. Lund HG, Reider BD, Whiting AB, Prichard JR. Sleep patterns and predictors of disturbed sleep in a large population of college students. J Adolesc Health 2010;46(2):124-32.

16. Serlachius A, Hamer M, Wardle J. Stress and weight change in university students in the United Kingdom. Physiol Behav 2007;92(4):548-53.

17. Strong KA, Parks SL, Anderson E, Winett R, Davy BM. Weight Gain Prevention: Identifying Theory-Based Targets for Health Behavior Change in Young Adults. J Am Diet Assoc 2008;108(10):1708-15.e3.

18. Greaney ML, Less FD, White AA, Dayton SF, Riebe D, Blissmer B, et al. College Students' Barriers and Enablers for Healthful Weight Management: A Qualitative Study. J Nut Educ Behav 2009;41(4):281-6.

19. Brunt AR, Rhee YS. Obesity and lifestyle in U.S. college students related to living arrangemeents. Appetite 2008;51(3):615-21.

20. Kremmyda L-S, Papadaki A, Hondros G, Kapsokefalou M, Scott JA. Differentiating between the effect of rapid dietary acculturation and the effect of living away from home for the first time, on the diets of Greek students studying in Glasgow. Appetite 2008;50(2):455-63.

21. Perry CL. Cardiovascular disease prevention among youth: visioning the future. Prev Med 1999;29(6 Pt 2):S79-83.

22. Kelder SH, Perry CL, Klepp KI, Lytle LL. Longitudinal tracking of adolescent smoking, physical activity, and food choice behaviors. Am J Public Health 1994;84(7):1121-6.

23. Mehio Sibai A, Nasreddine L, Mokdad AH, Adra N, Tabet M, Hwalla N. Nutrition transition and cardiovascular disease risk factors in Middle East and North Africa countries: reviewing the evidence. Ann Nutr Metab. 2010;57(3-4):193-203.

24. Mehio-Sibai A, Obeid O, Batal M, Adra N, El Khoury D, Hwalla N. Prevalence and Correlates of metabolic syndrome in an adult Lebanese population. Prevention and Control 2008;3.

25. Naja F, Nasreddine L, Itani L, Adra N, Sibai AM, Hwalla N. Association between dietary patterns and the risk of metabolic syndrome among Lebanese adults. Eur J Nutr 2013;52(1):97-105.

26. Salameh P, Jomaa L, Issa C, Farhat G, Salamé J, Zeidan N, et al. Assessment of Dietary Intake Patterns and Their Correlates among University Students in Lebanon. Frontiers in Public Health. 2014;2:185.

27. Yahia N, Achkar A, Abdallah A, Rizk S. Eating habits and obesity among Lebanese university students. Nutr J 2008;7(1):32.

28. Salameh P, Jomaa L, Issa C, Farhat G, Zeghondi H, Gerges N, et al. Assessment of health risk behaviours among university students: a cross-sectional study in Lebanon. Int J Adolesc Youth 2014;19(2):203-16.

29. Musharrafieh U, Tamim HM, Rahi AC, El-Hajj MA, Al-Sahab B, El-Asmar K, et al. Determinants of university students physical exercise: a study from Lebanon. Int J Public Health 2008;53(4):20813.

30. Ng M, Fleming T, Robinson M, Thomson B, Graetz N, Margono C, et al. Global, regional, and national prevalence of overweight and obesity in children and adults during 1980-2013: a systematic analysis for the Global Burden of Disease Study 2013. Lancet 2014;384(9945):766- 
81.

31. van der Kooy K, Seidell JC. Techniques for the measurement of visceral fat: a practical guide. Int J Obes Relat Metab Disord 1993;17(4):187-96.

32. Pickering TG, Hall JE, Appel LJ, Falkner BE, Graves J, Hill MN, et al. Recommendations for blood pressure measurement in humans and experimental animals: part 1: blood pressure measurement in humans: a statement for professionals from the Subcommittee of Professional and Public Education of the American Heart Association Council on High Blood Pressure Research. Circulation. 2005;111(5):697-716.

33. Batal M HS, Hwalla N, Kabbani N, Talhouk S. Wild edible plants: promoting dietary diversity in poor communities of Lebanon.Progress Report, March 2006.

34. Craig CL, Marshall AL, Sjostrom M, Bauman AE, Booth ML, Ainsworth BE, et al. International physical activity questionnaire: 12-country reliability and validity. Med Sci Sports Exerc 2003;35(8):1381-95.

35. Buysse DJ, Reynolds CF, 3rd, Monk TH, Berman SR, Kupfer DJ. The Pittsburgh Sleep Quality Index: a new instrument for psychiatric practice and research. Psychiatry Res 1989;28(2):193213.

36. Cohen S, Kamarck T, Mermelstein R. A global measure of perceived stress. J Health Soc Behav 1983;24(4):385-96.

37. Obesity: preventing and managing the global epidemic. Report of a WHO consultation. World Health Organization technical report series. 2000;894:i-xii, 1-253.

38. Nasreddine L, Naja F, Chamieh MC, Adra N, Sibai A-M, Hwalla N. Trends in overweight and obesity in Lebanon: evidence from two national cross-sectional surveys (1997 and 2009). BMC Public Health 2012;12(1):798.

39. Zeidan RK, Farah R, Chahine MN, Asmar R, Hosseini H, Salameh P, et al. Prevalence and correlates of coronary heart disease: first population-based study in Lebanon. Vasc Health Risk Manag 2016;12:75-84.

40. Al Dhaheri AS, Mohamad MN, Jarrar AH, Ohuma EO, Ismail LC, Al Meqbaali FT, et al. A CrossSectional Study of the Prevalence of Metabolic Syndrome among Young Female Emirati Adults. PLoS One 2016;11(7):e0159378.

41. Abolfotouh MA, Al-Alwan IA, Al-Rowaily MA. Prevalence of Metabolic Abnormalities and Association with Obesity among Saudi College Students. Int J Hypertens 2012;2012:819726.

42. Al-Isa A, Akanji AO, Thalib L. Prevalence of the metabolic syndrome among female Kuwaiti adolescents using two different criteria. Br J of Nutr 2009;103(1):77-81.

43. Ford ES, Giles WH, Dietz WH. Prevalence of the metabolic syndrome among us adults: Findings from the third national health and nutrition examination survey. JAMA 2002;287(3):356-9.

44. Keown TL, Smith CB, Harris MS. Metabolic Syndrome Among College Students. J Nurse Pract 2009;5(10):754-9.

45. de Freitas RW, Jr., de Araujo MF, Marinho NB, de Vasconcelos HC, Lima AC, Pereira DC, et al. Prevalence of the metabolic syndrome and its individual components in Brazilian college students. J Clin Nurs 2013;22(9-10):1291-8. 
46. Yen SL, Chiu TY, Lin YC, Lee YC, Lee LT, Huang KC. Obesity and hepatitis B infection are associated with increased risk of metabolic syndrome in university freshmen. Int J Obes (Lond) 2008;32(3):474-80.

47. Chedid R, Gannagé-Yared M-H, Khalifé S, Halaby G, Zoghbi F. Impact of different metabolic syndrome classifications on the metabolic syndrome prevalence in a young Middle Eastern population. Metabolism 2009;58(6):746-52.

48. Lance CD, Emily Marguerite K. The Prevalence of Metabolic Syndrome and Metabolic Syndrome Risk Factors in College-Aged Students. Am J Health Promot. 2012;27(1):37-42.

49. Jaber LA, Brown MB, Hammad A, Zhu Q, Herman WH. The prevalence of the metabolic syndrome among arab americans. Diabetes Care 2004;27(1):234-8.

50. Naja F, Nasreddine L, Itani L, Chamieh MC, Adra N, Sibai AM, et al. Dietary patterns and their association with obesity and sociodemographic factors in a national sample of Lebanese adults. Public Health Nutr 2011;14(9):1570-8.

51. Wilson PWF, D'Agostino RB, Levy D, Belanger AM, Silbershatz H, Kannel WB. Prediction of Coronary Heart Disease Using Risk Factor Categories. Circulation. 1998;97(18):1837-47.

52. Anderson CB, Bulik CM. Gender differences in compensatory behaviors, weight and shape salience, and drive for thinness. Eating Behav 2004;5(1):1-11.

53. Alberti KG, Zimmet P, Shaw J. The metabolic syndrome--a new worldwide definition. Lancet 2005;366(9491):1059-62.

54. Delavari A, Forouzanfar MH, Alikhani S, Sharifian A, Kelishadi R. First Nationwide Study of the Prevalence of the Metabolic Syndrome and Optimal Cutoff Points of Waist Circumference in the Middle East: The National Survey of Risk Factors for Noncommunicable Diseases of Iran. Diabetes Care 2009;32(6):1092-7.

55. Mattsson N, Rönnemaa T, Juonala M, Viikari JSA, Raitakari OT. The prevalence of the metabolic syndrome in young adults. The Cardiovascular Risk in Young Finns Study. J Intern Med 2007;261(2):159-69.

56. Morrell JS, Byrd-Bredbenner C, Quick V, Olfert M, Dent A, Carey GB. Metabolic Syndrome: Comparison of Prevalence in Young Adults at 3 Land-Grant Universities. J Am Coll Health 2014;62(1):1-9.

57. Fernandes J, Lofgren IE. Prevalence of Metabolic Syndrome and Individual Criteria in College Students. J Am Coll Health 2011;59(4):313-21. 
CHAPTER 


\section{The freshman weight gain phenomenon: Does it apply to Lebanese students}

Suzan A. Haidar, Nanne K. de Vries, Dimitrios Papandreou, Rana Rizk, Mirey Karavetian, 


\section{Abstract \\ The Freshman weight gain phenomenon: Does it apply to Lebanese Students? Objective:}

When transitioning from high school to university, students tend to gain weight. The aim of the study was to identify whether Lebanese students experience weight changes during the transition and identify predisposing factors.

\section{Participants:}

Eighty freshman students from four campuses in Lebanon were recruited in October 2015.

\section{Methods:}

Students were assessed anthropometrically and biochemically at two time points, seven months apart. Students filled out questionnaires assessing demographic and lifestyle habits, physical activity levels, nutrition knowledge, sleep quality, and stress.

\section{Results:}

The students gained approximately $4.19 \mathrm{lbs}$. (1.90kg). There was a significant increase in waist circumference, blood glucose and triglyceride levels. There were no significant changes in HDL-cholesterol, total cholesterol, knowledge score, stress level, physical activity, sleep and lifestyle habits.

\section{Conclusions:}

Lebanese students do gain weight during their first year of university enrollment. Future research is necessary to assess the reasons for weight gain and develop suitable prevention programs.

Keywords: Freshman 15, college students, weight gain, obesity, stress

\section{Introduction}

Obesity rates are at an all-time high and have reached epidemic magnitudes. According to World Health Organization data, more than 600 million adults were obese in 2014. ${ }^{1}$ These estimates are alarming since obesity increases the risk of a multitude of physiological and psychological chronic diseases and can lead to premature morbidity and mortality. The fight against obesity is fierce with researchers, health, and governmental organizations combining their efforts to restrict the up rise of this epidemic.

One strategy that is promising in combating obesity is to identify critical periods of weight gain; pinpoint vulnerable groups and accordingly, plan preventive interventions. One such identified critical period of weight gain is during student transition from high school to university or college. ${ }^{2}$ This critical period could potentially dictate whether these students will live as healthy adults or possibly become overweight or obese by acquiring unhealthy habits especially since nutrition habits acquired at an early age and weight problems tend 
to continue in adulthood. ${ }^{3,4}$ Unfortunately, once weight gain occurs, it becomes hard to manage and increases vulnerability to obesity and subsequent complications. ${ }^{5,6}$

University students are at an increased risk of gaining weight during the freshman year; it has previously been hypothesized that the average collegian may gain approximately 15 pounds; a phenomenon that has been coined "The Freshman 15".7 However, more recent empirical evidence, suggests that the 15-pound increase is exaggerated, and that a 3 to 5 pound weight gain is more realistic. 8,9 Nevertheless even a slight weight gain is still significant and is higher than the gain experienced by the general population ${ }^{9-11}$ which may negatively affect the future health of these students. Therefore, prevention of weight gain in such a vulnerable group during this critical period could prove to be key in fighting obesity in this population. ${ }^{12}$ Explanations for this weight gain vary; however, some key factors that have been previously identified as culprits include increased alcohol and fast food consumption, decreased physical activity, moving away from home accompanied by lack of parental supervision and increased stress levels. ${ }^{13,14}$ Notably, stress may have a differential effect of on $\mathrm{BMI}^{15}$; Serlachius and colleagues found that students with a lower body weight tend to lose weight as a consequence of high stress levels as opposed to students who have a higher BMI who tend to gain weight secondary to the increased stress $^{15}$.

Although, the freshman weight gain phenomena has been extensively researched and proven in the United States and Europe borders ${ }^{6}$; it is still not clear whether this phenomena also applies among Middle Eastern students. Therefore, the aim of this study was to investigate whether Lebanese students do gain weight during the freshman year, and determine the predisposing factors.

\section{Methods}

The study had a longitudinal design, and was conducted in a private university with many campuses in Lebanon. Using two-step sampling, four campuses from different geographical locations were selected. Afterwards, all first year students were invited to participate in the study via mass e-mail and through classroom visits made by the primary investigator. Students were informed about the objectives and methods of the study, in addition to their right to withdraw from the study at any time. Criteria for students to be included in the study were: 1) first semester of enrollment at the university, 2) free of disease, 3) not pregnant. Students were excluded from the study if they were sick at the time of the study, suffered from chronic diseases or were not fasting. Students who did not meet inclusion criteria were excluded. In total 80 students who volunteered met the inclusion criteria and consented. Ethical approval for this study was obtained from the university's committee on Research Ethics (CRE) (case number: LIUCRE-141117-2). Participants completed the primary assessment in their first semester (TO) and then 7 
months later during enrollment in the second semester (T1.) Only 40 students returned for follow-up out of which 27 consented to blood withdrawal. The reasons for the high dropout rate could be due to change in class schedules and fear of blood collection.

\section{Data collection}

\section{Sample Size:}

A statistical power analysis was performed using Power and sample size Calculations Software (version 3) to estimate the adequate number of participants needed for this study. Prior data indicate that the difference in the response of matched pairs is normally distributed with standard deviation of 8.67. If the true difference in the mean response of matched pairs is 4.19 , we would need 36 subjects to be able to reject the null hypothesis that this response different is zero with probability (power) 0.8. Type I error probability associated with this test of this null hypothesis is 0.05 . Therefore, this study was adequately powered.

Data collection took place during the first two weeks of the first semester, in the nutrition clinics of the selected campuses. The day before data collection, students were phonecalled to remind them about the necessity of fasting for 12 hours prior to the blood draw and were given information on location and time of meeting with the research team

\section{Anthropometric Data}

Trained licensed dietitians assessed participant anthropometric which included : 1) height (cm) using a portable stadiometer, (ADE, Germany), measured to the nearest $0.1 \mathrm{~cm}$, without shoes, with the subject stretching to the maximum height and the head positioned in the Frankfort plane; 2 ) weight ( $\mathrm{kg}$ ) using a calibrated beam scale, without shoes and while participants were wearing light clothes; waist circumference $(\mathrm{cm})$ measured the midpoint, half-way between the right iliac crest and the lower costal region; ${ }^{16}$ measured to the nearest $0.1 \mathrm{~cm}$, using Accugirth measuring tapes. Body mass index (BMI) which is the ratio of weight $(\mathrm{kg})$ and height squared $\left(\mathrm{m}^{2}\right)$ was calculated. All participants were contacted after 7 months $\left(T_{1}\right)$ to recollect data using the same procedures adopted at baseline $\left(T_{0}\right)$. Weight change was calculated by subtracting weight at $T_{1}$ from weight at $T_{0}$. A one pound difference $(0.45 \mathrm{~kg})$ was considered to be insignificant in terms of weight change and was unaccounted for.

\section{Biochemical tests:}

A blood sample of $5 \mathrm{ml}$ was drawn from students by a licensed phlebotomist and samples were transported to the laboratory using a thermally insulated box. Serum was analyzed for cholesterol (mg/dl), triglyceride ((TG (mg/dl)), HDL-cholesterol ((HDL-C (mg/dl)), and 
fasting blood glucose (FBS (mg/dl)) concentrations. LDL-cholesterol ((LDL-C mg/dl)) was calculated. The analyses were performed using a Cobas C111 automated biochemical analyzer (Roche Diagnostics, Indianapolis, IN, USA) based on spectrophotometric principles. Additionally, serum cortisol (nmol/L) was measured using Cobas e411 immunoassay automated analyzer (Roche Diagnostics, Indianapolis, IN, USA) based on the electrochemiluminescence (ECLIA) principle. All blood collection was done early in the morning, after an overnight fast. After blood collection, students were served a light breakfast.

\section{Questionnaires}

The students were then asked to fill a series of questionnaires:

1 Demographic and lifestyle habits questionnaire: adapted from Levitsky et al., $(2004)^{10}$, included 10 open-ended questions focused on number of meals consumed daily and outside the home, living arrangements, smoking status, alcohol consumption. The questionnaire included questions about perceived weight changes by the students and whether they thought their weight had increased, decreased or remained constant

2 The International Physical Activity Questionnaire (IPAQ) (2014) short form :a validated tool used to measure level of exercise ${ }^{17}$ and consisting of seven questions assessing duration and frequency of light, moderate and vigorous physical activity completed in the past week. The Metabolic equivalent of tasks (METs) was calculated by multiplying the total minutes spent in the corresponding activity with the frequency (days) and the constants of 3.3, 4.0 and 8.0 for light, moderate and vigorous activity respectively. The total MET value was computed by summing up the respective MET values for all activities that were done in bouts but were longer than 10 minutes in duration.

3 The General Nutrition Knowledge Questionnaire, adapted from Parmenter \& Wardle, (1999) ${ }^{18}$ : includes 28 open ended and multiple choice questions. The choices were made to be culturally sensitive and specific to the food options consumed by the sample population. Cronbach's alpha coefficient of the adapted questionnaire was 0.766 , which is considered satisfactory ;

4 The Pittsburgh Sleep Quality Index (PSQI), (2014), developed by Buysse et al $(1989)^{19}$ : a nine-item questionnaire where four questions assessed the duration (hours) of sleep, duration needed to fall asleep, time needed to wake up and awake time spent in bed; in addition to five other questions addressing the reasons of troubled sleep). Answers were converted to total scores using an algorithm adapted from the developers of the questionnaire, where higher scores indicated poor sleep quality. 
5 The Perceived Stress Questionnaire ${ }^{20}$ : a ten-item questionnaire measuring stress levels in the last month. Answers followed a five-point scale with frequencies ranging from never to very often. Total score ranged between 0 and 40, where higher scores indicated higher stress levels.

All questionnaires were available in both English and Arabic, and respondents were able to choose their language preference. All instruments were pilot-tested on a sample of students before the study was conducted for validation, the results of which were discarded. It took students between 30 and 50 minutes to complete the questionnaires.

\section{Data analyses}

All statistical analyses were conducted using Statistical Package for Social Sciences (SPSS) version 21.0, IBM. P-values $<0.05$ were considered statistically significant. Descriptive analyses were performed to summarize participants' characteristics and changes in measures and laboratory data through means and standard deviations for continuous variables and frequencies and percentages for categorical ones. The normality of the data distributions was evaluated using Shapiro-Wilk test. Within subjects significant differences of study parameters (nutrition knowledge, number of meals eaten per day, number of out of home meals per week, stress score, sleep score, physical activity and laboratory values) were assessed using paired sample T-test and Wilcoxon Signed Ranks Tests for normally distributed and skewed continuous variables, respectively. Additionally, a between subjects analysis of relevant study parameters(sub-group analysis) was conducted between participants who gained weight at $\mathrm{T} 1$ and those who did not using independent sample $T$ test for normally distributed continuous variables and Mann-Whitney $U$ test for skewed ones. Finally agreement between reported and actual weight change was calculated according to Cohen (1968) ${ }^{21}$ using the MedCalc statistical software (https:// www.medcalc.org). Linear weighted Kappa (k) values and their $95 \%$ confidence intervals were presented, whereby $k<0.2,0.21-0.40,0.41-0.6,0.61-0.80,0.81-1.00$ were interpreted as poor, fair, moderate, good and very good strength of agreement respectively.

\section{Results}

\section{Sample characteristics}

Out of a total of 80 participants, 40 completed the study. As evident in table one, the students had a mean age of $19.3 \pm 2.04$ years and had a waist circumference of 83.16 $\pm 11.15 \mathrm{~cm}$. On average, the participants consumed around 3 meals per day and ate approximately 5 meals out of home weekly. Their mean knowledge score was $50.14 \pm$ $10.08 \%$, where $100 \%$ indicates perfect knowledge. Mean stress level was 19.28 out of a total possible 40 points and where a higher score indicates higher stress. Average sleep score was 6.55 where a score above five indicates poor sleep quality. Weekly alcohol 
consumption average was fairly low $(0.18 \pm 0.63)$

More than half of the participants were females (55\%), the majority were single $(97.5 \%)$ and $90 \%$ lived with their parents. Approximately, $19.5 \%$ held jobs parallel to their studies and $32.5 \%$ smoked. The mean BMI of the participants was $23.74 \pm 4.49 \mathrm{~kg} / \mathrm{m}^{2}$, and around two-thirds (62.5\%) had a normal BMI. Forty percent of the participants had a moderately active lifestyle.

During the first year of university enrollment (over the course of 2 semesters), the cohort gained on average $4.19 \pm 8.67 \mathrm{Lbs}$. $(1.90 \pm 3.93 \mathrm{~kg})$, and the mean BMI of the participants significantly increased from $23.95 \pm 5.38$ to $24.64 \pm 5.38 \mathrm{~kg} / \mathrm{m}^{2}(\mathrm{p}=0.002)$ as evident in table 2. The vast majority of the students $(70 \% ; n=28)$ gained weight, and $40 \%$ of whom $(n=16)$ accumulated more than $5 \mathrm{lbs}$ ( $(2.26 \mathrm{~kg})$. Three students $(7.5 \%)$ gained $15 \mathrm{lbs}$. $(6.82 \mathrm{~kg})$. 
Table 1. Baseline characteristics of freshman students $(n=80)$

\begin{tabular}{|c|c|c|}
\hline & $\mathbf{N}$ & $\%$ \\
\hline Gender, male & 36 & 45.0 \\
\hline Social status, single & 78 & 97.5 \\
\hline Live with family, yes & 72 & 90.0 \\
\hline Employment, none & 62 & 80.5 \\
\hline Smoker, yes & 26 & 32.5 \\
\hline \multicolumn{3}{|l|}{ BMI category $\left(\mathrm{kg} / \mathrm{m}^{2}\right)$} \\
\hline Underweight & 5 & 6.3 \\
\hline Normal weight & 50 & 62.5 \\
\hline Overweight & 18 & 22.5 \\
\hline Obese & 7 & 8.8 \\
\hline \multicolumn{3}{|l|}{ Physical activity level } \\
\hline Light activity & 30 & 37.5 \\
\hline Moderate activity & 32 & 40.0 \\
\hline High activity & 18 & 22.5 \\
\hline & \multicolumn{2}{|c|}{ Mean \pm SD } \\
\hline Age (year) & \multicolumn{2}{|c|}{$19.30 \pm 2.04$} \\
\hline Waist Circumference (WC) (cm) & \multicolumn{2}{|c|}{$83.16 \pm 11.15$} \\
\hline \multicolumn{3}{|l|}{ Lifestyle Questionnaire } \\
\hline Number of meals per day & \multicolumn{2}{|c|}{$2.84 \pm 1.07$} \\
\hline Number of out of home meals per week & \multicolumn{2}{|c|}{$4.79 \pm 3.82$} \\
\hline Alcohol consumption (drinks per week) & \multicolumn{2}{|c|}{$0.18 \pm 0.63$} \\
\hline Nutrition knowledge (\%) & \multicolumn{2}{|c|}{$50.14 \pm 10.08$} \\
\hline Sleep score & \multicolumn{2}{|c|}{$6.55 \pm 3.11$} \\
\hline Stress score & \multicolumn{2}{|c|}{$19.28 \pm 5.95$} \\
\hline \multicolumn{3}{|l|}{ Biochemical tests } \\
\hline Fasting Blood Glucose ( FBG) (mg/dl) & \multicolumn{2}{|c|}{$82.09 \pm 7.49$} \\
\hline Total cholesterol (mg/dl) & \multicolumn{2}{|c|}{$158.71 \pm 27.13$} \\
\hline LDL cholesterol (mg/dl) & \multicolumn{2}{|c|}{$93.76 \pm 27.91$} \\
\hline HDL cholesterol (mg/dl) & \multicolumn{2}{|c|}{$51.79 \pm 11.70$} \\
\hline Triglycerides (mg/dl) & \multicolumn{2}{|c|}{$76.93 \pm 31.76$} \\
\hline Cortisol (nmol/L) & \multicolumn{2}{|c|}{$533.12 \pm 192.38$} \\
\hline
\end{tabular}

Data are expressed as mean \pm SD. LDL: low density lipoprotein, HDL: high density lipoprotein; Sleep score above five indicates poor sleep quality.BMI: body mass index 
Table 2. Actual Weight change $(n=40)$

\begin{tabular}{lllll}
\hline Weight change & $\mathbf{N}(\%)$ & Mean \pm SD & Amount (Lbs.) & N (\%) \\
\hline Weight loss & $6(15.0)$ & $-7.16 \pm 9.55$ Lbs. & $>15$ & $1(2.5)$ \\
& & & $5-15$ & $1(2.5)$ \\
Stable & & $<5$ & $4(10.0)$ \\
\hline Weight gain & $6(15.0)$ & 0 Lbs. & Stable $( \pm 1)$ & $6(15.0)$ \\
& $28(70.0)$ & $+7.55 \pm 6.87$ Lbs. & $<5$ & $12(30.0)$ \\
& & & $5-15$ & $13(32.5)$ \\
\hline
\end{tabular}

Overall agreement between reported and measured weight change among the participants was fair (weighted Kappa $=0.21 ; 95 \% \mathrm{Cl}$ : 0.05 to 0.38). Discrepancy between actual and perceived weight gain was highest among two subgroups of students which were the ones who perceived they lost weight (yet 50\% had gained weight) and the ones who perceived they had maintained weight (yet $71.4 \%$ had gained weight). The only subgroup of students who had perceived weight change which was in accordance with actual weight change were the ones who had reported weight gain (figure 1.)

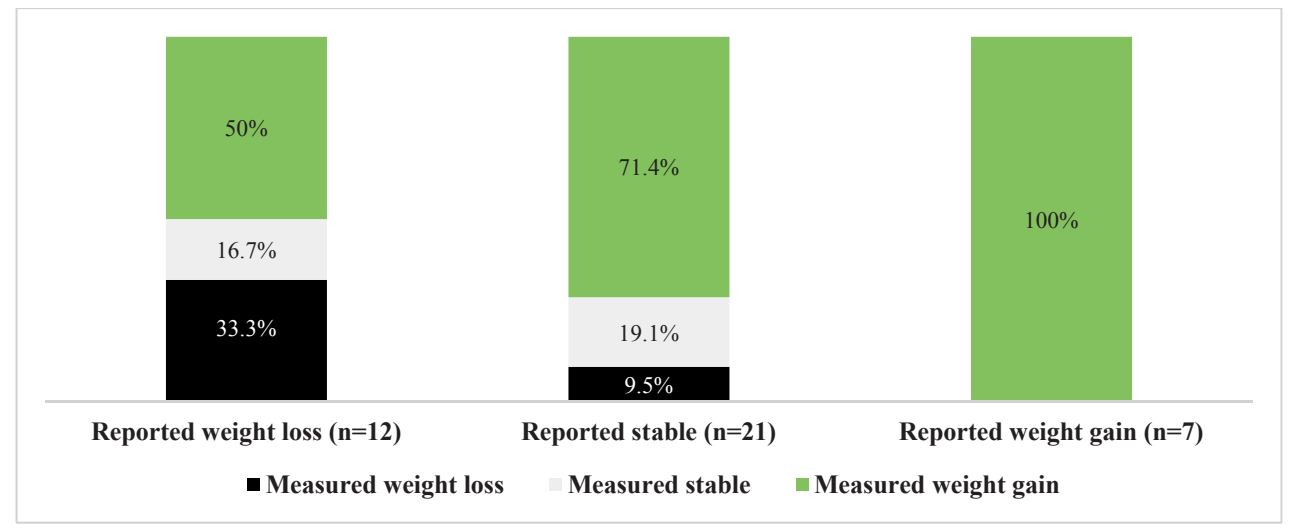

Figure 1: Weight change: Reported and actual

The effect of BMI on weight change in the first year of university is explained in Figure 2. The mean gain for all the 40 students was $4.2 \pm 8.65 \mathrm{lbs}$., whereby the underweight gained the most (7.2 lbs.), the normal and overweight participants gained approximately $5 \mathrm{lbs}$. , and the obese were the only subgroup who achieved weight loss during the $1^{\text {st }}$ year of university enrollment. 


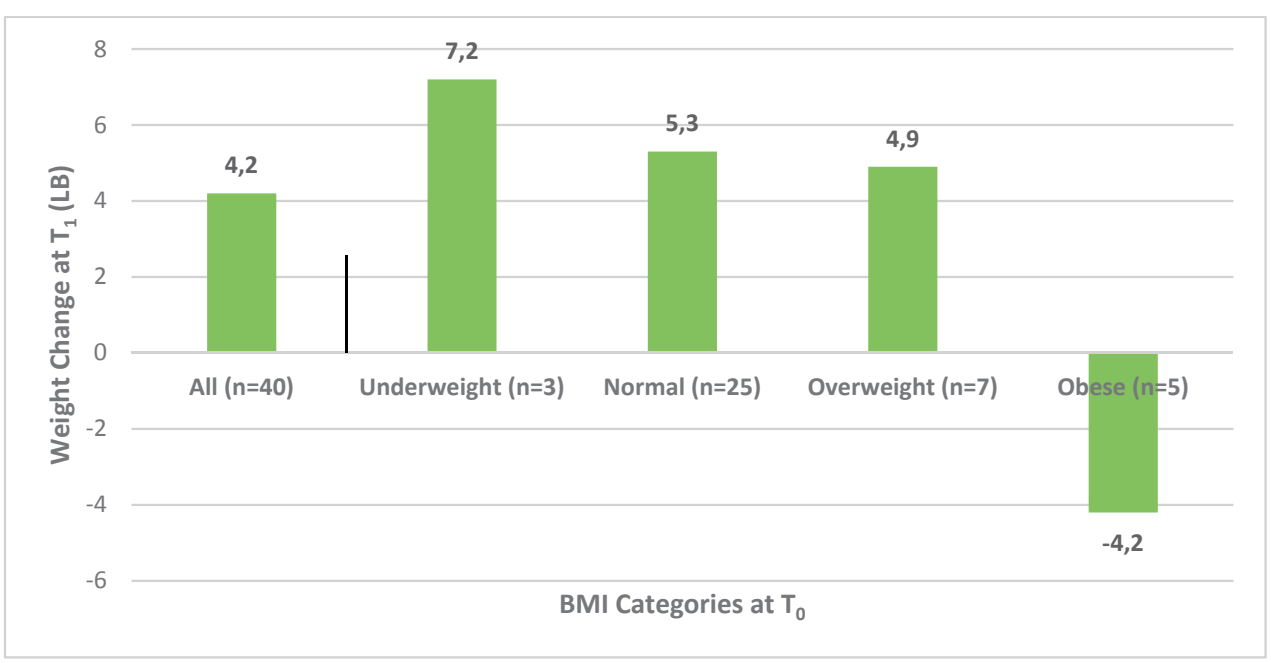

Figure 2. Effect of baseline BMI on Actual Weight Change

Lifestyle factors and, nutritional knowledge did not significantly change during the firstyear of university enrollment (Table 3). The absence of a pattern related to these characteristics was evident across the three weight change groups. No significant differences were noted between groups regarding the number of meals per day, the number of out of home meals consumed per week, nutrition knowledge (\%), stress score, and sleep score. 
Table 3. Freshman students' reported outcome measures and laboratory data

\begin{tabular}{|c|c|c|c|}
\hline Parameter $(n=40)$ & TO & T1 & $P$ value \\
\hline Nutrition knowledge (\%) & $49.48 \pm 10.29$ & $51.50 \pm 10.82$ & $p=0.25$ \\
\hline Number of meals eaten per day & $3.03 \pm 1.09$ & $2.73 \pm 0.96$ & $p=0.09$ \\
\hline Number of out of home meals per week & $5.11 \pm 4.23$ & $4.35 \pm 6.74$ & $p=0.06$ \\
\hline Stress score (max score: 40$)$ & $19.33 \pm 6.09$ & $19.90 \pm 4.89$ & $p=0.64$ \\
\hline Sleep score (>5=poor sleep) & $6.05 \pm 2.48$ & $6.40 \pm 3.19$ & $p=0.73$ \\
\hline Physical activity (METs) per day & $1880.4 \pm 2289.2$ & $2148.59 \pm 3078.61$ & $p=0.62$ \\
\hline Laboratory values $(n=27)$ & TO & $\mathbf{T 1}$ & P value \\
\hline FBG $(\mathrm{mg} / \mathrm{dl})$ & $81.59 \pm 6.29$ & $85.30 \pm 6.68$ & $p<0.001^{*}$ \\
\hline Cortisol (nmol/L) & $527.9 \pm 163.8$ & $393.1 \pm 133.9$ & $p=0.003^{*}$ \\
\hline Triglycerides (mg/dl) & $71.44 \pm 29.66$ & $83.44 \pm 36.10$ & $p=0.02^{* *}$ \\
\hline $\mathrm{LDL}(\mathrm{mg} / \mathrm{dl})$ & $91.37 \pm 27.32$ & $84.19 \pm 24.32$ & $p=0.01^{*}$ \\
\hline $\mathrm{HDL}(\mathrm{mg} / \mathrm{dl})$ & $54.33 \pm 13.59$ & $54.52 \pm 13.273$ & $p=0.85$ \\
\hline Cholesterol (mg/dl) & $159.37 \pm 26.77$ & $155.41 \pm 24.46$ & $p=0.15$ \\
\hline
\end{tabular}

METs: metabolic equivalent of task. FBG: fasting blood glucose; LDL: low density lipoprotein, HDL: high density lipoprotein. Data are expressed as mean \pm SD. Statistically significantly difference: $P<0.05$ (*Paired Samples Test; ** Wilcoxon Signed Ranks Test).

At last, all the objective study parameters were compared between $\mathrm{T} 0$ and $\mathrm{T} 1$ to detect changes over time. Results showed a significant increase in waist circumference in 40 students from $83.65 \pm 12.7 \mathrm{~cm}$ to $86.9 \pm 13.1 \mathrm{~cm}$ with $\mathrm{p}=0.05$. Additionally, as evident in Table 3, there was a significant increase in blood glucose and Triglyceride levels; on the other hand, there was a significant decrease in cortisol, and LDL. There were no significant changes in $\mathrm{HDL}$ cholesterol and total cholesterol between T0 and T1. Despite the changes, overall, all values were within normal limits. Furthermore, the results of the sub-analysis showed no statistically significant differences in all of the studied parameters between the weight gainers and non-weight gainers. 


\section{Discussion}

This was the first study to longitudinally assess weight change during the freshman year among a sample of Lebanese university students. On average, the students gained 4.2 Ibs. however there was considerable variability in weight change as $15 \%$ experienced no weight difference, $15 \%$ lost weight and $70 \%$ of the study participants put on weight. Health behaviors such as exercise, sleep, number of meals consumed and total amount of meals eaten outside the home did not significantly differ between the first and second semester. Moreover, there were no significant changes in stress scores and nutrition knowledge over the course of the study duration.

This study further supports evidence that freshman students do gain weight in the year of transition from high school to university. The changes in body weight are similar to previous literature as reported by Cooley and Turay, ${ }^{22}$ who found that students gained 4.4 pounds over a period of 7 months and found no predictors for the weight gain ${ }^{22}$. Our results are also similar to those of Levitsky and colleagues ${ }^{23}$ who concluded that their sample gained $4.4 \mathrm{lbs}$. in 12 weeks but were also unable to determine the reasons for the weight changes ${ }^{23}$.

There is however inconsistency in the literature about the average amount of weight that is typically gained during the freshman year as some studies have reported that the weight gain is typically lower than $5 \mathrm{lbs}$. For example Vella Zarb \& Elgar ${ }^{13}$ found average weight gain to be approximately $2 \mathrm{lbs} .(0.91 \mathrm{~kg})$ whereas Butler and colleagues ${ }^{24}$ found the increase to be $1.6 \mathrm{lbs}$. $(0.72 \mathrm{~kg})$. Speculation about the causes of the variability has been accounted to several factors which include length of the study duration, intercountry variation and the socials lifestyle norms that come with them, study design and selfselection bias. ${ }^{8,15,25}$ Additionally, the variation could be due to the method of how weight was reported, whether it was self-reported or measure by researchers. In the study conducted by Serlachius and colleagues, ${ }^{15}$ students gained approximately $3.4 \mathrm{lb}(1.54 \mathrm{~kg})$, however the changes were self-reported which may have resulted in underestimation of weight gain as students may not have realized that they had body mass. 15,25

One potentially alarming finding in this study was the discrepancy between perceived and actual weight change, especially among weight gainers since $70 \%$ of those who gained weight were unaware of their increase. Misperception of weight status among overweight and obese adults has been associated with decreased attempts at weight loss ${ }^{26}$, hence potentially exaggerating the obesity problem.

Many factors have been identified in the literature as possible determinants to weight gain during their freshman year which include stress, leading a sedentary lifestyle, moving away from home and increased alcohol intake. ${ }^{8,15,27}$ However, no association with any of the above factors as related to weight gain or loss was noticeable in the current study. Nutrition knowledge was very poor in our sample population at both times of data collection, and no relation with weight change was found. Nevertheless, this study did 
not have an educational component as participants were not exposed to any nutritional education within their curriculum that might have affected their knowledge scores or eating habits; which can explain the lack of association between these variables and weight change. Another possible explanation is that most individuals in the18-25 age category gain weight whether they attend college or not as this is a critical period, which has been named "emerging adulthood" and where individuals are at risk of gaining weight regardless of their circumstances. ${ }^{28}$

Our results revealed that the obese lost weight, however a sub-analysis of the data showed that only one of the students in this group had lost approximately $26 \mathrm{lbs}$. and therefore skewed the results.

In parallel to the weight gain in the study participants, we also noted a significant increase in serum triglycerides, glucose and waist circumference. Although not clinically significant, the increases revealed a worsened metabolic profile that could potentially raise the risk of future development metabolic syndrome. ${ }^{29}$ As for the other biochemical markers, there was a significant decrease in cortisol and LDL levels. The unexpected decrease in cortisol level could be due to the intra-individual variability in cortisol response secondary to stress. ${ }^{30}$

Our study presents numerous strengths. First, and to the best of the authors' knowledge, this research pioneers assessment of weight changes of university students during the freshman year in a Middle Eastern country, by recruiting a sample from several Lebanese regions. The study was appropriately powered as mentioned in the methods. Additionally, weight gain was assessed objectively by trained researchers, in parallel to blood parameters, and validated questionnaires. Furthermore, the study had a sufficient duration to assess the effect over the course of the whole academic year.

However, the present study also had a number of limitations. The sample used was a volunteer sample and that could bias the results as students who were are not health conscious may have been reluctant to participate in this study. Moreover, although the sample was recruited from several geographical areas, the students were recruited from only one university, which hinders the generalizability of our findings. One additional limitation was the high attrition rate (50\%), yet our analysis showed that participants who dropped out had similar baseline characteristics to those who completed the study; literature has shown that a low retention rate is common in such studies. ${ }^{8,9}$ Furthermore, the majority of the sample did not drink alcohol and lived at home; therefore these factors could not be appropriately analyzed. 


\section{Conclusions}

Our results provide evidence that Lebanese students do gain weight during their freshman year which could be a potential public health problem, especially since Lebanon is a country experiencing a nutrition transition and increasing obesity rates. ${ }^{31}$ Future research should be conducted on a more representative sample and for or a longer duration to examine the predictors of weight gain. Additionally, public health interventions should be implemented by health care providers within universities, to raise awareness and prevent future weight gain. 


\section{References}

1. World Health Organization. Obesity and overweight fact sheet (2016). Available at http:// www.who.int/mediacentre/factsheets/fs311/en/ Accessed January 2, 2018.

2. Pierce EF, Butterworth SW, Lynn TD, O'Shea J, Hammer WG. Fitness profiles and activity patterns of entering college students. J Am Coll Health. 1992;41(2):59-62.

3. Craigie AM, Lake AA, Kelly SA, Adamson AJ, Mathers JC. Tracking of obesity-related behaviours from childhood to adulthood: A systematic review. Maturitas. 2011;70(3):266-284.

4. Guo SS, Wu W, Chumlea WC, Roche AF. Predicting overweight and obesity in adulthood from body mass index values in childhood and adolescence. Am J Clin Nutr. 2002;76.

5. American College Health Association. The american college health association national college health assessment, spring 2003 reference group report. J Am Coll Health 53:199-210, 2005.

6. Steptoe A, Wardle J, Cui W, et al. Trends in smoking, diet, physical exercise, and attitudes toward health in European university students from 13 countries, 1990-2000. Preventive medicine. 2002;35(2):97-104.

7. Brown C. The information trail of the 'Freshman 15'-a systematic review of a health myth within the research and popular literature. Health Info Libr J. 2008;25.

8. Vella-Zarb RA, Elgar FJ. The 'freshman 5': a meta-analysis of weight gain in the freshman year of college. J Am Coll Health. 2009;58.

9. Vadeboncoeur C, Townsend N, Foster C. A meta-analysis of weight gain in first year university students: is freshman 15 a myth? BMC Obesity. 2015;2(1):22.

10. Levitsky DA, Halbmaier CA, Mrdjenovic G. The freshman weight gain: a model for the study of the epidemic of obesity. International journal of obesity and related metabolic disorders : journal of the International Association for the Study of Obesity. 2004;28(11):1435-1442.

11. Mihalopoulos NL, Auinger P, Klein JD. The Freshman 15: is it real? J Am Coll Health. 2008;56(5):531-533.

12. Girz L, Polivy J, Provencher V, et al. The four undergraduate years. Changes in weight, eating attitudes, and depression. Appetite. 2013;69:145-150.

13. Vella-Zarb RA, Elgar FJ. Predicting the 'freshman 15': Environmental and psychological predictors of weight gain in first-year university students. Health Educ J. 2010;69.

14. Economos CD, Hildebrandt ML, Hyatt RR. College freshman stress and weight change: differences by gender. Am J Health Behav. 2008;32.

15. Serlachius A, Hamer M, Wardle J. Stress and weight change in university students in the United Kingdom. Physiology and Behavior. 2007;92(4):548-553.

16. van der Kooy K, Seidell JC. Techniques for the measurement of visceral fat: a practical guide. International journal of obesity and related metabolic disorders : journal of the International Association for the Study of Obesity. 1993;17(4):187-196.

17. Craig CL, Marshall AL, Sjostrom M, et al. International physical activity questionnaire: 12-country reliability and validity. Med Sci Sports Exerc. 2003;35(8):1381-1395. 
18. Parmenter K, Wardle J. Development of a general nutrition knowledge questionnaire for adults. Eur J Clin Nutr. 1999;53(4):298-308.

19. Buysse DJ, Reynolds CF, 3rd, Monk TH, Berman SR, Kupfer DJ. The Pittsburgh Sleep Quality Index: a new instrument for psychiatric practice and research. Psychiatry research. 1989;28(2):193-213.

20. Cohen S, Kamarck T, Mermelstein R. A global measure of perceived stress. Journal of health and social behavior. 1983;24(4):385-396.

21. Cohen J. Weighted kappa: nominal scale agreement with provision for scaled disagreement or partial credit. Psychological bulletin. 1968;70(4):213-220.

22. Cooley E, Toray T. Disordered eating in college freshman women: a prospective study. J Am Coll Health. 2001;49.

23. Levitsky DA, Garay J, Nausbaum M, Neighbors L, Dellavalle DM. Monitoring weight daily blocks the freshman weight gain: a model for combating the epidemic of obesity. Int J Obes. 2006;30.

24. Butler SM, Black DR, Blue CL, Gretebeck RJ. Change in diet, physical activity, and body weight in female college freshman. Am J Health Behav. 2004;28.

25. Fedewa MV, Das BM, Evans EM, Dishman RK. Change in weight and adiposity in college students: a systematic review and meta-analysis. Am J Prev Med. 2014;47(5):641-652.

26. Duncan DT, Wolin KY, Scharoun-Lee M, Ding EL, Warner ET, Bennett GG. Does perception equal reality? Weight misperception in relation to weight-related attitudes and behaviors among overweight and obese US adults. International Journal of Behavioral Nutrition and Physical Activity. 2011;8(1):20.

27. de Vos $P$, Hanck C, Neisingh M, Prak D, Groen H, Faas MM. Weight gain in freshman college students and perceived health. Preventive medicine reports. 2015;2:229-234.

28. Nelson MC, Story M, Larson NI, Neumark-Sztainer D, Lytle LA. Emerging Adulthood and College-aged Youth: An Overlooked Age for Weight-related Behavior Change. Obesity. 2008;16(10):2205-2211.

29. Grundy SM. Overnutrition, ectopic lipid and the metabolic syndrome. Journal of Investigative Medicine. 2016.

30. van Eck MM, Nicolson NA, Berkhof H, Sulon J. Individual differences in cortisol responses to a laboratory speech task and their relationship to responses to stressful daily events. Biological psychology. 1996;43(1):69-84.

31. Nasreddine L, Naja F, Chamieh MC, Adra N, Sibai A-M, Hwalla N. Trends in overweight and obesity in Lebanon: evidence from two national cross-sectional surveys (1997 and 2009). BMC Public Health. 2012;12(1):798. 


\section{CHAPTER}

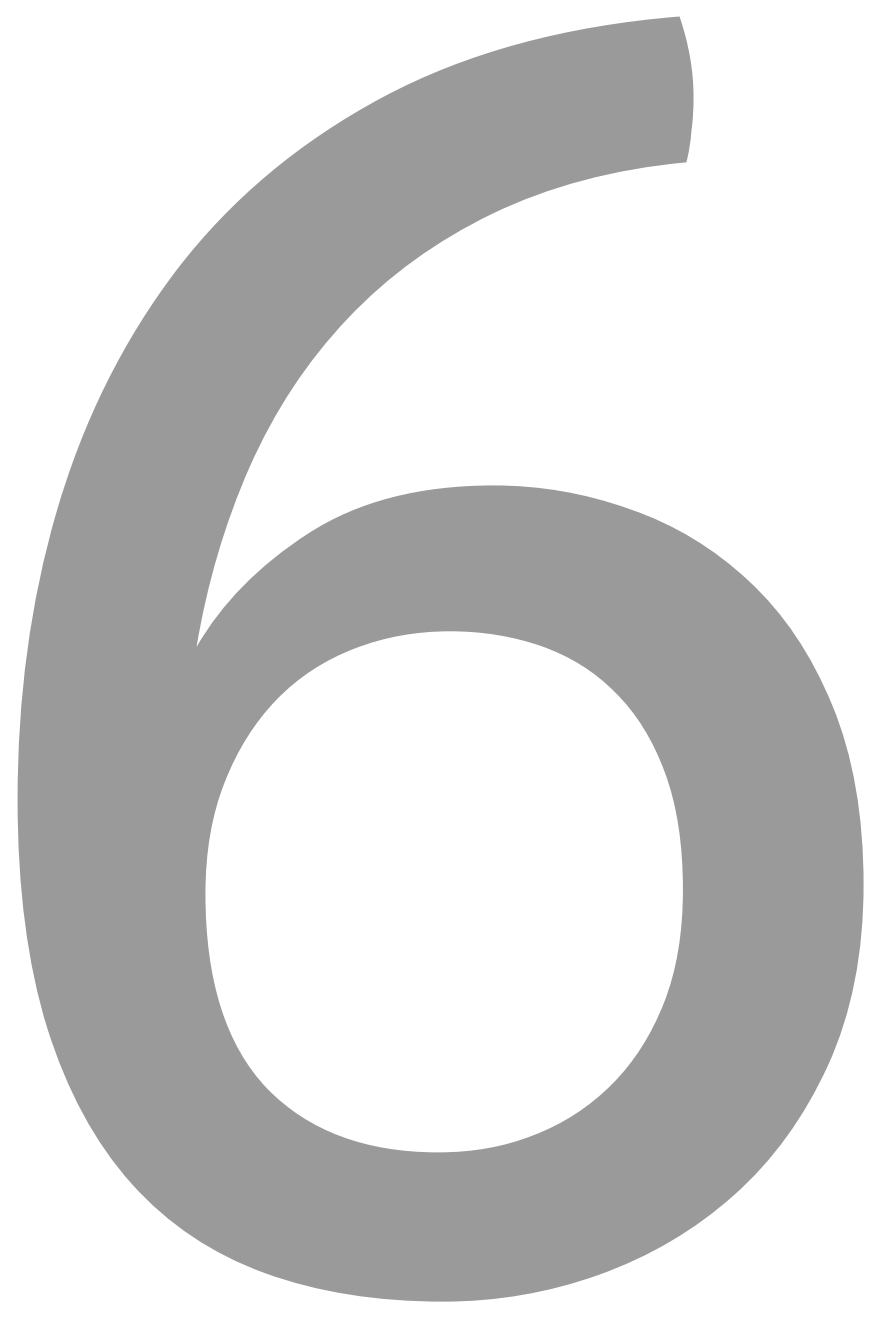


General Discussion 


\section{General Discussion}

The aim of this thesis was to collect dietary, anthropometric and lifestyle data from Lebanese university students and to assess the relationship of these parameters with cardiometabolic derangements. We also wanted to assess whether freshman university students would gain weight during the transitionary year as they move from high school to university. Furthermore, we wanted to understand whether an association exists between stress, anxiety, and weight status among university students. Therefore, we first conducted a systematic review to assess the relationship between stress, anxiety and weight among university and college students and we found limited evidence supporting the theory that higher stress levels were associated with weight gain in collegians. We then conducted two different studies, one of a cross-sectional design and another of a longitudinal nature, which was carried out over the course of the students' first year at university. As a result, we intended, through the cross-sectional study, to calculate the prevalence rate of metabolic syndrome (MetS) and pinpoint its determinants among the student sample. Subsequently we found a relatively high prevalence of MetS (6.4\%) and almost $90 \%$ of students had at least one risk factor related to it. We also investigated whether a relationship existed between weight status and the recently identified amino acid Beta-amino-isobutyric acid (BAIBA), as there has been recent evidence that BAIBA may have a role in weight control and a suggested cardioprotective role ${ }^{1}$, which can make it a potential supplement to aid in obesity management as so far strategies to control obesity have failed. BAIBA is an amino acid that may aid in browning of white adipose tissue and thus increasing fatty acid oxidation and the metabolic rate. Unfortunately, we did not find much evidence supporting a relationship between BAIBA and BMI.

Furthermore, we intended to assess, through a longitudinal study design, the freshman 15 phenomenon, in first year Lebanese university students, to determine whether they would gain weight during the year of transition from high school to university and decipher the cause of the weight gain, should it exist. We found that weight gain does occur during the freshman year on an average of 4.2 pounds $(1.9 \mathrm{~kg})$, concluding that the freshman 15 is a phenomenon that should be investigated further. We also discovered that Lebanese university students suffer from high stress levels; however, the stress levels were not associated neither with weight gain nor with risk of MetS.

\section{Chapter 2: Stress, anxiety and weight gain among university and college students: A systematic review ${ }^{2}$} PubMed, Medline, CINAHL, Embase, PSYCINFO and Open Access Theses and Dissertation databases were searched for studies assessing the relationship between stress and anxiety as related to weight status and adiposity in university and college students. Twenty-five observational studies met the inclusion criteria and all studies were observational in design, twenty-three of which were cross-sectional and two longitudinal. Seventeen of 
the included studies found no significant association between stress and/or anxiety and body mass index or weight change. Four of the studies found a significant association between stress and increased weight, and two additional studies found an association between anxiety and increased weight. Only one study found a negative association between stress and BMI and one study found a negative association between anxiety and BMI. However, most of the studies in this review had a potential of bias due mainly to the nature of the study design and absence of control of confounding factors. Therefore, due to the nonexistence of well-designed longitudinal and intervention studies, we could not draw a solid conclusion from the review about the role of stress and anxiety on weight status of students while enrolled in post-secondary institutions.

\section{Chapter 3: Association between $\beta$-amino-isobutyric acid and cardiometabolic risk factors: A preliminary study}

Obesity is now a recognized pandemic leading to numerous negative psychological and physiological consequences and having catastrophic costs on health care systems. Heavy research is being conducted to find potential solutions and effective treatments for the obesity problem. Literature is suggesting that a recently identified myokine, Beta-aminoisobutyric acid (BAIBA) could play a role in decreasing obesity and its levels may be raised by increased physical activity. Therefore, the aim of this study was to identify whether higher levels of the myokine Beta-amino-isobutyric acid (BAIBA) are inversely associated with obesity, physical activity and cardiometabolic risk factors. This study would then lead to generating a hypothesis that would help pave the way for future studies and clinical trials. However, we found that BAIBA levels were not associated with body mass index (BMI) nor with level of physical activity nor with any of the other cardiometabolic factors. The only exception was that BAIBA levels were inversely correlated with diastolic blood pressure among males. This study gave us less confidence in the therapeutic potential of BAIBA.

\section{Chapter 4: University Lebanese students are not immune to the metabolic syndrome}

The metabolic syndrome (MetS) is a cluster of conditions, defined by the International Diabetes Federation (IDF) ${ }^{3}$ as having central obesity (high waist circumference) , with two or more of the following abnormalities: elevated blood pressure (BP), fasting blood glucose (FBG), elevated triglycerides and reduced high-density lipoprotein (HDL)-cholesterol. The syndrome is dangerous as it leads to increased risk of both heart disease and diabetes. Due to its morbid consequences, we aimed to quantify its prevalence among a university sample and determine its predictors. We found that the MetS prevalence rate was $6.4 \%$, a high number in such a young age bracket. Even in the absence of the MetS, we also discovered that many students exhibited at least one of its components such as low HDL or high waist circumference. Age was the only variable found to increase the likeliness of developing MetS. 


\section{Chapter 5: The Freshman weight gain phenomenon: Does it apply to Lebanese Students?}

There is a complete absence of adequately designed longitudinal studies in Arab countries assessing weight gain during the transition year from high school to postsecondary institutions, otherwise known as the Freshman 15 phenomenon. Therefore, this longitudinal study was carried out to assess whether weight gain occurs among Lebanese university students during their freshman year and relate the weight gain to stress, physical activity, nutrition knowledge, change in demographics and sleep. Eighty students were recruited and followed up at two time points over a seven-month period to determine whether weight gain does actually occur and to determine the predisposing factors that are associated with the questioned weight gain. The results of the study were important, as we found that the students gained on average just as much weight as do Western students, as the mean weight gain was 4.2 pounds (1.9kg.) Additionally, $22.5 \%$ and $8.8 \%$ of students were overweight and obese respectively. This is of significance, since we were able to prove that university students in Lebanon are vulnerable to weight gain, which could predispose them to even more weight increase in the future and raise their risk of developing obesity and consequently development of obesity related comorbidities. Therefore, students should be properly educated about the aforementioned problem and universities should have a role in raising awareness amongst their students about the phenomena, since they are reliable institutions for presenting health and lifestyle recommendations. 
This study confirmed our hunch that Lebanese university students are a vulnerable subgroup to weight gain and to the development of cardiometabolic risk factors, which can propagate to a full diagnosis of the metabolic syndrome (MetS), even at such an early age. This is a serious health problem since a diagnosis of MetS increases the risk of several diseases such as non-insulin dependent diabetes and cardiovascular disease in a period as short as 5 to 10 years. ${ }^{3}$ Additionally the MetS doubles the risk of stroke and quadruples the risk of a myocardial infarction ${ }^{3}$ and increases all-cause mortality. ${ }^{4}$

In our sample, the prevalence of MetS and its individual components were substantial and were comparable to rates of MetS among university students in Western developed countries. ${ }^{5,6}$ Even in the absence of a full diagnosis, the prevalence of having one of the metabolic abnormalities necessary to diagnose MetS was extremely high and reached almost $90 \%$. Almost two thirds of the students had substandard HDL-C levels, which is known to be an independent risk factor for coronary heart disease.

Furthermore, more than half of the subjects had an elevated waist circumference, with females being more at risk. This statistic is unnerving since there is compelling evidence supporting the reliability of waist circumference as a marker for health risk even more so than $\mathrm{BMI}^{8}$ and it has been estimated that for every $11 \mathrm{~cm}$ increase in waist circumference, the risk of developing the MetS increases by $80 \%$ within 5 years. ${ }^{9}$ Thus, at least half of the students could be at risk for developing heart disease in the near future, even in the present absence of a full diagnosis of MetS, due to their elevated waist circumferences. We believe that these numbers may even be underestimation since there has been criticism of using waist circumference guidelines as recommended by the IDF $^{3}$ as they were originally intended for Europeans. It has been suggested that the cut off points are higher than those that should be used in Arab populations and thus our numbers could be underestimating the true percentage of students with elevated waist circumferences. ${ }^{10,11}$ If in fact that is the case, then the risk of MetS and obesity related comorbidities would be much higher than those reported.

One of the main objectives of this dissertation was to assess the factors that increase the risk of MetS. We however only found that age significantly increased the odds of the MetS. Nevertheless, scientific literature has identified many additional risk factors for developing the MetS, which were not assessed in our student population. One such possible contributor could be a Vitamin D deficiency, which is highly prevalent in Lebanon ${ }^{12}$ and which has been associated with impaired fasting blood glucose. ${ }^{13,14}$ Furthermore, the MetS has a striking similarity to polycystic ovary syndrome (PCOS) which is characterized by insulin resistance and an elevated waist circumference ${ }^{15}$ and it has been proven that women with PCOS, regardless of weight, frequently develop MetS. ${ }^{16}$ Since our sample population is predominantly young, females that are in their reproductive years, they could be at a high risk of developing PCOS and there may be an overlap in the diagnosis of the two conditions. Unfortunately, due to our limited resources, it was not feasible to assess neither PCOS risk nor vitamin D levels. It is important to mention however that there 
is a gap in the literature calculating prevalence rates for PCOS in collegians in Lebanon and future studies should focus on assessment of risk in females.

Additionally, stress eating has also been suggested to be a risk factor for acquiring the Met $S^{17}$ and although we found that our student sample suffered from high stress levels, we unfortunately did not inquire about stress eating. Therefore, we believe that this factor should be investigated in the future as a possible contributor for MetS at such a young age.

As for weight gain assessment, we were able to prove that Lebanese university students enrolled in the first year of university actually do gain a significant amount of weight similar to that experienced by collegians in developed countries. ${ }^{18-21}$ The weight of students transitioning from high school to university significantly increased approximately $4.2 \mathrm{lbs}$. $(1.9 \mathrm{~kg})$ over a seven-month period.

Unfortunately, the factors associated with weight gain were not as clear-cut as we had anticipated. Scientific research has identified many risk factors for weight gain during the freshman year, apart from stress. These factors include decrease in physical activity, 22,23 not consuming enough fruits and vegetables, ${ }^{23}$ peer pressure, ${ }^{24}$ increased alcohol consumption, ${ }^{20}$ increased intake of junk food, recent dieting, snacking during the evening and living away from home. ${ }^{25}$ We were not however able to prove that any of these factors were associated with the increase in weight in students, hence the need for larger trials. Especially since we did not obtain indications that these relations might exist.

In our student sample, it was both surprising and disappointing that we found no significant association between food intake and weight gain in the freshman students over the course of the time of the study. We also did not find an association with individual dietary components and MetS and we attribute that to several possible reasons. For one we assessed food consumption using a food frequency questionnaire ${ }^{26}$ and such questionnaires have been widely criticized for their limitations. ${ }^{27}$ However, it is worthy to note that all the current methods available for assessing dietary intake are known to have flaws and disadvantages. ${ }^{28}$ Furthermore, we now believe that it might have been better to analyze intake as a dietary pattern (quantities, proportions, variety and frequencies and combination of foods in diet) instead of quantifying intake via a food frequency questionnaire as the pattern approach captures a more broad picture of diet and can be better associated with disease. ${ }^{29}$ Naja and colleagues used dietary pattern analysis to assess the Lebanese youth and concluded that they were following a westernized $\operatorname{diet}^{30}$ which has proven to be pro-inflammatory and can increase odds of MetS. ${ }^{31}$ It has also been suggested that the quality of the diet is more important to analyze than individual dietary components, when offering protection against the MetS and hence a food frequency questionnaire would be limited in value when associating individual foods with disease risk. ${ }^{32}$ Additionally, a recent study conducted by Nasreddine and colleagues (2018), identified food patterns according to level of processing and found 
that following a diet composed of minimally processed foods tends to lower odds for MetS, hyperglycemia and low HDL cholesterol. ${ }^{33}$ Since university students spend more time outside their homes, they may be consuming more processed foods, which can thus increase odds for cardiometabolic derangements. Additionally, dietary restraint and dieting has also been associated with an increased susceptibility to weight gain ${ }^{34,35}$ but we did not assess previous dieting behavior in our study, as we did not want to burden the students with more questionnaires. Therefore, future studies should further focus on assessing dietary patterns, consumption of processed food and dietary restraint among Lebanese university students to determine whether the quality of food choices and dietary patterns are in fact the cause of high rates of metabolic derangements at such a young age.

We had also postulated that the reported levels of physical activity would decrease overtime, since students would have less time to exercise and spend more time being sedentary possibly due to increased time needed for studying. A study that was conducted in the United Kingdom found that university students spent almost 8 hours daily being sedentary. ${ }^{36}$ However, we did not find a decrease in physical activity levels in our student sample. However, almost $40 \%$ of students were exhibiting very low levels of physical activity and among the freshman ones and almost $15 \%$ were not conducting any form of exercise. Therefore, there might be a floor effect in this parameter. Additionally, there was a large variation in activity levels among the students since the standard variation was almost equal to the average level of physical activity reported, indicating a skewness in the data for physical activity. Furthermore, physical activity was self-reported in the questionnaire and it is obvious that there is a limitation of reporting bias with all the questionnaires used. It would have been ideal to provide students with pedometers or fitness-recording devices to measure physical activity level, which would have given findings that, are more objective and would have decreased self-reporting bias. Moreover, we do recognize that our sample size was small and significant associations are difficult to detect in such small-scale studies. Therefore, future studies should be carried out on a bigger student sample and data that are more objective should be collected from students to further evaluate the interplay of these factors.

Additionally, although we did not detect a change in either physical activity nor in food intake, the weight increase that occurred over a period of 7 months in our student sample could be due to a modest, yet undetectable, increase in energy balance. Letivsky and colleagues conducted a similar study and assessed female freshman students. The investigators concluded that students gained $2 \mathrm{~kg}$ in body weight due to a mere 24- $\mathrm{g} /$ day increase over a typical semester. Thus, such an imbalance would go unnoticed unless monitored frequently and even daily. ${ }^{21,37}$

Furthermore, we had postulated that increased stress level could be a possible risk factor for weight gain among freshman students however, our data proved otherwise and no significant association was found between stress and weight change. The results of our 
study were in line with the conclusion of the systematic review, which was conducted as a part of this thesis. The review aimed to investigate the relationship between stress and adiposity among students in post-secondary institutions. In the literature, no clear association was observed between stress and increased weight change among university and college students, as the data were inconsistent. ${ }^{2}$ Therefore, although university students have increased stress levels, stress did not seem to be the underlying factor predisposing students to weight gain. Since there is previous evidence that suggests that increased stress is associated with adiposity, ${ }^{38}$ it may be possible that stress may predispose some individuals (those with a higher $\mathrm{BMI}$ ) to weight gain and have an opposite effect on others (those with a lower BMI), ${ }^{19}$ hence a bidirectional effect may exist, since stress appears to alter food consumption by under or overeating. ${ }^{39}$

Previous literature has also identified that the level of education of parents is a factor that can influence weight gain. ${ }^{40}$ Therefore we believe in hindsight that we should have investigated parent education level since evidence suggests that higher maternal education is associated with better eating habits ${ }^{30}$ and since the majority of the student sample still lived at home, the influence would theoretically be more prominent.

Furthermore, we found nutrition knowledge to be inadequate among the students and did not increase over the course of the two semesters. Lower nutrition knowledge has also been associated with lower dietary adherence; moreover, scoring higher on nutrition knowledge surveys has been related to lower rates of obesity. ${ }^{41}$ Hence starting out with poor nutrition knowledge may be one of the factors that could be contributing to the weight gain of students. Additionally, increasing nutrition literacy may be a successful strategy to halting weight gain and hence making a basic health and nutrition courses available for students to register in during the first year of university could prove to be a successful strategy in raising awareness about common nutrition myths, correcting falsified health beliefs and encouraging students to adopt healthier habits. This strategy has shown to be effective in a prior study. ${ }^{42}$

There is unanimous agreement that weight gain experienced at a young age is a problem that should not be taken lightly, but what we discovered to be more alarming was that the students were unaware about the weight increase they were experiencing in their transitionary year. Discrepancy between actual and perceived weight gain was highest among those who thought they had lost weight (yet 50\% had gained weight) and those who perceived they had maintained their original weight (yet $71.4 \%$ had gained weight). This lack of self-perception of weight gain is obviously a pressing issue that needs to be addressed among university students since empirical evidence suggests that weight monitoring leads to more effective weight control and dietary vigilance. ${ }^{43}$

When weight gain was stratified according to gender it was clear that males gained more weight than females, but at the same time had no significant increase in waist circumference. 
It has been suggested that males could be undergoing a muscle growth spurt during the freshman year and that weight gain may be a result of a later maturation. ${ }^{44}$ However, this proposition can be investigated and confirmed only by assessing body composition. If this reasoning would be supported by data, we believe that although all students are at risk of gaining weight, females should be targeted more furiously for prevention. The severity and consequences of the weight gain, at such an early age, became evident in our student sample because in parallel to the weight increase, blood glucose and triglyceride levels increased over the 7-month period. Thus, negative health consequences were already becoming evident, even at such an early age and hence putting the students at a higher risk of developing MetS and consequent heart disease and diabetes. ${ }^{3}$ Weight gain is also a risk factor for MetS, heart disease and diabetes and it has been estimated that for each $4.5 \mathrm{~kg}$ weight increase the risk of Mets increases by $23 \% .{ }^{45}$ Therefore it is not a coincidence that both weight gain and MetS were observed in our student population.

Since it cannot be disputed that Lebanese students are a high risk group susceptible to weight gain and to developing the MetS and thus vulnerable to suffering from subsequent health risks such as cardiovascular disease and diabetes, we had had high hopes that we would find that the myokine BAIBA would show cardioprotective potential and that its levels would be positively correlated with increased physical activity levels and be associated with healthier body weight and would thus have therapeutic potential. Unfortunately, we were unable to prove that BAIBA, BMI and physical activity were related, as did other authors. ${ }^{46}$ Although animal studies have proved that BAIBA could be a potential treatment modality for obesity in animals ${ }^{1}$, there does not seem to be such an association in humans and thus, it is evident that there is a need for controlled clinical trials to further evaluate the therapeutic potential, as we found a strong inverse correlation between BAIBA and diastolic blood pressure among males.

In conclusion, our results provide evidence that university students are a high-risk group, vulnerable to weight gain during the freshman year and prone to development of MetS and subsequent cardiovascular disease. Unfortunately, once weight gain occurs, it becomes hard to manage and increases vulnerability to obesity and subsequent comorbidities ${ }^{47}$ and tends to track into the rest of life. ${ }^{48}$ This is especially problematic in a country with substandard access to preventive health care and health promotion. It is therefore not surprising that the Lebanese adults are a population with high rates of cardiovascular disease ${ }^{49}$ and with coronary heart disease being the leading cause of death in Lebanon. ${ }^{50,51}$ These findings are alarming, since prevention of obesity, rather than management, is essential to reversing the obesity epidemic and its morbid consequences. ${ }^{52,53}$ Therefore we feel it is necessary for universities to understand and assess health needs of their students and subsequently implement evidence based public health programs and interventions to raise awareness about the freshman phenomenon, increase nutrition knowledge and guide students in adopting healthy lifestyle and dietary habits in addition to implementing sound weight self-monitoring techniques. When healthy habits are adopted early on, they 
would likely continue throughout life and ultimately lead to a healthier adult generation. ${ }^{54}$ Such prevention programs should ideally be carried out on university campuses, preferably during the freshman year, as universities are reliable and trustworthy platforms to provide health related information. Unfortunately, Lebanese ministries do not encourage universities to provide such programs. Subsequently, access to fitness facilities and healthy food options are limited in many campuses. Therefore, universities should be proactive and take initiative in providing facilities and food outlets that can positively influence student choice, enabling them to pursue a healthy lifestyle.

Furthermore, the findings of this study should be disseminated to health practitioners as they should be attentive about the fact that students are not immune to chronic disease and should proactively screen young people for cardiometabolic risk and disease.

\section{Strengths of the study}

It is worthy to mention that this study has several strengths. First, we were able to recruit students from several campuses from different geographical locations in Lebanon, which allows us to believe that the sample was diversified in terms of socioeconomic status. Second, all the questionnaires were appropriately translated and then back translated so they could be easily understood by students and they were then validated for comprehensibility before the actual study was started. Third, our longitudinal study was adequately powered. Moreover, all the objective data was collected by trained research assistants. Furthermore, the longitudinal study had a 55\% female participation, which is reflective of the overall percentage of females registered in the hosting university. On a final note, according to our knowledge this is the first study to assess the freshman 15 phenomenon in an Arabic country.

\section{Limitations of the study}

As with any study design, it is important to acknowledge that there are several limitations with the studies conducted to produce this dissertation. An obvious drawback is partly due to the observational nature of the study, which precludes casual inferences; hence, only associations could be identified. Additionally females were overrepresented in the cross sectional part of the study (66.5\%). Furthermore, self-selection bias was unavoidable and although the studies were carried out on several campuses, they still took place at only one university and therefore generalizing the results of our studies to all Lebanese students should be done with caution. However, it is worthy to note that to decrease bias, we recruited students from several campuses from different geographical regions in Lebanon and hence because of the geographical diversity we were able to recruit students at all 
socioeconomic levels from both urban and rural locations. A further limitations is that we used European standards for waist circumference cut-off points ${ }^{3}$ since no official numbers have been released for the Lebanese; we believe that the prevalence rate of MetS could be underestimated. Moreover, body composition, which is a better measure of adiposity than $\mathrm{BMI}$, was not analyzed. ${ }^{55}$ In addition to all of the above, the longitudinal study had a high attrition rate (50\%) and only $33.7 \%$ of students agreed to undergo further biochemical testing. Finally, the students who accepted to return to participate at the second time point completed the same questionnaires as they did during first time of data collection and this could possibly bias the results. However, we found that their nutrition knowledge score did not increase over time, which indicates a genuine nutritional knowledge deficit. Also due to budgetary constraints and lack of willingness of students to participate in the study, we could not recruit a large sample size, although the longitudinal study was adequately powered.

\section{Tools Used}

Dietary intake was assessed using a food frequency questionnaire ${ }^{26}$ which has been criticized for effectiveness. However, it was the first and only Lebanese specific tool that was available at the time of conducting the study. Furthermore, we did not use a 24 hour recall instead of the since it has been reported that one collection of 24 hour recall represents a significant underreporting of total caloric intake. ${ }^{56}$ Additionally we believe that stress eating and dietary restraint scales could have resulted in a better prediction of weight change. Furthermore, all the questionnaires that were used were self-reported by the students and therefore self-reporting bias could not be avoided.

When collecting information related to physical activity, we used the IPAQ short form, which is one of the most popular tools used by researchers. ${ }^{57}$ However there is evidence that the IPAQ overestimates physical activity by almost $84 \% .^{58}$ Still, we found a high percentage of students with low or no physical activity. Additionally some researchers are against its use when quantification of physical activity is as it does not take into consideration sedentary time during analysis. ${ }^{59}$

We also assessed nutrition knowledge with a questionnaire that was self-administered and this may have caused a reporting bias as almost most of the questions were not open ended, which is usually recommended when assessing. ${ }^{60}$ Furthermore we used the Pittsburgh sleep quality index (PSQI), which is a widely used screening tool to assess quality and quantity of sleep. Although studies have reported PSQI to be a good questionnaire to assess sleep among collegians; however, sleep diaries are more informative and objective. ${ }^{61}$ Moreover, the stress scale we used has proven to be both reliable and valid tool to assesses stress of students. ${ }^{62}$

On a final note, it is also important to mention that the questionnaires were given twice to 
the students in the longitudinal study and this could bias the results.

However, it is important to note that all the scales we used were back translated from English to Arabic and then to English again so that we would be sure that there mistakes occurred during the translation process. We also piloted all the questionnaires on students before we used them in the study to be sure that the questions were clear and well understood.

\section{Future studies:}

We have established in this dissertation that university students are a high-risk group to weight gain and many have cardiometabolic risk and MetS. The significant weight gain at university needs to be further understood if we are to fight the rising adult obesity prevalence. Indeed, weight gain occurring during that critical period may persist and poor life habits may continue in into adulthood. ${ }^{54}$

Unfortunately, in Lebanon, students are an over-looked population, thought to be protected by age. However, we were able to prove in this thesis that that is not the case and that more studies should be carried out on post-secondary students to identify the robust predictors of susceptibility to weight gain and increased risk of cardiovascular disease. Furthermore since the IDF criteria ${ }^{3}$ does not specify cutoff points specific for Arab populations to evaluate waist circumference, more studies should be conducted to quantify Lebanese specific waist circumference values.

Furthermore, future studies should focus on recruiting a bigger, more representative sample, which is equal in gender division. Similar studies should also be carried out at more universities and colleges, with more student recruitment, to assess whether the Freshman 15 phenomenon is indeed generalizable to all Lebanese students. Future largescale studies could further evaluate weight changes over a longer period, continuing well beyond the first year. When devising future clinical research, inclusion of body composition analysis appears key to better assess obesity as BMI and the current waist circumference measurements have limitations. ${ }^{55}$

Additionally qualitative studies should be carried out to identify causes of weight gain since they can give some insight in overlooked factors that have not been yet been identified. Furthermore, qualitative studies can also identify motivational factors, which can allow more student recruitment and decrease dropout rate for studies like the present one. Therefore, future qualitative studies should analyze what incentives are effective among Lebanese university students to pave the way for bigger more generalizable studies.

Prospective studies should also implement and assess efficacy of evidence based health promotion interventions among Lebanese collegians to help students alter unhealthy lifestyle behaviors, which may be contributing to the low HDL levels and thus increased risk of MetS and CVD. Furthermore, randomized control trials with relevant stratification, 
according to the type and level of activity/exercise, should also be carried out to identify how and when BAIBA is synthesized.

However, despite all limitations of this study, we were pioneers in assessing freshman 15 phenomena in an Arab country and proving its existence and the need to address it proactively. Furthermore, we were able to collect baseline data from university students and identify them as a high-risk group vulnerable to weight gain, MetS, stress and suffering from low quality of sleep and decreased nutrition knowledge. Therefore, our findings give us confidence to identify and advise university boards and relevant ministries to raise awareness about these pressing issues and to encourage implementation of relevant evidence based policies and programs, provide physical activity facilities and healthier food options.

\section{Main findings of the thesis}

\section{Box 1: Main findings}

- Associations between stress and anxiety and weight change during university or college enrollment seem to be negligible as the evidence is inconsistent.

- Metabolic syndrome is prevalent in Lebanese University students, at an estimated rate of $6.4 \%$.

- Almost $90 \%$ of Lebanese collegians suffer from at least one cardio metabolic risk factor.

- Lebanese freshman students are at risk of gaining weight (on average 4.2 pounds) during their freshman year and are thus vulnerable to the freshman 15/5 phenomenon.

- Serum, Beta-amino-isobutyric acid are not correlated with BMI nor with physical activity levels.

- Serum Beta-amino-isobutyric acid levels are inversely correlated to diastolic blood pressure in males. 


\section{References}

1. Roberts LD, Bostrom P, O'Sullivan JF, et al. beta-Aminoisobutyric acid induces browning of white fat and hepatic beta-oxidation and is inversely correlated with cardiometabolic risk factors. Cell metabolism. 2014;19(1):96-108.

2. Haidar SA, de Vries NK, Karavetian M, El-Rassi R. Stress, Anxiety, and Weight Gain among University and College Students: A Systematic Review. Journal of the Academy of Nutrition and Dietetics. 2018;118(2):261-274.

3. Alberti KG, Eckel RH, Grundy SM, et al. Harmonizing the metabolic syndrome: a joint interim statement of the International Diabetes Federation Task Force on Epidemiology and Prevention; National Heart, Lung, and Blood Institute; American Heart Association; World Heart Federation; International Atherosclerosis Society; and International Association for the Study of Obesity. Circulation. 2009;120(16):1640-1645.

4. Kaur J. A Comprehensive Review on Metabolic Syndrome. Cardiology Research and Practice. 2014;2014:943162.

5. Ford ES, Giles WH, Dietz WH. Prevalence of the metabolic syndrome among us adults: Findings from the third national health and nutrition examination survey. JAMA. 2002;287(3):356-359.

6. Dalleck LC, Kjelland EM. The prevalence of metabolic syndrome and metabolic syndrome risk factors in college-aged students. American journal of health promotion : AJHP. 2012;27(1):37-42.

7. Wilson PWF, D'Agostino RB, Levy D, Belanger AM, Silbershatz $\mathrm{H}$, Kannel WB. Prediction of Coronary Heart Disease Using Risk Factor Categories. Circulation. 1998;97(18):1837-1847.

8. Janssen I, Katzmarzyk PT, Ross R. Waist circumference and not body mass index explains obesity-related health risk. Am J Clin Nutr. 2004;79(3):379-384.

9. Palaniappan L, Carnethon MR, Wang Y, et al. Predictors of the incident metabolic syndrome in adults: the Insulin Resistance Atherosclerosis Study. Diabetes Care. 2004;27(3):788-793.

10. Al-Lawati JA, Barakat NM, Al-Lawati AM, Mohammed AJ. Optimal cut-points for body mass index, waist circumference and waist-to-hip ratio using the Framingham coronary heart disease risk score in an Arab population of the Middle East. Diabetes \& vascular disease research. 2008;5(4):304-309.

11. Khader YS, Batieha A, Jaddou H, Batieha Z, El-Khateeb M, Ajlouni K. Anthropometric cutoff values for detecting metabolic abnormalities in Jordanian adults. Diabetes, metabolic syndrome and obesity: targets and therapy. 2010;3:395-402.

12. Gannage-Yared MH, Chemali R, Yaacoub N, Halaby G. Hypovitaminosis D in a sunny country: relation to lifestyle and bone markers. Journal of bone and mineral research : the official journal of the American Society for Bone and Mineral Research. 2000;15(9):1856-1862.

13. Rafraf M, Hasanabad SK, Jafarabadi MA. Vitamin D status and its relationship with metabolic syndrome risk factors among adolescent girls in Boukan, Iran. Public Health Nutr. 2014;17(4):803-809.

14. Ju SY, Jeong HS, Kim DH. Blood vitamin D status and metabolic syndrome in the general adult population: a dose-response meta-analysis. J Clin Endocrinol Metab. 2014;99(3):1053-1063. 
15. Ali AT. Polycystic ovary syndrome and metabolic syndrome. Ceska gynekologie. 2015;80(4):279289.

16. Mortada R, Williams T. Metabolic Syndrome: Polycystic Ovary Syndrome. FP essentials. 2015;435:30-42.

17. Epel E, Jimenez S, Brownell K, Stroud L, Stoney C, Niaura R. Are Stress Eaters at Risk for the Metabolic Syndrome? Annals of the New York Academy of Sciences. 2004;1032(1):208-210.

18. Vella-Zarb RA, Elgar FJ. Predicting the 'freshman 15': Environmental and psychological predictors of weight gain in first-year university students. Health Educ J. 2010;69.

19. Serlachius A, Hamer M, Wardle J. Stress and weight change in university students in the United Kingdom. Physiology \& Behavior. 2007;92(4):548-553.

20. Vadeboncoeur C, Townsend N, Foster C. A meta-analysis of weight gain in first year university students: is freshman 15 a myth? BMC Obesity. 2015;2(1):22.

21. Levitsky DA, Halbmaier CA, Mrdjenovic G. The freshman weight gain: a model for the study of the epidemic of obesity. International journal of obesity and related metabolic disorders : journal of the International Association for the Study of Obesity. 2004;28(11):1435-1442.

22. Plotnikoff R, Collins CE, Williams R, Germov J, Callister R. Effectiveness of interventions targeting health behaviors in university and college staff: a systematic review. American journal of health promotion : AJHP. 2015;29(5):e169-187.

23. Plotnikoff RC, Costigan SA, Williams RL, et al. Effectiveness of interventions targeting physical activity, nutrition and healthy weight for university and college students: a systematic review and meta-analysis. International Journal of Behavioral Nutrition and Physical Activity. 2015;12(1):45.

24. Cluskey, M. And Grobe D. College Weight Gain and Behavior Transitions: Male and Female Differences. Journal of the Academy of Nutrition and Dietetics.2009; 109(2):325 - 329

25. Vella-Zarb RA, Elgar FJ. The 'freshman 5': a meta-analysis of weight gain in the freshman year of college. J Am Coll Health. 2009;58.

26. Batal M HS, Hwalla N, Kabbani N, Talhouk S. Wild edible plants: promoting dietary diversity in poor communities of Lebanon. March 2006.

27. Brown D. Do Food Frequency Questionnaires Have Too Many Limitations? Journal of the American Dietetic Association. 2006;106(10):1541-1542.

28. Bingham SA. Limitations of the various methods for collecting dietary intake data. Ann Nutr Metab. 1991;35(3):117-127.

29. Hu FB. Dietary pattern analysis: a new direction in nutritional epidemiology. Current opinion in lipidology. 2002;13(1):3-9.

30. Naja F, Hwalla N, Itani L, Karam S, Sibai AM, Nasreddine L. A Western dietary pattern is associated with overweight and obesity in a national sample of Lebanese adolescents (13-19 years): a cross-sectional study. Br J Nutr. 2015;114(11):1909-1919.

31. Giugliano D, Ceriello A, Esposito K. The effects of diet on inflammation: emphasis on the metabolic syndrome. J Am Coll Cardiol. 2006;48(4):677-685.

32. Baxter AJ, Coyne T, McClintock C. Dietary patterns and metabolic syndrome--a review of 
epidemiologic evidence. Asia Pacific journal of clinical nutrition. 2006;15(2):134-142.

33. Nasreddine $L$, Tamim $H$, Itani $L$, et al. A minimally processed dietary pattern is associated with lower odds of metabolic syndrome among Lebanese adults. Public Health Nutr. 2018;21(1):160171.

34. Lowe M, Doshi S, Katterman S, Feig E. Dieting and restrained eating as prospective predictors of weight gain. Frontiers in Psychology. 2013;4(577).

35. Neumark-Sztainer D, Wall M, Guo J, Story M, Haines J, Eisenberg M. Obesity, disordered eating, and eating disorders in a longitudinal study of adolescents: how do dieters fare 5 years later? $\mathrm{J}$ Am Diet Assoc. 2006;106(4):559-568.

36. Rouse PC, Biddle SJH. An ecological momentary assessment of the physical activity and sedentary behaviour patterns of university students. Health Education Journal. 2010;69(1):116125.

37. Levitsky DA, Garay J, Nausbaum M, Neighbors L, Dellavalle DM. Monitoring weight daily blocks the freshman weight gain: a model for combating the epidemic of obesity. Int J Obes. 2006;30.

38. Wardle J, Chida Y, Gibson EL, Whitaker KL, Steptoe A. Stress and adiposity: a meta-analysis of longitudinal studies. Obesity (Silver Spring). 2011;19(4):771-778.

39. Torres SJ, Nowson CA. Relationship between stress, eating behavior, and obesity. Nutrition. 2007;23(11-12):887-894.

40. Aranceta J, Perez-Rodrigo C, Ribas L, Serra-Majem L. Sociodemographic and lifestyle determinants of food patterns in Spanish children and adolescents: the enKid study. Eur J Clin Nutr. 2003;57 Suppl 1:S40-44.

41. Bonaccio M, Di Castelnuovo A, Costanzo S, et al. Nutrition knowledge is associated with higher adherence to Mediterranean diet and lower prevalence of obesity. Results from the Moli-sani study. Appetite. 2013;68:139-146.

42. Matvienko O, Lewis DS, Schafer E. A college nutrition science course as an intervention to prevent weight gain in female college freshmen. J Nutr Educ. 2001;33.

43. Butryn ML, Phelan S, Hill JO, Wing RR. Consistent self-monitoring of weight: a key component of successful weight loss maintenance. Obesity (Silver Spring). 2007;15(12):3091-3096.

44. Zagorsky JL, Smith PK. The Freshman 15: A Critical Time for Obesity Intervention or Media Myth? Social Science Quarterly. 2011;92(5):1389-1407.

45. Carnethon MR, Loria CM, Hill JO, Sidney S, Savage PJ, Liu K. Risk Factors for the Metabolic Syndrome. Diabetes Care. 2004;27(11):2707.

46. Molfino A, Amabile MI, Ammann T, et al. The metabolite beta-aminoisobutyric acid and physical inactivity among hemodialysis patients. Nutrition. 2017;34:101-107.

47. Steptoe A, Wardle J, Cui W, et al. Trends in smoking, diet, physical exercise, and attitudes toward health in European university students from 13 countries, 1990-2000. Preventive medicine. 2002;35(2):97-104.

48. The NS, Suchindran C, North KE, Popkin BM, Gordon-Larsen P. Association of adolescent obesity with risk of severe obesity in adulthood. Jama. 2010;304(18):2042-2047. 
49. Zeidan RK, Farah R, Chahine MN, et al. Prevalence and correlates of coronary heart disease: first population-based study in Lebanon. Vascular Health and Risk Management. 2016;12:75-84.

50. World Health organization. Cardiovascular diseases fact sheet. 2017; http://www.who.int/ mediacentre/factsheets/fs317/en/. Accessed 22 April, 2018.

51. Mehio-Sibai A, Obeid O, Batal M, Adra N, El Khoury D, Hwalla N. Prevalence and Correlates of metabolic syndrome in an adult Lebanese population. Prevention and Control. 2008;3.

52. Hill JO, Peters JC. Environmental Contributions to the Obesity Epidemic. Science. 1998;280(5368):1371-1374.

53. Wofford LG. Systematic Review of Childhood Obesity Prevention. Journal of Pediatric Nursing. 2008;23(1):5-19.

54. Craigie AM, Lake AA, Kelly SA, Adamson AJ, Mathers JC. Tracking of obesity-related behaviours from childhood to adulthood: A systematic review. Maturitas. 2011;70(3):266-284.

55. Liu P, Ma F, Lou H, Liu Y. The utility of fat mass index vs. body mass index and percentage of body fat in the screening of metabolic syndrome. BMC Public Health. 2013;13:629-629.

56. Ma Y, Olendzki BC, Pagoto SL, et al. Number of 24-Hour Diet Recalls Needed to Estimate Energy Intake. Annals of epidemiology. 2009;19(8):553-559.

57. Craig $C L$, Marshall AL, Sjostrom $M$, et al. International physical activity questionnaire: 12-country reliability and validity. Med Sci Sports Exerc. 2003;35(8):1381-1395.

58. Lee PH, Macfarlane DJ, Lam TH, Stewart SM. Validity of the international physical activity questionnaire short form (IPAQ-SF): A systematic review. The International Journal of Behavioral Nutrition and Physical Activity. 2011;8:115-115.

59. van der Ploeg HP, Tudor-Locke $C$, Marshall AL, et al. Reliability and validity of the international physical activity questionnaire for assessing walking. Res Q Exerc Sport. 2010;81(1):97-101.

60. Choi BCK, Pak AWP. A Catalog of Biases in Questionnaires. Preventing Chronic Disease. 2005;2(1):A13.

61. Dietch JR, Taylor DJ, Sethi K, Kelly K, Bramoweth AD, Roane BM. Psychometric Evaluation of the PSQI in U.S. College Students. Journal of clinical sleep medicine : JCSM : official publication of the American Academy of Sleep Medicine. 2016;12(8):1121-1129.

62. Siqueira Reis R, Ferreira Hino AA, Romélio Rodriguez Añez C. Perceived Stress Scale: Reliability and Validity Study in Brazil. Journal of Health Psychology. 2010;15(1):107-114. 
CHAPTER

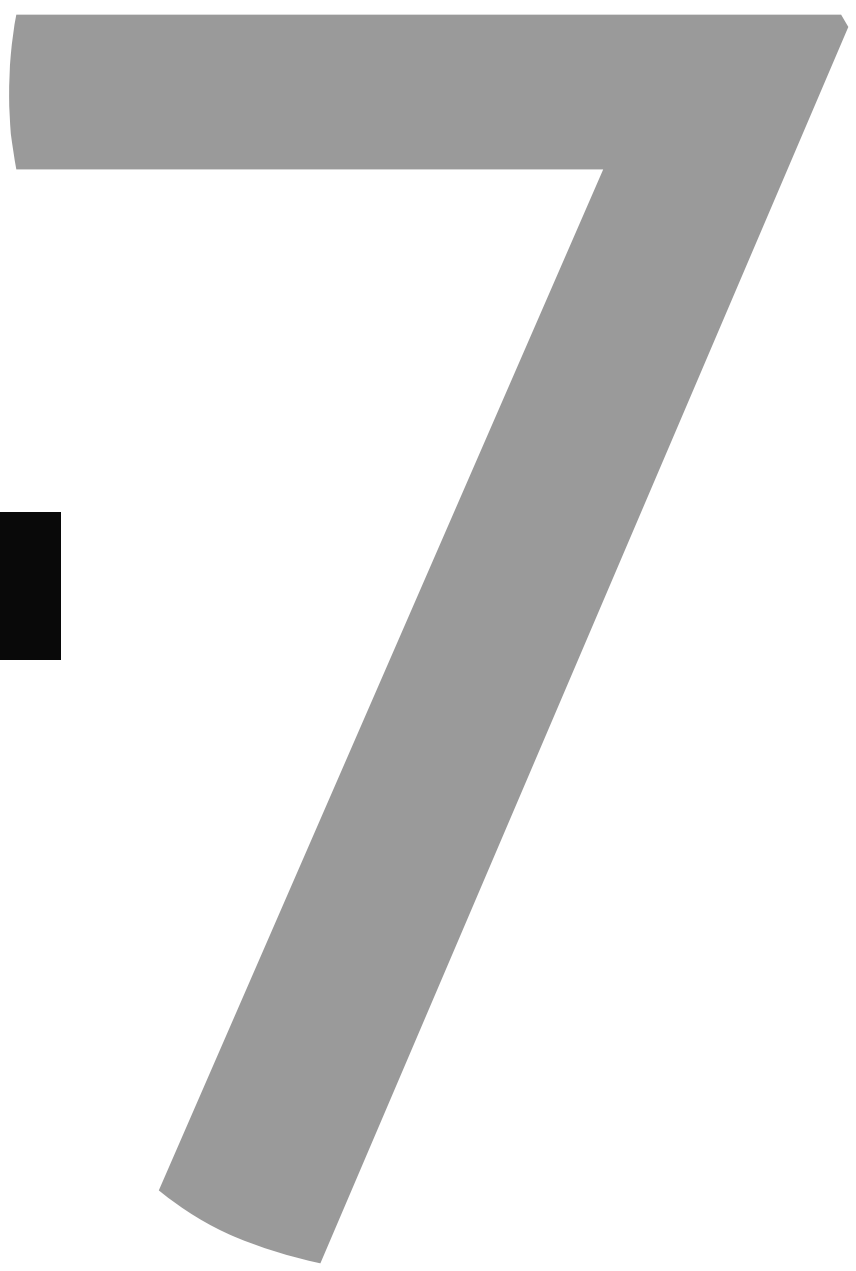


Future health promotion programs 


\section{Future Health Promotion Programs}

We were able to prove in this current thesis that the Lebanese university students are an at risk group susceptible to weight gain and cardiometabolic risk. Additionally, we found that more than $10 \%$ of the students sampled were not doing any form of physical activity and more than $30 \%$ were far from meeting physical activity requirements. ${ }^{1}$ We also discovered that a striking $40 \%$ of the students were consuming less than five fruits and vegetables per day and thus not meeting dietary recommendations. ${ }^{2}$ Similarly, many students were stressed and suffering from inadequate sleep and we were able to prove that the students enrolled in our study did not have a high level of nutritional knowledge which did not improve over the course of two semesters. Hence, we were able to provide a baseline assessment of Lebanese university students and identify them as subgroup that is at risk to developing future chronic diseases, should they continue to follow unhealthy lifestyle habits; hence, the need for their target with evidence based health promotion programs. Fortunately, these students are in a transition phase where they are gaining more autonomy over their choices and becoming more independent and thus have a potential for positive behavior change and enabling healthy habits. ${ }^{3}$ They are also at a stage in their life where their health behaviors can still impact their health in the future. ${ }^{4}$ Therefore, supporting healthy habits through lifestyle interventions and health promotion programs at such a critical time, could be key to building a healthier adult population. Post-secondary institutions are ideal settings for such interventions since they are centers of research and creativity and can develop, apply and assess effectiveness of theory and evidence-based health promotion programs. ${ }^{5}$ Furthermore, universities have the ability to engage a large number of students and can provide a venue where resources are easily accessible and where there is an abundance of qualified, multi-disciplinary, healthcare professionals. ${ }^{3}$

Regrettably, not all universities in Lebanon have adopted a health-oriented approach and there seems to be a lack of sustainable and effective health promotion programs a possible reason being that students are thought of as healthy and are a long haul from acquiring chronic disease. ${ }^{6}$ Although no studies have been conducted to assess how health promoting Lebanese campuses are, it only takes a casual walk through some of them to notice that unhealthy food choices dominate the menus in food service outlets and an almost absent availability of physical activity facilities. Auspiciously, we have in the literature many examples where introduction of such programs in universities have been successful. Particularly interventions that empower individuals by education and providing support for health improvement seem to work best. ${ }^{7}$ In a randomized control trial that was conducted in the United States, freshman students, who were assigned to a nutrition course maintained their body weight as opposed to the controls who ended up gaining a significant amount of weight. ${ }^{8}$ Similar studies have yielded beneficial results in terms of weight maintenance and loss. ${ }^{9,10}$ Even online interventions among freshman students have shown a benefit in terms of weight control. ${ }^{11}$ Furthermore, interferences 
that seek to empower individuals by teaching and support for health improvement have the highest success. ${ }^{7}$ Additionally interventions that were most successful provided students with progress feedback ${ }^{3}$ and therefore monitoring should be an essential part of any program.

Finally we suggest that whatever intervention that would be planned in the future be based on the intervention mapping (IM) approach, which provides health promotion program developers with a framework for effective decision making to make appropriate and informed decisions through the steps of planning, implementing and evaluation. ${ }^{2} \mathrm{lt}$ is a systematic process composed of six steps as simplified in the figure below.

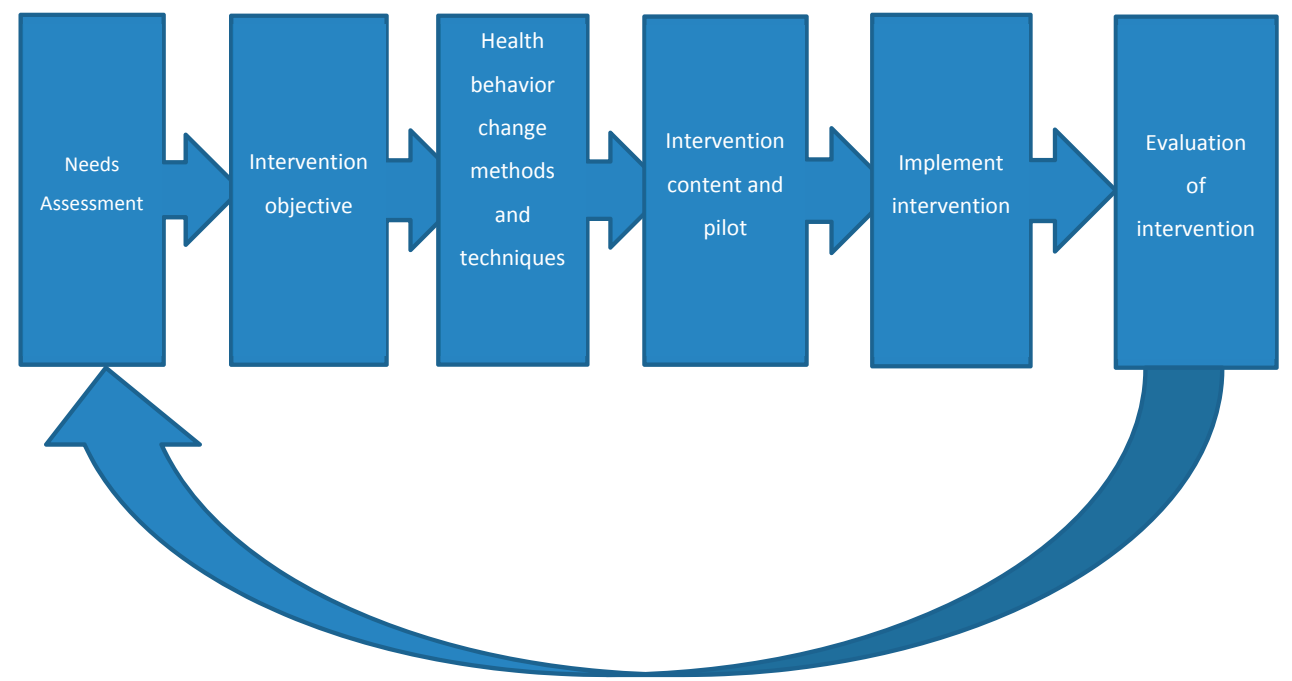

Figure 1: Stages of Intervention Mapping Approach

We have from the results of this thesis been able to conduct the needs assessment (step 1) and define intervention objectives (step 2) which are necessary to implement an evidence-based intervention.

\section{Step 1: Needs assessment:}

We assessed lifestyle habits and weight gain during the freshman year along with a biochemical assessment to detect cardiovascular disease risk in Lebanese university students. Our study did in fact confirm that freshman students are at risk for gaining weight and for developing heart disease. We found that a high number of students were not exercising enough and not consuming their recommended servings of fruits and 
vegetables. Additionally, nutrition knowledge was fair and could be greatly improved and we recognized that students were stressed and suffered from suboptimal sleep quality. We also conducted a systematic review to identify whether the cause of the weight gain was due to stress and found that the evidence on that was inconclusive. Moreover, we identified and contacted several stakeholders in Lebanon to better assess the magnitude of the problem qualitatively and to help pinpoint the causes of the problem and to gain input for solutions. There was unanimous agreement that obesity is a problem in Lebanon and that university students are an especially vulnerable group due to their heavy consumption of energy dense food served at food outlets in universities and their proximity and which are sold at affordable prices. Students seemed to be moving towards a consumption of a Westernized diet and ingesting too many sweetened beverages in addition to simultaneously engaging in sedentary behaviors. Furthermore the media is marketing unhealthy food choices to the Lebanese consumers and simultaneously health campaigns are almost nonexistent.

\section{Step 2: Intervention objectives:}

Accordingly, we identified from our research and from stakeholder input the following objectives which should be addressed through future interventions:

- $\quad$ Raise awareness about the freshman 15 phenomenon early on during first weeks of university enrollment and implement a strategy for self-monitoring of body weight.

- Develop educational material to help raise awareness about early risk of cardiovascular disease and provide affordable primary screening.

- Provide physical activity facilities or solutions that can empower students to exercise, even when such facilities are absent and even make physical activity a part of the curriculum.

- $\quad$ Provide easily accessible and affordable health clinics, which include sleep and stress experts in addition to trained psychologist to help students cope.

- Increase nutrition knowledge among students and correct false nutritional myths, which can empower students to make healthier choices.

- Adopt programs that encourage consumption of a Mediterranean style diet

- Collaborate with university cafeteria to provide healthy choices.

In the future, a thorough literature review should be conducted to choose the most appropriate health change model (step 3), to create program content (step 4) and pilot it (step 4.) Finally implementation (step 5) of the program and evaluation (step 6) will ensure its efficacy and whether modification is required. 


\section{References}

1. World Health Organization. Global recommendations on physical activity for health. Geneva, Switzerland World Health Organization; 2010.

2. World Health Organization (2005) Fruit and vegetables for health : report of the Joint FAO/ WHO Workshop on Fruit and Vegetables for Health. Geneva. http://www.who.int/iris/ handle/10665/43143

3. Plotnikoff R, Collins CE, Williams R, Germov J, Callister R. Effectiveness of interventions targeting health behaviors in university and college staff: a systematic review. American journal of health promotion : AJHP. 2015;29(5):e169-187.

4. Von Ah D, Ebert S, Ngamvitroj A, Park N, Kang D-H. Predictors of health behaviours in college students. Journal of Advanced Nursing. 2004;48(5):463-474.

5. Organization WH. Health promoting universities: Concept, experience and framework for action. Copenhagen: World Health Organization; 1998.

6. Kattelmann KK, White AA, Greene GW, et al. Development of Young Adults Eating and Active for Health (YEAH) internet-based intervention via a community-based participatory research model. J Nutr Educ Behav. 2014;46(2):S10-25.

7. Knight A, La Placa V. Healthy Universities: taking the University of Greenwich Healthy Universities Initiative forward. International Journal of Health Promotion and Education. 2013;51(1):41-49.

8. Matvienko O, Lewis DS, Schafer E. A college nutrition science course as an intervention to prevent weight gain in female college freshmen. J Nutr Educ. 2001;33(2):95-101.

9. Sloan CL, Tobias DL, Stapell CA, Ho MT, Beagle WS. A weight control program for students using diet and behavior therapy. J Am Diet Assoc. 1976;68(5):466-468.

10. Hudiburgh NK. A multidisciplinary approach to weight control. J Am Diet Assoc. 1984;84(4):447-450.

11. Gow RW, Trace SE, Mazzeo SE. Preventing weight gain in first year college students: an online intervention to prevent the "freshman fifteen". Eat Behav. 2010;11.

12. Kay bartholomew Eldredge CMM, Robert A C. Ruiter, Gerjo Kok, Maria E. Fernandex, Guy S. Parcel. Planning Health Promotion Programs: An Intervention Mapping Approach. Vol 4. United States of America: Jossey-Bass; 2016. 
118 Chapter 7 


\section{List of publications of the thesis}


Haidar S., de Vries N.K ", Karavetian M., El Rassi, R. Stress, anxiety and weight gain among university and college students; A systematic review. Journal of Academy of Nutrition and Dietetics, 2018, 118(2), 261-274.

Haidar S., Karavetian M., Rashwan, H., de Vries N.K... University Lebanese Students are not Immune to the Metabolic Syndrome. Mediterranean Journal of Nutrition and Metabolism, 2018 Pre-press, pp. 1-10, 2018.

Haidar S., de Vries N.K., Dimitrios P, Rizk R, Karavetian M. The freshman weight gain phenomenon: Does it apply to Lebanese Students? Open Access Macedonian Journal of Medical Sciences, 2018 6(11):2214-2220. https://doi.org/10.3889/oamjms.2018.431.

Haidar S., Karavetian M., de Vries N.K., Laviano, A., Rached, M. Association between $\beta$-amino-isobutyric acid and cardiometabolic risk factors: A Preliminary Study [Submitted] 


\section{Valorization}


Cardiovascular disease (CVD) is the leading cause of death globally and it is estimated that more than three quarters of CVD deaths occur in low- and middle-income countries, a classification to which Lebanon belongs. ${ }^{1}$ Outdated statistics have accounted a third of all cause death to be related to heart disease in Lebanon, and more than one third of all Lebanese suffer from the Metabolic syndrome which doubles future risk of developing cardiovascular disease. $^{2}$

Unfortunately, in Lebanon, heart disease is considered a disease that affects only the elderly and those who are younger are often thought to be protected by their age. Initiatives for screening and prevention are mostly implemented for those who are older ${ }^{3}$ and screening programs are limited for younger adults, who are below 40 years of age, as they are not considered priority. This is problematic, as empirical evidence suggest that heart disease and its risk factors start early on, as early as childhood, and progress with age. $^{4}$

Fortunately, heart disease is preventable, as many of its risk factors are modifiable. It is estimated that $75 \%$ of cardiovascular events can be explained by the presence of such risk factors ${ }^{5}$ and therefore the alteration of the risk factors could prevent CVD. One such causative risk factor is obesity, which Lebanon has witnessed a remarkable rise in, especially in the proportion of youth affected.

In view of the above, this dissertation aimed to collect baseline data about lifestyle, dietary and behavioral habits in an understudied population, that being university students. Furthermore, we associated these factors with weight changes that occurred during the freshman year and calculated the prevalence rate of Metabolic syndrome as a fulminant disease, as well as its individual criteria, necessary for diagnosis.

As suspected, we found that students witnessed an increase in weight over the course of the first year and started out with high stress levels and low quality of sleep. What was unsuspected however was that levels of physical activity and eating habits did not change with time. Furthermore, nutrition knowledge was inadequate at both time points of data collection, which could theoretically prevent students from making wise and healthy food choices.

It was alarming to discover that approximately $90 \%$ of students exhibited at least one metabolic abnormality related to the metabolic syndrome. The most common abnormality was low HDL-C (65.0\%), followed by elevated waist circumference, which was higher than recommended cut off values suggested for the Middle Eastern populations.

The results described in this thesis demonstrate that university students are a highrisk group, vulnerable to weight gain and suffering significantly from metabolic and anthropometric derangements. Stress levels were not associated with increased risk of weight gain neither in the observational studies nor in the findings of the systematic review that was conducted as a part of this thesis, which revealed non consistent evidence when assessing the relationship between stress and anxiety and weight status of collegians.

Furthermore, we did not find an association between $\beta$-amino-isobutyric acid (BAIBA), 
a recently identified myokine, and cardiovascular risk nor with level of physical activity, which raises doubts about the efficacy of BAIBA as a potential obesity treatment.

Since the students in our study sample experienced significant weight gain during their freshman year and since a majority of students had developed at least one risk factor for Metabolic syndrome and CVD, the findings of this thesis has several implications.

First and foremost, university boards and university health care providers should be aware that the students are not immune to metabolic derangements and are a high-risk group that should be targeted with appropriate primary prevention programs. Such programs should focus on increasing nutrition knowledge, correcting nutritional myths, teaching stress management techniques and focusing on self-monitoring of weight. Additionally, they should provide access to fitness facilities in order to increase levels of physical activity while students are on campus. The results of this thesis should also be disseminated to students so that they actually do partake in such health initiatives and understand the importance of self-monitoring. The results of this thesis should also be propagated to the ministry of higher education so that they can advise post-secondary institutions to implement basic health courses as a part of their curriculum, provide access to physical activity facilities and make healthy food more accessible.

Secondly, if current health trends continue as predicted, the Lebanese health care systems may become incapable of coping with the burdens of obesity and cardiovascular disease comorbidities, especially in the absence of access to full coverage health, where the patient has to pay for health care from own pocket hence economic productivity will be jeopardized. Therefore, the information presented in this dissertation should also be disseminated to the Lebanese Ministry of Public Health in order to provide primary health care initiatives and free CVD screening to those who are below 40 years of age, since initiatives have so far overlooked the youth. Furthermore, worldwide, effective measures have been undertaken and proved successful in decreasing risk of disease, which include taxation of foods that are high in fat, sugar and salt in order to reduce their consumption. ${ }^{1}$ Such laws and policies should be implemented in Lebanon and as a consequence of implementation students may be empowered to make more sound dietary choices.

The results of this dissertation should also be circulated to health care practitioners. The results are essential to highlighting the fact that young adults are at risk of developing heart disease early on in life. Health care practitioners should therefore acknowledge the fact that age alone is not protective against heart disease; accordingly, they should primarily screen younger patients and provide them with appropriate motivational counseling, since most of the heart diseases can be prevented by modifying behavioral risk factors. ${ }^{1}$

As for scholars and scientists in the Middle East, the results of this thesis have proved that more research and funding should be invested in the health of university students, since both obesity and CVD are preventable, can start at an early age and progress into adulthood. Additionally qualitative and quantitative studies should be carried out to gain 
more understanding of the predictors of these modifiable risks, which can thus aid in designing evidence based public health programs to reduce risk of non-communicable disease. Since an ounce of prevention is worth a pound of cure, targeting students at an early age could reduce risk of disease and lead to a rise of a healthier more productive populations. 


\section{References}

1. World Health Organization. Cardiovascular diseases fact sheet. 2017. http://www.who.int/ mediacentre/factsheets/fs317/en/. Accessed 22 April, 2018.

2. Mottillo S, Filion KB, Genest J, et al. The metabolic syndrome and cardiovascular risk a systematic review and meta-analysis. J Am Coll Cardiol. 2010;56(14):1113-1132.

3. Yamout WAR. The Initiative of Cardiovascular Service in the PHC Network of Lebanon. Lebanon: Ministry of Public Health.

4. Dahl-Jorgensen K, Larsen JR, Hanssen KF. Atherosclerosis in childhood and adolescent type 1 diabetes: early disease, early treatment? Diabetologia. 2005;48(8):1445-1453.

5. Mendis S. Cardiovascular Risk Assessment and Management in Developing Countries. Vascular Health and Risk Management. 2005;1(1):15-18. 
Chapter 7 


\section{Summary}




\section{Summary}

Cardiovascular disease (CVD) is the leading cause of death in Lebanon, and more than a third of the Lebanese Population suffers from a full diagnosis of the Metabolic syndrome which in turn increases the risk for diabetes, stroke and further developing heart disease. Furthermore, obesity rates in Lebanon are at an all time high with the highest rise being among the young. The financial burden of heart disease is hefty and prevention programs must be implemented to decrease the economical strain secondary to the disease. Such prevention programs should be evidence based and should target vulnerable groups to initiate appropriate change since most of the risk factors for metabolic syndrome, heart disease and obesity are modifiable. Therefore our aim, in this thesis, was to assess whether university students are a high risk group vulnerable to weight gain during the freshman year as are students in more developed countries. Therefore in chapter 3 we assessed, via a longitudinal study, the freshman 15 phenomena and its predictors in a sample of Lebanese students and found that students did gain on average 4,2 lb(1.9 kg) and where unaware of the increase in the weight they had experience thus necessitating the need for awareness programs which focus on self monitoring of weight.

We also assessed stress level in our student sample and we did not find that increased stress levels were significantly associated with weight gain( Chapter 3.) Additionally a systematic review was conducted to further assess the association between stress, anxiety and weight change among collegians (Chapter 2) however no firm conclusions could be generated form from the studies used in the review as there were inconsistent results and most of the studies were observational in design.

Furthermore, we were able to estimate the prevalence rate of the metabolic syndrome in university students, through a cross-sectional study (chapter 4.) The prevalence rate was found to be approximately $6.4 \%$. Moreover, $90 \%$ of the students were found to suffer from at least one metabolic abnormality, the most common being substandard levels of HDLcholesterol The second most common abnormality was an elevated waist circumference which was observed in more than $50 \%$ of the students sampled.

Furthermore, since preclinical studies suggest that circulating levels of a recently identified myokine, $\beta$-amino-isobutyric acid (BAIBA), may have a role in obesity management and may and improve cardiometabolic health, we aimed at assessing among our student sample whether serum BAIBA is) associated with level of physical activity, BMI and other markers of cardiometabolic risk (chapter 5.)

However serum BAIBA levels were not find to be related to nutritional status, metabolic status, and physical activity, but were found to be inversely related to diastolic blood 
pressure in males. This has decreased the confidence in its therapeutic potential.

As a result of the data presented in this thesis we can conclude that university students are a high risk and vulnerable group to weight gain and cardiometabolic derangements and thus should be targeted proactively with evidence based prevention programs which should ideally be implemented at a university level. 
Chapter 7 
Words of thanks 
I would first like to express the most sincere gratitude and appreciation to my promotor and advisor, Dr. Nanne de Vries. Ever since our first contact, you have given nothing short of continuous praise, motivation and encouragement. Your generosity and support know no boundaries. Your immense knowledge and wisdom have guided me through every step of this thesis and for that, I cannot be more grateful. I would like to confess now that I was terrified every time I rang the buzzer to be let in to your gated office before our yearly meetings. Dear Dr. Nanne, I will always be forever grateful to you for taking me under your wing, for teaching me how to become a researcher and continuously helping me whenever I needed support.

To my dearest friend, Dr. Mirey Karavetian, words cannot express how thankful I am to have you in my life. You have been a precious friend and confidant; not to mention copromotor, advisor, mentor and many times psychologist. You tolerated and supported my sleepless, withering brain during pregnancy and post-partum. You were always understanding and lenient, when I had work or family obligations and when my brain died from juggling all of those activities. Without you, the dream of pursuing a PhD would have stayed a far-fetched one. None of this would have been remotely possible was it not for you. I am forever in debt to you.

To my loving, supporting and caring parents, I will never be able to thank you enough for all that you have done for me. You have supported and loved me unconditionally in every possible and conceivable way. You instilled in me a passion for education ever since I can remember. From the moment I took my first cry and the many, many, many cries I had thereafter, you stood by me as strong as can be. You encouraged and me when I needed encouragement and you cheered for me when I achieved the smallest things. Without your love and support, I would have accomplished nothing. I owe everything I have and all that I am to you.

To my dear and supportive husband, I thank you for always standing by me, encouraging me and helping me realize this dream.. You made so many sacrifices and was at many times both a mother and father to our kids, while I was away either physically or mentally. I am forever appreciative for having you as a partner.

My wonderful sons, it is because of you that I have the desire to excel and succeed. I hope that I can make you proud and return some of the happiness and joy that you have given me. I know that at times, I was distant because of my travel and work obligations, but I promise I will always be your number one fan. I would also like to thank you for teaching me how to become a professional multitasker and to keep writing even when you were climbing on our furniture and asking me one million questions. Such multitasking skills were necessary to acquire to finish this thesis.

I would also like to thank Maastricht University and especially CAPHRI school for accepting me as a part of their team and for providing such a great program for external students. I found nothing but friendliness, support and genuineness from every member of your team. I feel a sense of belonging to your prestigious institution and your charming city. 
Thank you for loving what you do and sharing it with others.

Last but not least, I cannot express enough appreciativeness to the administration and the students of the Lebanese International University for allowing me to conduct the research on their premises and for giving me access to equipment, facilities and clinics Last but not least, I would to also express my gratitude to Zayed University for generously giving me the grant which allowed me to pursue this PhD.

\section{Suzan}


134 | Chapter 7 


\section{Curriculum Vitae}




\section{About the author}

Suzan Haidar is a licensed dietitian who obtained double bachelor degrees in Biology (medical sciences) and Nutrition and Dietetics (honors) from the University of Western Ontario in London, Canada. She later pursued a master's degree in human nutrition from the American University of Beirut, Lebanon.

Ms. Haidar worked in several hospitals in Lebanon as head of dietetic department. She later worked in obesity management and then moved to a career in academics where she has since 2008 been teaching and coordinating the internship program at the Lebanese International University. Ms. Haidar also worked on several projects for regional food shows and has made numerous television appearances and for some time was a part of a weekly nutrition radio.

Suzan is a member of the Lebanese Academy of Nutrition and Dietetics (LAND) and has actively participated in contributing to and unifying the dietetic colloquium exam that is run by the Ministry of Higher Education. 
